\title{
DEVELOPMENT OF A NUTRITIOUS ACCEPTABLE SNACK BAR USING MICRONIZED FLAKED LENTILS
}

\author{
BY \\ DONNA RYLAND
}

\author{
A Thesis \\ Submitted to the Faculty of Graduate Studies \\ In Partial Fulfillment of the Requirements for the Degree of \\ MASTER OF SCIENCE
}
Department of Human Nutritional Sciences
University of Manitoba
Winnipeg, Manitoba

CDonna Ryland, August 2003 
THE UNIVERSITY OF MANITOBA

\author{
FACULTY OF GRADUATE STUDIES
}

COPYRIGHT PERMISSION PAGE

\title{
DEVELOPMENT OF A NUTRITIOUS ACCEPTABLE SNACK BAR USING MICRONIZED FLAKED LENTILS
}

\section{BY}

\section{DONNA RYLAND}

A Thesis/Practicum submitted to the Faculty of Graduate Studies of The University of Manitoba in partial fulfillment of the requirements of the degree

of

MASTER OF SCIENCE

Donna Ryland (C) 2003

Permission has been granted to the Library of The University of Manitoba to lend or sell copies of this thesis/practicum, to the National Library of Canada to microfilm this thesis and to lend or sell copies of the film, and to University Microfilm Inc. to publish an abstract of this thesis/practicum.

This reproduction or copy of this thesis has been made available by authority of the copyright owner solely for the purpose of private study and research, and may only be reproduced and copied as permitted by copyright laws or with express written authorization from the copyright owner. 
I hereby declare that I am the sole author of this thesis.

I authorize the University of Manitoba to lend this thesis to other institutions or individuals for the purpose of scholarly research.

Donna Ryland

I further authorize the University of Manitoba to reproduce this thesis by photocopying or other means, in total or in part, at the request of other institutions or individuals for the purpose of scholarly research.

Donna Ryland 


\begin{abstract}
Micronization, an infrared heat process, is used to partially cook food products that have been tempered under optimum conditions. Flaking increases the hydration capacity of foods. It was hypothesized that these processes would permit partial replacement of oats with lentils in snack bar formulations to produce a nutritious acceptable snack bar. Lentils contain less fat and more protein, fibre and folate than oats. This substitution would provide the health benefit sought by many snack bar consumers especially women of child bearing age due to the higher folate content. Snack bar products containing intact pulse seeds such as lentils have not appeared in the market place to date. Development of a new product meeting with consumer approval would increase demand for value added lentils.
\end{abstract}

Four focus groups were conducted to obtain opinions of women aged 35 to 55 inquiring as to why they choose snack bars, what they look for in snack bars as well as comments regarding sensory attributes of a lentil bar with and without cranberries and two commercial snack bars. A mixture design experiment was conducted varying the levels of five components of the lentil snack bar formulation. Sensory responses measured by a seven member expert panel yielded models for four flavor and six texture attributes. These models were used to determine six formulations for lentil snack bars ranging in sweetness, oat, toasted and fruit flavor, softness, moistness and chewiness.

Sixty-two women from 18 to 50 years of age who consume snack bars rated the acceptability of the six lentil snack bars and two commercial snack bars on a nine point hedonic scale from "dislike extremely" to "like extremely". Commercial snack bars on 
average were "liked moderately". Five of the six lentil snack bars were "liked slightly". Three lentil bars were found to be not significantly different from one of the commercial bars $(\mathrm{p}<0.05)$. Purchase behaviour was measured on a seven point scale from "never" to "every opportunity" with the mean values for the commercial bars corresponding to "sometimes". Mean values corresponded to "not very often" for all of the lentil bars. Significant differences for purchase behaviour for the eight snack bars followed the same trend as for the acceptability. Based on "just right" scales lentil bars could be improved by increasing sweetness for four of the bars and decreasing cereal/grain flavor for five of the lentil snack bars.

An eleven member descriptive panel evaluated the intensity of four flavor and seven texture attributes of the same eight snack bars. Attribute intensity ratings were related to consumer acceptability/purchase behaviour to provide insight into what consumers find acceptable in snack bars. Based on the magnitude and the direction of the loadings from partial least squares regression it was found that sweetness and hardness had the highest positive influence on acceptability and grainy and lentil flavors had the highest negative influence on consumer acceptability. Prediction equations were determined that could be used in future development to assess the acceptability of lentil snack bar prototypes.

A 30 gram lentil snack bar would provide about $9 \%$ of the daily recommended nutrient intake of folate for adults compared with approximately $1 \%$ for a similar snack bar made with oats.

A nutritious acceptable snack bar can be made by partially replacing oats with 
micronized flaked lentils. Continued product development work would include descriptive testing of new prototypes to find the optimum lentil snack bar formulation. 


\section{ACKNOWLEDGEMENTS}

I would like to thank my advisor Marion Vaisey-Genser, Professor Emeritus and committee members Dr. Susan Arntfield and Dr. Linda Malcolmson whose encouragement and support throughout this project has kept me inspired and focused, and especially to Marion who gave me the opportunity to work with her.

Thanks is also due to many others that have made this project possible including all of the dedicated panelists participating in the preliminary work, consumer focus groups, and the expert, consumer and descriptive panels. The administrative and technical assistance from members of the departments of Human Nutritional Sciences and Food Science as well as their genuine interest in this work has been greatly appreciated. Assistance from the Department of Statistics for data analysis is acknowledged.

The financial support for this research was provided by the Natural Sciences and Engineering Council of Canada, SaskEnergy and Manitoba Hydro. Infra-Ready Products (1998) Limited supplied the processed lentils.

Faith of family and friends in my ability to succeed has been invaluable. 
PAGE

CHAPTER 1 INTRODUCTION 1

CHAPTER 2 REVIEW OF LITERATURE

2.1 LENTILS

2.1.1 Production 4

2.1.2 Usage 4

2.1.3 Demand 6

2.1.4 Nutrient Content 7

2.2 LENTIL PROCESSING 11

2.2.1 Micronization 11

2.2.2 Flaking $\quad 14$

2.3 SHELF LIFE TESTING

2.4 PRODUCT DEVELOPMENT

2.4.1 New Product Definition 15

2.4.2 New Product Rationale $\quad 15$

2.5 SNACK BAR PRODUCTION 20

$\begin{array}{ll}2.5 .1 \text { Processing } & 20\end{array}$

2.5.2 Formulation $\quad 22$

2.5.3 Ready Made Bars $\quad 27$

2.5.4 Ideal Characteristics of Snack Bars 28

2.6 THE PRODUCT DEVELOPMENT PROCESS 29

2.7 TOOLS FOR PRODUCT DEVELOPMENT

2.7.1 Internal Preference Mapping $\quad 32$

2.7.2 External Preference Mapping 33

2.7.3 Experiment Design for Recipe Formulations 38

CHAPTER 3 MATERIALS AND METHODS 42

$\begin{array}{ll}3.1 \text { Materials } & 42\end{array}$

3.1.1 Micronized Flaked Lentils $\quad 42$

3.1.2 Ingredients 42

3.1.3 Commercial Samples $\quad 42$

3.2 Methods $\quad 42$

3.2.1 Bar Formulation and Feasibility 42

3.2.2 Quality Criteria 49

3.2.2.1 Lentil Quality 49

3.2.2.2 Moisture Content $\quad 50$

3.2.2.3 Water Activity $\quad 50$

3.2.2.4 Nutrient Content 51

3.2.3 Consumer Focus Groups $\quad 51$ 
3.2.3.1 Samples $\quad 51$

3.2.3.2 Panelist Recruitment and Selection $\quad 52$

3.2.3.3 Methods $\quad 52$

3.2.4 Mixture Design Experiment 53

3.2.4.1 Sample Preparation $\quad 56$

3.2.4.2 Measurement of Response Variables 56

3.2.4.2.1 Part 1: Development of Sensory Evaluation Method 58

3.2.4.2.2 Part 2: Evaluation of Twenty-Five Formulations 58

3.2.5 Consumer Panel 58

3.2.5.1 Sample Preparation $\quad 58$

3.2.5.2 Commercial Samples $\quad 62$

3.2.5.3 Panelist Recruitment and Selection $\quad 62$

3.2.5.4 Sensory Evaluation Methods $\quad 63$

3.2.6 Descriptive Panel 66

3.2.6.1 Sample Preparation $\quad 66$

3.2.6.2 Commercial Samples $\quad 66$

3.2.6.3 Panelist Recruitment and Selection $\quad 67$

$\begin{array}{ll}\text { 3.2.6.4 Sensory Evaluation Methods } & 67\end{array}$

3.2.6 Statistical Analyses $\quad 75$

$\begin{array}{ll}\text { 3.2.6.1. Bar Formulation and Feasibility } & 75\end{array}$

$\begin{array}{ll}\text { 3.2.6.2 Quality Criteria } & 75\end{array}$

3.2.6.3 Mixture Design Experiment $\quad 75$

3.2.6.4 Consumer Panel 76

3.2.6.5 Descriptive Panel $\quad 76$

$\begin{array}{ll}\text { 3.8.6 External Preference Mapping } & 78\end{array}$

CHAPTER 4 RESULTS AND DISCUSSION 79

$\begin{array}{ll}\text { 4.1 Bar Formulation and Feasibility } & 79\end{array}$

4.2 Quality Criteria $\quad 84$

4.2.1 Lentil Quality $\quad 84$

4.2.2 Moisture Content $\quad 86$

4.2.3 Water Activity $\quad 86$

4.2.4 Nutrient Content $\quad 89$

4.3 Consumer Focus Groups 91

4.3.1 Consumer Profiles $\quad 91$

4.3.2 Consumer Responses 93

4.4 Mixture Design Experiment 100

$\begin{array}{ll}4.4 .1 \text { Yield } & 100\end{array}$

$\begin{array}{ll}\text { 4.4.2 Cost of Production Estimate } & 100\end{array}$

4.4.3 Expert Panel 104

4.5 Consumer Panel 106

4.5.1 Demographic Data 106

4.5.2 Acceptability and Purchase Behaviour 106 
$\begin{array}{ll}\text { 4.5.3 Attribute Appropriateness } & 118\end{array}$

4.5.4 Internal Preference Mapping 121

4.6 Descriptive Panel 124

4.6.1 Multivariate Analysis of Variance $\quad 124$

4.6.2 Analysis of Variance $\quad 125$

4.6.3 Principal Component Analysis 134

4.6.4 External Preference Mapping $\quad 141$

\section{CHAPTER 5 CONCLUSIONS AND LIMITATIONS AND}

RECOMMENDATIONS 152

$\begin{array}{ll}5.1 \text { Conclusions } & 152\end{array}$

5.2 Limitations 154

5.3 Recommendations $\quad 155$

$\begin{array}{ll}\text { References } & 157\end{array}$

$\begin{array}{ll}\text { Appendices } & 166\end{array}$ 


\section{LIST OF TABLES}

Table

Description

Page

2.1 Acreage and production of lentils in Canada

5

2.2 Nutrient content in $100 \mathrm{~g}$ of products that are commonly used in snack bar formulations

2.3 Essential amino acid content in $100 \mathrm{~g}$ edible portion of products that are commonly used in snack bar formulations

2.4 Snack bar/granola bar sales by brand

$2.5 \quad$ Typical formulation for snack bars

3.1 Detailed processing parameters for micronized flaked lentils

3.2 Product, manufacturer, ingredients, nutrient information and other comments for components of lentil snack bars

3.3 Manufacturer, ingredients and nutrient content for commercial snack bar samples

3.4 Ingredient proportions used with corresponding percentages of preliminary formulation

3.5 Proportions of ingredients used for 25 runs in mixture design experiment

3.6 Baking schedule for mixture design experiment

3.7 Attribute definitions, reference point and endpoint descriptors used by expert panel $n=7$

3.8 Flavor attribute definitions, endpoint descriptors with corresponding standard samples for descriptive panel $\mathrm{n}=11$

3.9 Texture attribute definitions, endpoint descriptors with corresponding standard samples for descriptive panel $\mathrm{n}=11$ 
3.10 Range of standard deviations for each attribute for four samples evaluated during the last training session

4.1 Number of responses in each category for attributes from "just right" scales from preliminary consumer study $n=10$

4.2 Raw and micronized flaked lentil (MFL) means and standard deviations (SD) for lentil starch DSC, gelatinization temperature and enthalpy change

4.3 Snack bar sample means and standard deviations (SD) for \% total solids

4.4 Snack bar sample means and standard deviations (SD) for $\mathrm{a}_{\mathrm{w}}$

4.5 Major nutrients in lentil bars (30 g serving size) 90

4.6 Lentil bar ingredients in grams for one batch 92

4.7 Comments from focus groups regarding what consumers look for in snack bars

4.8 Comments from four focus groups regarding commercial snack bars

4.9 Comments from four focus groups regarding micronized flaked lentil snack bars

4.10 Cooked yield of one batch of lentil bars for 25 formulations from the mixture design experiment

4.11 Cost estimate and market pricing comparison for 30 gram micronized flaked lentil bar production

4.12 Mean values for sensory attributes evaluated by the expert panel used to construct models for all of the attributes

4.13 Criteria entered into the Design-Expert numerical

optimization option for selecting six lentil bar samples

4.14 Solutions (Sol) for six lentil bar samples generated from the Design-Expert numerical optimization option 
4.15 Bar formulations selected from the Design-Expert numerical optimization option for presenting to consumer and descriptive panels

4.16 Percentage of attributes in "just right" category and suggested improvements for snack bars

4.17 Summary of probabiities for main effects and two-way interactions of attributes for eight lentil bars measured by descriptive panel $n=11$

4.18 Snack bars sample means and standard deviations (SD) for sensory attributes

4.19 Variance, eigenvalues and loadings for sensory attributes measured by the descriptive panel determined by principal component analysis

4.20 Variance, loadings, weights and regression coefficients for attributes ( $\mathrm{x}$ variables) and consumer data (y variables) for the first two factors from the partial least squares regression

4.21 Constraints for selecting lentil bar sample based on attributes from coefficients used in prediction equations for factor 1 and factor 2

4.22 Proposed $2^{2}$ factorial design for formulations used to develop lentil bar prototypes 


\section{LIST OF FIGURES}

Figure

Page

2.1 Summary of the five stages of product development adapted from Cooper (1993)

2.2 Region in the simplex coordinate system for a three component mixture design with design points $1=$ constraint plane centroid (PlaneCent); 2=interior (Interior); 3=vertex (Vertex); 4=centre of edges (CentEdge)

3.1 Ballot used for flavor evaluation by expert panel in mixture design experiment

3.2 Ballot used for texture evaluation by expert panel in mixture design experiment

3.3 Ballot used by consumer panel for overall acceptability and purchase behaviour

3.4 Ballot used by consumer panel for rating of attributes using "just right" scales

3.5 Ballot used by descriptive analysis panel for rating of flavor and texture attributes

4.1 Consumer group for bar formulation and feasibility: age, gender and snack bar consumption patterns

4.2 Percentage of responses for each hedonic category for experimental and commercial blueberry snack bars from preliminary consumer study $n=10$

4.3 Consumer focus groups: age and snack bar consumption patterns

4.4 Consumer panel: age and snack bar consumption patterns

4.5 Mean snack bar sample means for acceptability and purchase behaviour from consumer panel $n=62$

4.6 Percentage of responses for each category for purchase behaviour 
4.7 Number of responses for each category for acceptability of snack bars by consumer panel $n=62$

4.8 Percentage of responses for each category for acceptability of snack bars from consumer panel $n=62$

4.9 Frequencies (\%) in "not enough", "just right" and "too much" categories for all attributes from" "just scales" from consumer panel $n=62$

4.10 Groupings of consumers based on acceptability of snack bars using loadings from two principal components $n=62$

4.11 Plot of sample*replication interaction for stickiness to touch from descriptive panel $n=11$

4.12 Plots of panelist*replication interaction for grainy flavor, lentil flavor, cohesiveness of mass and chewiness from descriptive panel $n=11$

4.13 Plots of panelist*sample interaction for stickiness to touch, sweetness, sour/fruity flavor, grainy flavor, lentil flavor, hardness and cohesiveness of mass from descriptive panel $n=11$

4.14 Scree plot for determination of number of factors to retain from the principal component analysis of attributes evaluated by the descriptive panel $n=11$

4.15 Loadings from the first and second principal components for attributes and snack bars evaluated by the descriptive panel $n=11$

4.16 Illustration for determining relative amount of stickiness to touch for snack bar samples

4.17 Loadings from the second and third principal components for attributes and snack bars evaluated by the descriptive panel $n=11$

4.18 Loadings from the first and third principal components for attributes and snack bars evaluated by the descriptive panel $n=11$

4.19 Loadings of acceptability and purchase behaviour (y variables) 
with snack bar attributes ( $x$ variables) evaluated by the descriptive panel $n=11$ 


\section{LIST OF APPENDICES}

List

Page

$1 \mathrm{~A} \quad$ Formulation and rationale for selecting ingredient proportions for blueberry lentil snack bars

1B Formulation for plain lentil bars presented to focus groups

1C Formulation for cranberry lentil bars presented to focus groups

1D Formulations for cranberry lentil bars presented as a reference sample to the expert panel

2A Ethics approval for consumer focus groups

2B Ethics approval for consumer and descriptive panels

174

3A Recruitment package for consumer focus groups 177

3B Recruitment package for consumer panel 181

3C Recruitment package for descriptive panel $\quad 186$

$4 \quad$ Outline of focus group session for snack bars 191

$5 \quad$ Exercise used during training to teach panelists The appropriate way to use the $15 \mathrm{~cm}$ line scale for Measuring attribute intensities

6 Demographic characteristics of groupings created from internal preference mapping

7 Analysis of variance tables for all attributes evaluated by the descriptive panel 
4 


\section{CHAPTER 1}

\section{INTRODUCTION}

Most of the lentil production in Canada is found in Saskatchewan with smaller amounts in the two neighbouring provinces. Canada is the world's largest exporter of lentils with overall production of 914,000 tonnes in 2000 . Production dropped to 566,000 tonnes in 2001 and dropped further in 2002 to 354,000 tonnes due to drought (Agriculture and Agri-Food Canada, 2003). Markets include Western Europe, the Middle East, northern Africa as well as Mexico (Skrypetz, 2000).

The nutrient content of conventionally processed cooked lentils is such that they are included in the meat and alternates group in Canada's Food Guide. They provide a source of protein and dietary fibre and an excellent source of non-heme iron and folate with very little fat. Folate is of interest especially to women of child bearing age for its role in preventing neural tube defects in newborns (Ray et al., 2002). It is also believed to provide some benefit in reducing the incidence of atheroclerosis and colon cancer (Boushey et al., 1995; Prinz-Langenhol et al., 2001).

Micronization, an infrared heat process, has been used in conjunction with appropriate tempering levels and times to partially gelatinize the starch in the lentil endosperm which shortens the cooking time (Arntfield et al., 1997). Immediately after micronization, flaking, a process that crushes the hot seeds between rollers, increases the capacity for hydration. A commercial food processing plant (InfraReady Products (1998) Limited, Saskatoon, SK) is currently supplying micronized lentils to customers for use in the traditional applications with shorter preparation times. Development of a new 
product containing the value added lentils would increase demand for both raw and processed lentils.

To satisfy consumers" needs "new" food products should contain nutritional benefits, be convenient, taste good and provide some element of fun (Sloan, 2003). Developing a product that includes these attributes should enhance the opportunity of success in the market place. A snack bar formulation can be easily adapted to include new products (Estevez et al., 1995). Snack bars are consumed because of their nutritional benefit (Boustani and Mitchell, 1990); their suitability for travel, ease of eating due to cleanliness, consumability at work or in public, inexpensive price and convenience (Jack et al., 1997). They are shelf-stable at room temperature, individually wrapped and small enough to carry in a pocket or purse.

Results of consumer testing on existing commercially available bars have indicated that flavor is what drives consumer liking with sweetness, caramel, cereal and nut base flavors receiving heavier weights for acceptability (Bower and Whitten, 2000). The growth in snack bar sales as well as introductions has been steadily increasing (Burn, 2003). Specific consumer segments, especially women, are being targeted for specific snack bar products (Hollingsworth, 2002).

Multivariate statistical techniques are being used more frequently in the analysis of sensory evaluation data especially to determine the relationship between attribute intensities measured by a descriptive panel and acceptability ratings from a consumer panel (Greenhoff and MacFie, 1994). This technique is referred to as external preference mapping and is well suited in situations of new product development. Results can 
provide information regarding which attributes drive consumer preference which in turn can direct formulations appropriately (Jaeger et al., 2003). Internal preference mapping helps to separate products based on preference and can provide information regarding similar demographic characteristics of consumers for preferred products (Greenhoff and MacFie,1994).

The product development process logically progresses from product concept or idea to marketing, financial and technical feasibility and then to product production from initial to final stages when it can be released for test market. Decisions throughout the process are critical with continual consumer input key to product success (Cooper, 1993). This study was designed with hypotheses and objectives as follows:

Hypothesis 1: A nutritious snack bar can be made using micronized flaked lentils (MFL). Objective: To develop a nutritious snack bar partially replacing oats with MFL. Hypothesis 2: A snack bar acceptable to women can be formulated with MFL. Objective: To determine the acceptability of MFL snack bars compared to commercial bars using analysis of variance and internal preference mapping. Hypothesis 3: Sensory attributes of snack bars influence consumer acceptability. Objective: To relate sensory attributes of snack bars to consumer acceptance using external preference mapping. 


\section{CHAPTER 2}

\section{REVIEW OF LITERATURE}

\subsection{Lentils}

\subsubsection{Lentil Production}

Canada has become the largest exporter of lentils with an estimated 65-70\% share of the world's market (Skrypetz, 2000). Canadian export markets for lentils are diverse. Listed in order of importance they include Turkey, Colombia, Algeria, Morocco, Spain, Egypt, Italy, Mexico, France and Belgium (Skrypetz, 2000). Saskatchewan is the major growing area in Canada with smaller amounts grown in Manitoba and Alberta in areas bordering Saskatchewan. Harvested area and production increased overall from 1991 to 2000 when the all time high of 914,000 tonnes of lentils was produced (Table 2.1). Although the harvested area remained similar for 2001, production decreased due mainly to drought in Saskatchewan and excess moisture in Manitoba (Pulse Canada, 2003). Production fell by $37 \%$ in 2002 due to reduction in the area planted as well as drought (Pulse Canada, 2003) but yield and price remained similar to the previous year (Table 2.1). In 2002, compared to the Laird variety, the smaller Eston/Milestone varieties had better quality with $30 \%$ grading Number 1 and $40 \%$ grading Number 2 vs $2 \%$ Number 1 and $7 \%$ Number 2 for the Laird variety. A production increase is forecast for 2003-2004 with similar yield and price to the previous year (Table 2.1).

\subsubsection{Usage}

Lentils are traditionally used in soups, stews, casseroles, salads and vegetable dishes (Skrypetz, 2000). A hard-to-cook phenomenon has been observed in lentils 
Table 2.1. Acreage and production of lentils in Canada.

\begin{tabular}{lcccc}
\hline Year $^{1}$ & $\begin{array}{c}\text { Harvested Area } \\
(000 \text { ha })\end{array}$ & $\begin{array}{c}\text { Production } \\
\text { (tonnes })\end{array}$ & $\begin{array}{c}\text { Yield } \\
(\mathrm{t} / \mathrm{ha})\end{array}$ & $\begin{array}{c}\text { Average Price } \\
(\mathrm{e})(\$ / \mathrm{t})\end{array}$ \\
\hline & & & & \\
$1991-1992$ & 238 & 343,000 & 1.44 & 312 \\
$1992-1993$ & 267 & 349,000 & 1.30 & 296 \\
$1993-1994$ & 328 & 349,000 & 1.06 & 273 \\
$1994-1995$ & 386 & 450,000 & 1.16 & 343 \\
$1995-1996$ & 327 & 432,000 & 1.32 & 395 \\
$1996-1997$ & 304 & 403,000 & 1.32 & 470 \\
$1997-1998$ & 329 & 379,000 & 1.15 & 324 \\
$1998-1999$ & 372 & 480,000 & 1.29 & 324 \\
$1999-2000$ & 497 & 724,000 & 1.46 & 381 \\
$2000-2001$ & 688 & 914,000 & 1.33 & 295 \\
$2001-2002$ & 664 & 566,000 & 0.85 & 320 \\
$2002-2003$ & 387 & 354,000 & 0.91 & 390 \\
$2003-2004 *$ & 520 & 550,000 & 1.06 & $360-390$ \\
\hline
\end{tabular}

${ }^{1}$ Aug to July

*forecast

Source: Agriculture and Agri-food Canada, Market Analysis Division Online, 2003. 
similar to that in beans. This phenomenon has been attributed to environmental conditions such as location of growth and season but the mechanism is not yet completely understood (Bhatty and Slinkard, 1989).

In the Canadian market the Laird variety (light green seed coat with yellow cotyledons) is the most common due to its large size (13-14 seeds per gram) and attractive color with Eston, a small seeded (26-28 seeds per gram) green variety, also of importance (Muehlbauer and Slinkard, 2000). CDC Milestone, a small seeded green variety, registered in 1997, will eventually replace the Eston (Pulse Canada, 2000). It is resistant to ascochyta blight, a disease which can affect yield and quality. Disease free seed results in lentils of more consistent, shape and size. Development of a new product for the use of lentils would increase the demand for lentils. Products have been developed for legume based flours (Panchuk et al., 1979; Kon and Dunlap, 1978) and cooked legumes (Rockland and Radke, 1978; Maurer et al., 2002; Sipahioglu et al., 2002) but not for intact dry pulses.

\subsubsection{Demand}

Demand for pulses including lentils is growing due to the increase in population in developing countries. In India, for example, production cannot keep pace with the demand generated by the doubling of the population. Demand for pulses is increasing in developed countries due to people becoming more health conscious as well as the trend toward consumption of ethnic based foods from areas that traditionally use pulses such as the Middle East, Asia, the Mediterranean and Africa. Other possibilities are opening in the area of product development for pulses due to the trends of eating more meals away 
from home, convenience and the desire for high quality foods (Lovett and Gent, 2000).

Presenting new products that are desirable for target markets both domestically and internationally can lead to production increases.

\subsubsection{Nutrient Content}

A survey of the ingredients contained in seventeen nutrition/snack bars found in local supermarkets marketplace was done by the author. Compared to oatmeal, an ingredient found in 59\% of the bars, lentils contain less energy, carbohydrate and fat and more protein, iron, folate and total dietary fibre in the raw form (Table 2.2). Crispy rice, a snack bar ingredient listed $71 \%$ of the time, is higher in energy and folate than lentils. Comparing the crispy rice to raw brown rice it appears that the crispy rice may be fortified as the raw grain contains only $20 \mu \mathrm{g}$ vs $494 \mu \mathrm{g}$ of folate for the crispy rice. Some form of soybeans was also listed $71 \%$ of the time in the snack bars surveyed. Both boiled and raw soybeans have higher values than lentils for energy, fat, protein and iron and lower values for carbohydrates, folate and dietary fibre.

In addition to amount of protein, the essential amino acid content of a protein is an indication of nutritional quality. Essential amino acids are those that cannot be made in sufficient quantity, or at all, by the body. Of the 18 amino acids contained in foods nine are essential: histidine, isoleucine, leucine, lysine, methionine, phenylalanine, threonine, tryptophan and valine (Williams, 1993). For lentils, the essential amino acid present in the smallest amount, referred to as the first limiting amino acid, is methionine (Table 2.3). When eaten with other cereal products such as wheat and rice it no longer becomes a concern (Bhatty, 1995). The levels of all of the essential amino acids in lentils are 
Table 2.2. Nutrient content in $100 \mathrm{~g}$ of products that are commonly used in snack bar formulations.

\begin{tabular}{|c|c|c|c|c|c|c|c|}
\hline Product & $\begin{array}{l}\text { Energy } \\
(\mathrm{kcal})\end{array}$ & $\begin{array}{l}\text { Total } \\
\text { Fat } \\
(\mathrm{g})\end{array}$ & $\begin{array}{l}\text { Total } \\
\text { Carbo- } \\
\text { hydrate } \\
(\mathrm{g})\end{array}$ & $\begin{array}{l}\text { Dietary } \\
\text { Fibre } \\
\text { (g) }\end{array}$ & $\begin{array}{l}\text { Protein } \\
(\mathrm{g})\end{array}$ & $\begin{array}{l}\text { Iron } \\
(\mathrm{g})\end{array}$ & $\begin{array}{l}\text { Folate } \\
(\mu \mathrm{g})\end{array}$ \\
\hline Lentils, boiled & 116 & 0.4 & 20.1 & 7.9 & 9.0 & 3.3 & 181.0 \\
\hline Lentils, raw & 338 & 1.0 & 57.1 & 30.5 & 28.1 & 9.0 & 433.0 \\
\hline $\begin{array}{l}\text { Oatmeal, cooked, } \\
\text { regular, quick }\end{array}$ & 62 & 1.0 & 10.8 & 1.7 & 2.6 & 0.7 & 4.0 \\
\hline $\begin{array}{l}\text { Oatmeal, dry, regular, } \\
\text { quick }\end{array}$ & 384 & 6.3 & 67.0 & 10.6 & 16.0 & 4.2 & 32.0 \\
\hline $\begin{array}{l}\text { Rice, brown, long- } \\
\text { grain, cooked }\end{array}$ & 111 & 1.0 & 23.0 & 1.8 & 2.6 & 0.4 & 4.0 \\
\hline $\begin{array}{l}\text { Rice, brown, long- } \\
\text { grain, raw }\end{array}$ & 370 & 2.9 & 77.2 & 3.5 & 7.9 & 1.5 & 20.0 \\
\hline $\begin{array}{l}\text { Crispy Rice, } \\
\text { ready-to-eat cereal }\end{array}$ & 396 & 0.4 & 88.6 & 1.2 & 6.4 & 2.5 & 494.0 \\
\hline Soybeans, dry, boiled & 173 & 9.0 & 9.9 & 6.0 & 16.6 & 5.1 & 54.0 \\
\hline Soybeans, raw & 416 & 19.9 & 30.2 & 9.3 & 36.5 & 15.7 & 375.0 \\
\hline
\end{tabular}

Source: USDA Nutrient Database for Standard Reference, 2002. 
Table 2.3. Essential amino acid content in $100 \mathrm{~g}$ edible portion of products that are commonly used in snack bar formulations.

\begin{tabular}{|c|c|c|c|c|c|c|c|c|c|c|}
\hline $\begin{array}{l}\text { Product } \\
\text { (Protein) }\end{array}$ & $\begin{array}{l}\text { Trypto- } \\
\text { phan }\end{array}$ & $\begin{array}{l}\text { Threo- } \\
\text { nine }\end{array}$ & $\begin{array}{l}\text { Iso- } \\
\text { Leucine }\end{array}$ & Leucine & Lysine & $\begin{array}{l}\text { Methio- } \\
\text { nine }\end{array}$ & $\begin{array}{l}\text { Phenyl- } \\
\text { alanine }\end{array}$ & Valine & $\begin{array}{l}\text { Histi- } \\
\text { dine }\end{array}$ & Arginine $^{1}$ \\
\hline $\begin{array}{l}\text { Lentils }{ }^{2}, \text { cooked } \\
(9 \%)\end{array}$ & 0.081 & 0.323 & 0.390 & 0.654 & 0.630 & 0.077 & 0.445 & 0.448 & 0.254 & 0.697 \\
\hline $\begin{array}{l}\text { Oatmeal }{ }^{2}, \text { cooked } \\
(2.6 \%)\end{array}$ & 0.036 & 0.088 & 0.106 & 0.196 & 0.196 & 0.048 & 0.137 & 0.143 & 0.062 & 0.182 \\
\hline $\begin{array}{l}\text { Rice, } \\
\text { flakes or puffed } \\
(5.9 \%)\end{array}$ & 0.046 & -.-- & $\cdots$ & $-\cdots$ & 0.056 & $\cdots$ & 0.286 & ---- & 0.137 & 0.137 \\
\hline $\begin{array}{l}\text { Rice, brown, long } \\
(2.6 \%)\end{array}$ & $\begin{array}{c}\text { grain, cc } \\
0.033\end{array}$ & $\begin{array}{l}\text { ooked } \\
0.095\end{array}$ & 0.109 & 0.214 & 0.099 & 0.058 & 0.133 & 0.151 & 0.066 & 0.196 \\
\hline $\begin{array}{l}\text { Soybeans, boiled }{ }^{2} \\
(16.6 \%)\end{array}$ & 0.242 & 0.723 & 0.807 & 1.355 & 1.108 & 0.224 & 0.869 & 0.831 & 0.449 & 1.291 \\
\hline
\end{tabular}

${ }^{1}$ regarded as semi-essential amino acid as it is required for growth therefore essential for children ${ }^{2}$ Source: USDA Nutrient Database for Standard Reference, 2002.

${ }^{3}$ Source: Williams, 1993. 
higher than in oatmeal and rice products (Table 2.3). Soybeans have a higher level of all of the essential amino acids than lentils.

Research in both animal and human nutrition has been conducted to determine the role of L-arginine in preventing heart disease. This amino acid reportedly increases blood flow by relaxing and widening blood vessels (Pszczola, 1999). Lentils have a higher value for arginine than the oatmeal and rice products (Table 2.3). Lentils also have been found to produce a lowering of blood glucose levels after a meal in normal and diabetic subjects which may be of particular benefit to people suffering from diabetes (Jenkins et al., 1980).

Folate has been shown to reduce the risk of neural tube defects in newborns which led to the mandatory folic acid fortification of Canadian cereal products in 1998. This fortification has resulted in significantly lower incidence of neural tube defects ( $\mathrm{p}<0.0001$ ) based on a study of 336,963 Ontario residents (Ray et al., 2002).

Other research has shown that insufficient levels of folate intake may increase atheroclerosis due to its effect on increasing homocysteine levels in blood plasma (Boushey et al., 1995). In his review of the role of folate in cancer prevention, PrinzLangenhol et al., (2001) noted that evidence from human studies suggests that folic acid may play a role especially in reducing the risk of colon cancer.

Tucker et al., (1996) studied the content of common foods containing folate to determine if supplementation was warranted in the elderly population. They concluded that those who took a supplement received almost the same amount of folate as those that ate cereals, fruit and vegetables. It has been found that there is a direct relationship 
between dietary folate and blood folate levels (Jacques et al., 1993) so that by increasing consumption of foods containing folate, folate status should improve. Therefore, by substituting lentils for oats, folate status should be positively affected.

Levels of anti-nutritional factors including: trypsin inhibitors, lectin and phytic acid are lower in lentils than other pulse crops. The exception is the saponins which are still at acceptably low levels (Elkowicz and Sosulski, 1982). In comparison to other pulses, lentils have lower levels of the flatulence-producing oligosaccharides, raffinose, stachyose and verbascose (Fleming, 1981) which can be further reduced by soaking and cooking in water (Vidal-Valverde et al., 1992).

\subsection{Lentil Processing}

\subsubsection{Micronization}

Micronization is a process which uses electromagnetic energy transmitted as waves which penetrate the food product. Infrared wavelengths are between the visible and microwave spectrum from $10^{-4}$ to $10^{-2} \mathrm{~cm}$ and frequencies of $10^{14}$ to $10^{12} \mathrm{~Hz}$ (Vanzetti, 1972). The lower the frequency the higher the penetration. Surface characteristics and colour of the food also affect heat penetration since infrared energy is absorbed at the surface of the food and converted to heat (Fellows, 1990). Micronization is an efficient method of heating as it is short-time, high-temperature (Zheng et al., 1998). For example, soybeans were heated to an average temperature of 110 to $115^{\circ} \mathrm{C}$ in 90 seconds (Metussin et al., 1992). According to Fellows (1990) the fast heating seals in moisture and retains flavor and aroma characteristics.

Optimum tempering levels and time are crucial for final product quality. 
Sufficient moisture is required to gelatinize the starch. For example, Arntfield at al., (1997) found that Laird lentils micronized with a pre-treatment of 33\% tempering in distilled water for 16 hours resulted in over $50 \%$ starch gelatinization. As the percentage of starch gelatinization increased, cooking time decreased $\left(\mathrm{r}^{2}=-0.46, \mathrm{p} \leq 0.01\right)$. According to Atwell et al., (1988) starch gelatinization is defined as the collapse (disruption) of molecular orders within the starch granule manifested in irreversible changes in properties such as granular swelling, native crystallite melting, loss of birefringence, and starch solubilization .

According to Stevens and Elton (1971) differential scanning calorimetry (DSC) is the preferred method to quantitatively measure starch gelatinization since the plot produced is based on time and area under the curve. Area under the curve corresponds to the change in heat (enthalpy value) caused by differential heat flow (Biliaderis, 1983). Of particular benefit is the fact that the starch/water transitions can be studied at wide ranges in temperature and water levels. Results from DSC can be used to study food transformations and interactions that are heat-induced as well as provide insight for product development and quality control applications.

Differential scanning calorimetry has been used to study the starch gelatinzation of various pulse products (Garcia-Vela and Stanley, 1989; Biliaderis et al., 1980; Bhatty, 1984; Sosulski et al., 1985; Cenkowski and Sosulski, 1997) with varying degrees of success. From their study of lentil, smooth pea and adzuki bean starch Biliaderis et al., (1980) determined that more highly branched starch resulted in greater starch gelatinization. Garcia-Vela and Stanley (1989) found that as storage time increased 
enthalpies of gelatinization in black bean flours increased and gelatinization temperature decreased. Bhatty (1984) found inconsistent results when comparing enthalpy values of good and poor cooking lentils of different varieties and crop years. Cenkowski and Sosulski (1997) used DSC to measure the starch gelatinized in micronized lentil seeds. Approximately $45-65 \%$ of the starch was gelatinized as a result of micronization. The majority of the remaining starch was gelatinized after a five minute cooking period.

Applications of infrared energy for the food industry include partial cooking by gelatinizing starch (Arntfield et al., 1997), inactivating enzymes responsible for offflavors, decreasing microbial contamination, dry blanching of products prior to canning treatment, dehulling of seeds as well as various drying and thawing applications. Use of infrared energy therefore, can be focused on the products' outer layer, the internal composition of the product or both external and internal components (Van Zuilichem et al., 1986).

Micronization has been found to improve functional and chemical properties by: decreasing the cooking time of lentils (Cenkowski and Sosulski,1997; Arntfield et al., 2001), split peas (Cenkowski and Sosulski, 1998) and chickpeas (Sarantinos and Black, 1996); reducing bitterness in raw pea protein (McCurdy, 1992); inactivating lipoxygenase in soybeans (Van Zuilichem et al., 1986) and keeping protein denaturation to a minimum which improves brewing performance (South, 1992). Nutritional properties have also been improved by the reduction of phytic acid and phenolic compounds in lentils (Zhao, 2000; Arntfield et al., 2001), the increase of in vitro protein digestibility and available lysine in soybean milk (Metussin et al., 1992), the increase in \% soluble dietary fibre and 
decrease in insoluble dietary fibre in lentils (Zhao, 2000), and the decrease in protein solubility (which increases digestibility due to the higher protein denaturation) (Arntfield et al., 2001, Zheng et al., 1998). Microbiological quality has also been improved by the reduction of mold formation in chickpeas (Sarantinos and Black, 1996).

\subsubsection{Flaking}

Cereal products are flaked to enhance starch digestibility by gelatinizing the starch as well as to increase the ability for water absorption (Rhymer, 2002). Grains are tempered, heated and subjected to roller crushing. Optimum process conditions vary for each cereal and for each end use. Too little moisture results in breakage of kernels and dust formation and insufficient starch gelatinization (McDonough et al., 1997).

Coming from the micronizer the lentils are hot and can be successfully compressed between rollers to produce a flaked product which, as noted above, has increased starch digestibility and capability for moisture absorption. The more pliable texture of the lentils increases their suitability for inclusion in snack products without further pretreatment.

\subsection{Shelf Life Testing}

According to Perchonok (2002) shelf life is the point which the product no longer represents its initial definition. Measurements need to be taken that reflect the characteristic product quality. Microbiological safety needs to be addressed. Initial testing can serve as an indication of the likelihood that the product will remain free from contamination. A pH below 4.6 , storage below $21^{\circ} \mathrm{C}$ or above $38^{\circ} \mathrm{C}$, and low water activity $\left(\mathrm{a}_{\mathrm{w}}\right)$ will inhibit microbial growth. 
Water activity is a measure of the free water that is available within the product that can be used to sustain microorganisms. By definition it is the ratio of partial pressure of water in the food to the vapor pressure of water at the same temperature (Baker et al., 1988). The lower the $\mathrm{a}_{\mathrm{w}}$ the less chance enough water will be available to support microbial growth or to promote undesirable chemical changes within the food such as lipid oxidation and enzymatic activity. As moisture increases water activity increases along with reaction rates. A water activity below 0.6 can prevent growth since mold and yeasts require 6.1 and bacteria requires an $\mathrm{a}_{\mathrm{w}}$ of 0.91 to survive (Perchonok, 2002).

Water activity may change throughout the storage period if moisture uptake or loss occurs. Testing of shelf-life should be done on the final product as well as ingredients which may be a limiting factor in the longevity of the product. It should also be conducted after the product has gone through the distribution chain to see if any stresses occur due to handling. In addition to sensory evaluation, analytical testing including moisture, nutrient content, color and texture/viscosity can be done if this is suitable to the product in addition to sensory evaluation (Perchonok, 2002).

\subsection{Product Development}

\subsubsection{New Product Definition}

A snack bar made from MFL qualifies as a new product under two of the seven categories as noted by Fuller (1994). It uses a new form of an existing product and it is a reformulation of an existing product as seventeen nutritional/energy/granola/cereal bars surveyed in the marketplace contained no lentils or pulses of any kind.

\subsubsection{New Product Rationale}


A snack bar made from micronized flaked lentils addresses all of the five reasons noted by Fuller (1994) for developing new food products.

One reason is to extend the product life cycle of the snack bar. This product has been in the market place for many years with original marketing strategies aimed at athletes and fitness-minded individuals to replace energy stores lost during exercise (Matz, 1996). Recently this food product has been targeted at more specialized markets in order to lengthen the growth period. For example, snack bars are being manufactured especially for women. Clif Bar Inc. has developed a product specifically targeted to women fortified with nutrients to specifically address women's needs including soy protein, calcium, folic acid, zinc, iron, and antioxidants. The snack bar contains 170 to 180 calories and 3 to 4.5 grams of fat, relatively low amounts compared to a chocolate bar (Hollingsworth, 2002). Other snack bars have been made specifically for those with diabetes, as nutrition supplements, as having particular nutrients such as protein, and simply as energy bars. Snack bars are used as health remedies as well (Pszczola, 1999). According to Sloan (2003) teen and young adults 16-24 years old are the largest group of snack eaters so that targeting bars to this specific group would also lead to expansion of the growth phase.

In the United States snack bars/granola bars sales were reported at approximately 1.3 billion U.S. dollars for 1999 (Anon, 2000) and represented a 13.1\% increase over the prior year. Drug stores accounted for $43 \%$ of the 1999 sales, mass merchandisers $40 \%$, and food/grocery retailers the remainder. A list of the ten brands which comprised these sales are given in Table 2.4. In 2002 the U.S. snack bar/granola bar sales increased $21 \%$ 
Table 2.4. Snack bar/granola bar sales by brand.

\begin{tabular}{llccc}
\hline Rank & \multicolumn{1}{c}{ Brand } & $1999 \$$ Sales & $\begin{array}{c}\text { \% Change } \\
\text { Year Ago }\end{array}$ & $\begin{array}{c}\text { \% Share of } \\
\text { Category }\end{array}$ \\
& & & & 11.2 \\
1 & Kellogg's Rice Krispie Treats & $140,071,552$ & 3.0 & 10.9 \\
2 & Kellogg's Nutri-Grain & $135,499,664$ & -12.6 & 10.2 \\
3 & Quaker Chewy & $127,030,696$ & -0.6 & 5.8 \\
4 & Private Label & $71,952,432$ & 5.9 & 4.9 \\
5 & Sunbelt & $62,853,480$ & 13.6 & 4.6 \\
6 & Quaker Fruit and Oatmeal & $60,562,288$ & 62.6 & 4.5 \\
8 & Slim Fast & $56,954,516$ & 488.2 & 4.2 \\
9 & Kellogg's Nutri-Grain Twists & $55,815,048$ & 403.6 & 3.8 \\
10 & Nature Valley & $52,520,012$ & 21.9 & 100.0 \\
\hline
\end{tabular}

Source: Anon, 2000. 
over 2001 indicating that snack bars are still in the growth period of the product life cycle (Sloan, 2003).

Retail sales of energy and nutritional bars have also increased in Canada (Burn, 2003). Sales for the 52 week period ending February 22,2003 increased $33 \%$ in terms of dollars and $40 \%$ in terms of volume over the prior year. The confectionary category accounted for $\$ 40$ million of these retail sales (Anon, 2003).

Changes in the marketplace provides a second reason for development of new products. Sloan (2003) suggests that the reason snack bars are one of the fastest growing market segments in food history is due to new nutrient recommendations, busy lifestyles and promotion of new nutritional benefits and functional ingredients. For example, Sun-Rype fruit and veggie bars, containing 100\% fruit and vegetables, are a new market entry and are becoming very popular due to the claim that a single bar will provide three servings of fruits and vegetables, a food group promoted by health professionals (Burn, 2003).

Functional ingredients can be found in snack bars. Oats contain $\beta$-glucans which affect the lowering of low-density lipoprotein (LDL) cholesterol. Antioxidants in blueberries may reduce the risk of cancer and heart disease as well as provide protection against oxidative stress which has been linked to aging (Payne, 2000). Cranberries also have provide a source of antioxidants and contribute to urinary health. Other essential nutrients include anthocyanins, proanthocyanins, phenolics, organic acids vitamins and minerals (Van Drunen, 2002). According to Van Drunen (2002) cranberries are also beneficial in fighting periodontal disease and high blood pressure. 
Health promoting components (functional ingredients) found naturally in lentils/pulses include oligosacharides, which act as prebiotics to promote healthy flora in the intestine (Klahorst, 2000); fibre, which has a cholesterol reducing effect; L-arginine, which helps to reduce the risk of heart disease (Pszczola, 1999); folate, which reduces the risk of neural tube defects in newborns (Burrington, 2000); calcium, needed to maintain strong bones; phytate, which is thought to potentially prevent cancers and cardiovascular disease (Messina, 1997); and trypsin inhibitors which may be anti-carcinogenic (Kennedy, 1995). These ingredients may provide health benefits if found in sufficient quantities in the micronized flaked lentil snack bar being developed in this study.

Technological advancement, a third reason for developing new products, makes it possible to develop snack bars from intact lentils because of the partial cooking and increased water hydration capacity offered by the new micronization process. Methods available for identifying and quantifying low levels of nutrients in foods as well as determination of the beneficial effect of these nutrients when ingested by humans provides the opportunity to include these "health" components in snack bars.

Government policy is keeping pace with the trend toward eating healthy food. Mandatory nutrition labeling has been legislated federally so that by 2006 all packaged products in Canada will contain nutrient content information in a consistent format to enable nutrient comparisons between products. In addition, five nutrient claims will be allowed. Low sodium to reduce hypertension, high calcium to reduce osteoporosis, saturated and trans fat to reduce risk heart disease, high fruit and vegetables for reduction of some cancers, and low fermentable carbohydrate to reduce tooth decay (Canada 
Gazette, 2002). New products being developed should keep these claims in mind.

A local processing company wants new products developed from micronized flaked lentils in order to promote corporate and financial growth. The company has developed a variety of processed pulse and cereal products for food use to expand their sale opportunities. Adding value to the micronized flaked lentils by developing a food product incorporating their use provides an additional purpose for buying lentils and increases the processor's return.

\subsection{Snack Bar Production}

\subsubsection{Processing}

Review of the literature suggests a number of methods for preparation of snack bars. Azlyn et al., (1989) prepared bars in a single batch method combining all of the ingredients and baking to produce bars that were 2 inches long by 1 inch wide and $1 / 2$ inch thick. Berglund et al., (1992) used a similar method but cooked the binder to $82^{\circ} \mathrm{C}$ before combining it with the cereal mixture. Bars were $2.5 \mathrm{~cm}$ square and $1.6 \mathrm{~cm}$ thick. This is similar to a method described by Matz (1996) which used a moister, cohesive dough followed by mild baking to preserve nutrients forming a bar-like structure. This method can be compared to bar cookies where both batch and continuous processing parameters are available.

A process for producing fruit and nut bars for army rations was reported by Gillies in 1974. Fruits such as dates, figs, maraschino and raisins were chopped and dried to approximately $7-14 \%$ to facilitate the production process and optimize palatability. Too much moisture resulted in too much pulp and too little moisture resulted in a dry product. 
A mixture of 43 grams of dehydrated fruit (average $8 \%$ moisture) and nuts or sesame seeds were mixed and pressed with about 200 pounds of force per square inch to form bars that were 1 inch by 3 inches by $1 / 2$ inch thick. Addition of lecithin was required to soften the texture. It was also used to prevent the bars from sticking in the press. Samples stored for 6 months at $100^{\circ} \mathrm{F}$ were fair to good as judged by a ten member trained sensory panel and showed no significant changes in color, flavor and texture. Changes also were not observed for color, texture and flavor of bars stored at $70^{\circ} \mathrm{F}$ for 12 months. After 24 months, flavor ratings were significantly lower although still deemed to be a good quality product. Color did not change over the two year period. These products had been packaged under vacuum and sealed in a flexible pouch composed of polyester, aluminum foil and polyolefin.

Mass production of snack bars is similar to that of other types of confectionary bar products where a continuous process of extrusion and layering is implemented (Murphy, 1990). The first step, done in either continuous or batch format, is to combine the dry products with the binder ensuring that the binder is distributed thoroughly in order to coat all of the dry products completely. The mixture is directed to pass between cooled forming drums. The resulting material is extruded as a sheet onto a belt for the layering process. This belt consists of a series of rollers which are set to control the size and density of the product. After cooling, rotary knives cut the sheets into strips. The strips are fed to a guillotine cutter which cuts the appropriate length. A drying step may be required to lower moisture to attain the water activity level needed for preservation (Matz, 1996). Estevaz et al., (1995) used a flow line design for bar manufacture similar 
to that shown in Murphy (1990) which includes optional processing steps of layering with caramel or chocolate for example and enrobing the bar totally or partially with caramel or chocolate.

In large scale production, a critical point in the process is rolling of the bars. Levine (2002) notes that this is not like rolling dough as the flow property of the mixture is particulate in nature rather than viscous. In both cases, successful rolling depends on the pressure set at the first contact and that set at the end. In viscous flow, the effect of force being exerted is seen sideways and from the top while with particulate flow is it only seen from the top. With particulate flow the contact of the material with the rollers is uneven as some components may exert a different force than others. Dough surface is constant and sticks to the roller surface. Dough under pressure will not compress because density is consistent. Snack bar material, on the other hand, is not of a consistent density and therefore will be altered as pressure is applied. According to Levine (2002) a totally satisfactory process has not been developed to address this phenomenon of particulate flow. Hopper fill, where the product mass is in the centre, has an effect on the final product. Product may be more dense at the centre which undergoes higher pressure than at the edges where a smaller portion of the material is fed.

\subsubsection{Formulation}

Studies have been done that use snack bars as a product for incorporation of various food ingredients that offer specific benefits. Ingredients included in a typical recipe attests to the adaptability of the snack bar for inclusion of a wide variety of ingredients (Table 2.5). 
Table 2.5. Typical formulation for snack bars.

Ingredient

Parts by Weight

$\%$

Binding Syrup

40

Oats

25

Crisped Rice

10

Coconut

10

Almonds

10

Raisins

5

Source: Murphy, 1990. 
Bergland and coworkers (1992) made granola bars in order to demonstrate the use of waxy hull-less barley. Bars containing barley flakes in addition to a barley extruded crisp cereal or a 50/50 blend of barley and rice extruded crisp cereal were compared with bars made from old fashioned oatmeal and extruded crisp rice cereal. The binder used was granulated sugar, high fructose corn syrup, skim milk and a maltodextrin. Bars with barley flakes and 50/50 crisp barley/rice cereal had significantly higher acceptability scores for appearance, texture and flavor than the oatmeal bars based on evaluations from eighty-five consumers.

The purpose of a study by Azlyn et al., (1989) was to develop a high fibre, low calorie snack bar. Fibre sources came from corn and wheat bran and were included at 10, 20 and $30 \%$ of either bran type. Nine combinations making up 10,20 and 30\% total fibre from both wheat and corn were produced. Wheat flour was used to make up to the $30 \%$ level where necessary. Other ingredients included fructose, corn oil, water lecithin, nonfat dry milk powder, salt and gum. Fifteen trained panelists evaluated the 15 bars in duplicate for flavor, appearance and texture acceptability using the hedonic scale where $1=$ poor or unacceptable; $5=$ neither/nor; $9=$ optimum. Three samples with the highest flavor, appearance and texture values as determined by the trained panel, were evaluated by a 75 member consumer panel. No significant difference was found in the acceptability value (neither like nor dislike) between these three bars $(\mathrm{p}<0.05)$. The authors concluded that all three bars were acceptable as the average score was above 5 which was the level arbitrarily set in a study done by Polizzoto et al., (1983). Moisture for the three bars ranged from 32.5 to $32.8 \%$. 
The objective of a study conducted by Estevez et al., (1995) was to develop high energy, high protein snack bars by including walnuts in the formulation and to determine shelf life. Cereal nut formula 1 included oats, wheat germ, and walnuts as dry ingredients. Binder composition included honey, brown sugar syrup and palm syrup, sunflower, oil, lecithin and glycerol. Cereal nut formula 2 had all of the ingredients of formula 1 plus wheat extrudates and puffed amaranth with brown sugar cover. Cereal nut formula 3 had all of the ingredients of formula 1 plus wheat extrudates and toasted amaranth with brown sugar cover. These three samples all contained $18 \%$ walnuts. Three more samples were prepared replacing $18 \%$ walnuts with $12 \%$ walnuts by adding more oats and wheat germ. In addition to proximate analysis to determine energy and protein of the bars, moisture content and water activity were measured as an indication of shelf life.

All samples had a protein efficiency ratio higher than $80 \%$ indicating good protein quality compared to casein, with lysine being the most limiting amino acid. The bar containing oats and wheat germ with no amaranth contained the highest protein content, intermediate lipid and carbohydrate content. All of the bars had caloric content which was similar and high due to the high carbohydrate and lipid content.

Quality and acceptance were judged on samples containing $18 \%$ walnuts which were the samples that also contained the higher moisture levels. Twelve judges evaluated quality of the bars for appearance, colour, aroma, acidity, sweetness, astringency, crispness, bitterness and taste. The snack bar containing puffed amaranth had significantly higher mean scores for colour and aroma than the bar containing no 
amaranth, and significantly higher taste scores than both of the other samples $(\mathrm{p}<0.05)$.

Before storage, acceptability was highest for the sample containing no amaranth. After storage at $37^{\circ} \mathrm{C}$ for 15 days the sample containing the toasted amaranth had the highest acceptability, changing very little over the time period. The sample containing puffed amaranth also changed little but had a lower acceptability score overall perhaps due to the higher bitterness, astringency and acidity, and lower sweetness and crispness than the other samples. Initial moisture content ranged from 7.7 for the bars containing no amaranth to 9.4 for those containing the puffed amaranth. Water activity ranged from 0.56 to 0.50 . Bars with nuts had higher moisture and water activity.

Energy bars containing various carbohydrate and protein levels were formulated by Painter and Prisecaru (2002) and their corresponding glycemic index (GI) levels measured in young adult females. The GI is a measure of how fast and for how long the blood glucose level rises after consuming a food. Higher GI levels have been thought to be associated with type II diabetes and obesity. Relating the ingredients in the snack bars to the corresponding GI patterns may lead to the recommendation of certain ingredient combinations for particular energy requirements.

Three types of bars formulated included protein bars consisting of soy, rice, casein and 50\% soy, complex carbohydrate bars made from wholewheat flour, white flour, oats and barley, and sugar bars made from sucrose, fructose, high fructose corn syrup and glucose. All bars were $200 \mathrm{kcal}$, the most common amount for energy bars, and contained $23 \%$ fat. They found that generally the protein bars produced the lowest GI level with the sugar bars producing the highest. Since glucose containing sugar bars 
produced the most drastic increase in GI they suggested using only a small amount of this ingredient in bar formulations suitable for sustained energy activities. Fructose, oats and barley would be more suitable for this application. Bars containing the highest protein levels were least acceptable with the simple sugar bars rated most acceptable overall. Sucrose was the most acceptable of the four sweeteners with glucose the least (Painter and Prisecaru, 2002).

Maurer et al., (2002) developed a granola bar containing 31\% corn syrup, $30 \%$ toasted oats, $16 \%$ dehydrated cooked red or black beans and $9 \%$ sucrose. Water activity of the bars was 0.28 and final formulations contained protein, fibre, folic acid and fat in levels allowable for nutrient claims. Latin American consumers rated the bars more acceptable than the group from the United States with almost $75 \%$ stating they would purchase the bar.

Sipahioglu et al., (2002) utilized a variety of grains and legumes in a fruit flavored cereal bar. Wheat, brown rice, barley, oats, buckwheat and beans were soaked for 4 hours prior to cooking at $120^{\circ} \mathrm{C}$ for 30 and 60 minutes. After 30 minutes soaking dried fruit was mixed with modified starch and cooked at $100^{\circ} \mathrm{C}$ for 10 minutes. These mixtures along with flavor and color were blended and packed to produce the bars. The product had a $\mathrm{pH}$ of 4.9 , water activity of 0.97 and average acceptability of 7.6 on a 9 point scale.

Patents found in the U.S. patent office list ingredients as well as proportions for inclusion in snack bars (Leach, 1997) and methods for snack bar manufacture (McKenzie, 2000).

\subsubsection{Ready Made Bars}


Jack et al., (1997) compared consumer perception of fresh fruit with manufactured snacks including snack bars. Manufactured snacks generally were perceived as convenient which included the storability aspect and lack of waste and mess, and were consistent in quality.

Boustani and Mitchell (1990) studied the acceptability of seven commonly available cereal bars. Results from eight consumers who evaluated the bars in pairs for preference revealed that the two bars containing chocolate were most preferred. An apple, hazelnut bar was least preferred. Differences in preferences were not statistically significant $(\mathrm{p}<0.05)$.

King et al., (1998) used a range of eighteen snack bars including cereal fruit bars, energy bars and chocolate bars to investigate two new projective mapping techniques compared with sorting data collection. The objective was to determine the ability of these techniques to produce spatial product maps useful in sorting bars by attributes from data generated by twenty-four consumers. All of the methods distinguished the bars based on use although one method (unstructured projective mapping with multidimensional scaling) also distinguished the bars by the chocolate content which suggests that this method may provide more information. King et al., (1998) concluded that this process could be beneficial in consumer focus groups where more information, in addition to acceptance, is being sought.

\subsubsection{Ideal Characteristics of Snack Bars}

Snack bar quality depends on the quality and amounts of ingredients in relation to each other (Murphy, 1990). Oats is the major ingredient of snack bars. Too many oats 
can lead to unpleasant texture of snack bars. The amount needs to be balanced with the other ingredients so that the oat flavor and texture do not dominate. Including nuts tends to increase acceptability providing a less mealy texture. Soft and chewy bars are sweetened using a binding syrup of various sugars as well as fat, possibly milk and flavorings. The amount of sweetener is similar to that in chocolate bars. To ensure that the integrity and the crispness of the cereal portion is maintained, glycerol may be added. Other sweetening components could include malt extract, molasses, honey and natural flavorings.

\subsection{The Product Development Process}

The five stages of the product development process as outlined by Cooper (1993) are shown in Figure 2.1. Initial production feasibility and development of the product are found in stages 1 and 3. Stage 2 is detailed work on production, financial analysis and product descriptions so that a business plan can be developed. Stage 4 involves testing and validation of the new product which includes ensuring product quality. Results from consumer preference tests should conclude that at least $50 \%$ of the consumers like the new product at least somewhat more than the product they are using now. Stage 5 is launching of the marketing plan and the final product.

The product development process involves a great deal of work. At each sequential stage it is essential that a "Go" decision is assessed very carefully before proceeding to the next stage. According to Best (1991) one rule of thumb states that only $10 \%$ of the products ever make it to consumer testing and only $10 \%$ of those appear in the marketplace. 
Figure 2.1. Summary of the five stages of product development as adapted by Cooper (1993).

$\begin{array}{lll}\text { Stage } & \text { Overall Objective } & \text { Overview }\end{array}$

1 Preliminary Investigation

2 Detailed Investigation

3

Develop the Product

Final Justification, Testing

Final prototype plans
A quick purview of the project

Major homework completed business case plans compiled

Following through with the business case

5 Full Production and Launch of Product
Preliminary market assessment ${ }^{1,2}$ Preliminary technical assessment ${ }^{1,2}$ Preliminary financial assessment ${ }^{1}$

Make recommendations and plan for Stage $2^{1}$

Conduct user needs-and-wants study (Step 1$)^{1}$

Do competitor analysis (Step 2)

Do market analysis (Step 3)

Perform detailed technical assessment (Step 4)

Run a concept test (Step 5)

Conduct financial analysis (Step 6)

Develop the business case including the product definition or protocol, the project justification from information gathered to date and from this case, plan for Stage 3 and further (Step 7)

Continual consumer input and feedback is sought throughout the process as prototypes are manufactured and tested ${ }^{1,2}$

Work out reasonable time frames and adhere to them to keep project on track in as little time as possible.

Review previous analysis of competitors, markets and finances as these can change as the development process continues.

Conduct extended lab tests to meet product quality and specifications. Conduct preference tests (recommend at least 50\% prefer the product "somewhat" or very much over the brand they are currently using). Do a limited production run.

Ensure regulations and legal issues are dealt with.

Revision and finalization of marketing and production plans.

Revisions and finalization of financial plans.

${ }^{1}$ activities to be conducted in this study ${ }^{2}$ consumer input (focus groups) will be a part of the product formulation, market and technical assessment 
Use of consumer focus groups is a qualitative research method that is versatile and is the technique most commonly used (Chambers and Smith, 1991). Focus groups can be used during four of the first five main stages in product development as outlined by Baker et al., (1988).

Idea generation can include opinions from consumers regarding products that they would like to have or changes to existing products which would satisfy their needs. During initial development consumers are asked to provide attributes for the products which help determine the attributes for testing by consumer panels. Preliminary evaluation of the products, the third stage of the development process, will be the opportunity for consumers to relate the liking of the product to attributes that they can describe. After this information has been used in the consumer testing a focus group might again provide input regarding the results and whether interpretation was correct. After the final product testing other issues such as packaging, preparation instructions and labeling can be probed with the use of focus groups (Chambers and Smith, 1991).

Once feasibility is determined the actual development of the product proceeds. Two problems can occur. The data collected thus far may be misinterpreted so that what consumers described is not necessarily translated into the developed product. Things change over the product development process so that, compared to when the project started, the product no longer holds value to the customer (Cooper, 1993).

\subsection{Tools for Product Development}

The goal is to develop a product that consumers like. There are some constraints and difficulties in collecting and analyzing preference data from consumers. Consumers 
may not understand the meaning of attributes provided on a questionnaire or be able to provide them if none are given. It may be difficult for them to separate attributes which are positive when overall the product is disliked. Data collected from hedonic testing may not produce a normal distribution but a bi- or multi-modal distribution (Greenhoff and MacFie, 1994).

Multi-dimensional preference mapping techniques have been used to overcome some of these problems. Data are collected from consumers who assess six or more products on a number of criteria. These data can include scaled acceptance (dislike extremely to like extremely) and ranking for preference, or suitability of the product for a specific use (Greenhoff and MacFie, 1994).

Responses to the products are analyzed using multivariate statistical procedures which are graphically represented in a two or three dimensional plot containing individual consumer responses and test products or, data from consumers are plotted on space containing data from descriptive sensory or instrumental analysis.

\subsubsection{Internal Preference Mapping}

Internal preference mapping, also known as MDPREF, looks at the consumer responses alone. Instead of assuming that all of the consumers in the group are following the same behaviour when assessing their acceptability, data from each consumer are assessed separately.

Yackinous et al., (1999) found that traditional methods of determining preferences for ranch salad dressings i.e. analysis of variance, multiple comparisons procedures and response surface methodology for sample selection yielded small differences among the 
mean acceptability values. Internal preference mapping indicated that especially for younger women, liking increased as garlic amounts increased. Garlic flavor was a stronger driver of acceptance than fat level. The least liked samples in terms of texture were those that contained the highest fat level.

\subsubsection{External Preference Mapping}

External preference mapping (also known as PREFMAP) relates the product acceptability to attributes intensity measurements obtained from a descriptive panel, and/or instrumental and chemical data. It is a way to divide a number of products on the basis of sensory characteristics and consumer acceptance simultaneously (Greenhoff and MacFie, 1994).

Hough and Sanchez (1998) used external preference mapping to study the effect of flavor and texture of powdered chocolate milk drinks made with gums. Preferences of adults and children were related to descriptive profiles as well as viscosity testing. Statistically no advantage was found for selecting the vector model over the ideal point model. The circular ideal point model contained the ranges of the formulation whereas the vector model did not, therefore, it was not the preferred model choice. Adults were in agreement about the drink characteristics they preferred while the children had more variable preferences indicating segmentation.

To relate descriptive sensory data to consumer acceptability of wheat noodles, Tang et al., (2000) used external preference maps that were developed from models derived from partial least squares regression. Independent variables in the model, or the predictors, were the mean descriptive attribute intensities. Consumer acceptance overall, 
as well as for specific attributes were the dependent variables. High weighted regression coefficients indicated the attributes with the most important contribution to the consumer acceptance parameters. Salty aftertaste had the greatest influence on consumer overall acceptance. This was related to results from "just right" scales. For samples that were least preferred the salt level was deemed to be too low by at least $50 \%$ of respondents. Overall, samples that were most accepted received $60 \%$ or more of the responses in the "just right" category with less than $30 \%$ in the "too low" categories.

The preference mapping method is gaining in popularity and can be successfully used to aid in decisions regarding which of several product formulations should be moved forward to market launch, and for specific product categories to provide information on possible consumer use segmentation and brand positioning (Jaeger et al., 2000).

Advantages of using the statistical techniques associated with preference mapping include:

1) the possibility of understanding why people prefer some products more than others when the differences between products can be detected. Sensory descriptive profiling and/or instrumental data can help to determine which differences impact on consumer acceptance (Greenhoff and MacFie, 1994).

2) individual responses may yield clusters of respondents which have particular demographic characteristics such as similar age, ethnic background, socio-economic status, etc. These groups could have totally opposing product preferences, i.e. a bimodal distribution could result. A mean score of 5 from data collected using the 9 point scale may erroneously suggest consumers neither like nor dislike the product when in fact 
some may really like it and others really dislike it depending on a particular demographic characteristic such as age, gender, etc. (Greenhoff and MacFie, 1994).

3) in external mapping it is possible to determine the relationship between the preference for a characteristic and its amount so that either a continued increase or decrease in a characteristic will result in increased preference (vector model). It is also possible to develop a more complex model and determine an optimum level (ideal point model) This is most appropriate particularly if the sample set contains high and low levels in an attempt to arrive at an optimum (Schiffman et al., 1981).

Disadvantages of external preference mapping include:

1) quality of instrumental/sensory data has a great impact on the interpretation of the data (Greenhoff and MacFie, 1994).

2) usually the external data through principal component analysis are reduced to one to three dimensions which explain a large portion of the variability. The assumption is made that these same three dimensions are what drive consumer preference. Usually they do and you can always go back and examine the other dimensions if they do not. (Greenhoff and MacFie, 1994).

3) it is difficult to assess the significance of the models that are derived. One method is to include one or more duplicate samples to see if their position on the map is similar. Another method would be to obtain responses from double the number of consumers as required, divide the group arbitrarily in half, produce the maps and find out if they are similar. (Lawless and Heymann, 1998).

4) at least six products need to be evaluated (Greenhoff and MacFie, 1994). 
5) research suggests that trained panel responses to sensory stimuli are not similar to those of consumers (Jaeger et al., 2000).

Heyd and Danzart (1998) used the evaluation of coffee by an expert panel, and 369 consumers to illustrate some of the disadvantages of external preference mapping. In this example the expert panel did not discriminate between two samples which were given different preference ratings by the consumers. In other words the data from the expert panel could not be satisfactorily modeled to the preference data.

In their study on apple varieties, Daillant-Spinnler and coworkers (1996) found that internal preference mapping using the vector model for consumer acceptability separated the varieties differently based on whether the apples were peeled or unpeeled. They also found that most consumers prefer firm, juicy and sweet apples. Also indicated was the possibility of a new breeding line as consumer vectors lay in the direction of acidity. Heyd and Danzart (1998) suggested that a quadratic model may be more appropriate noting that using the vector model for relating the consumer preference to sensory descriptors may not reflect what consumers actually think about the attributes as it contains no optimum.

Elmore et al., (1999) used internal and external preference mapping to study the creaminess of 8 pudding samples as it related to consumer preference and descriptive panel data. They evaluated 22 descriptive attributes and did analysis of variance with sample, judge and replicate as main effects and all two-way interaction effects. Sixteen of the twenty-two attributes resulted in a significant sample effect so these attributes were chosen for further analysis. Principal component analysis of the sensory data from eleven 
panelists found that $81 \%$ of the variability was explained by the first three principal components. Subsequently, data from 75 consumers were analyzed individually and models chosen according to the AUTOFIT procedure. The vector model was selected for the majority of consumers although the elliptical and circular models also were selected for some consumers suggesting that the "more is better" concept for the vector model does not apply to all consumers who prefer particular levels or a small range of levels. Flavor and appearance attributes impacted on creaminess preference so that in future it was recommended that these attributes be included in textural studies.

A study conducted by Bower and Whitten (2000) examined eight cereal bars for their preference attributes. Fifty-six consumers who regularly ate cereal bars were asked to complete a number of tasks including evaluation of preference on a 9 point hedonic scale. Eleven trained panelists evaluated the snack bars for fifty attributes including texture, color, appearance, aroma and flavor. They used partial least squares regression to determine what characteristics of the snack bars drove consumer acceptance.

Partial least squares regression is a multivariate statistical method which can be used to relate the consumers' opinions of products to the product attributes in order to better understand what drives consumer preferences. This method explains both the response variation and the prediction variation so that when the predictors are highly correlated and prediction can be made for new observations from the equation that is formed. Factors are sought which explain both the response and the predictor variation. The first factor is the first approximation to $\mathrm{X}$ and the first approximation to $\mathrm{Y}$. The second factor is the second approximation to $\mathrm{X}$ and the second approximation to $\mathrm{Y}$. 
Loadings are the correlations between how each of the consumers and each attribute relates to the principal components or factors that are generated. Weights are the linear combinations of the original variables and are similar to eigenvalues in the analysis. The weights show which predictors are represented the most in each factor. Large weights in absolute value are more important than small weights in representing the factors (SAS. 1999).

Bower and Whitten (2000) found that caramel flavor, nutty aroma, thick appearance and chocolate flavor were attributes that positively influenced the degree of liking. Liking was negatively influenced by fruity bars with sour, aromatic and sweet attributes attached to them. Textural attributes were less influential but "partial resistance", a characteristic related to chewiness, seemed to have some positive influence on degree of liking. Bower and Whitten (2000) concluded that the bars in this study were found to be significantly different in acceptability. Information regarding the attributes responsible for product liking provided more information than the acceptability testing on its own.

\subsubsection{Experimental Design for Recipe Formulations}

A number of advantages have been cited for using the experimental design approach to product development in contrast to the one variable at a time technique. Successful implementation of the experimental design hinges on identifying the important product attributes and what ingredients and processes lead to these and then measuring appropriate responses. In selecting the design, a smaller number of runs is preferred due to cost considerations but it is necessary to include enough runs so that the experimental 
error and goodness of the model fit can be tested ( $\mathrm{Hu}, 1999)$.

In recipe formulation a change in one ingredient results in the change of at least one other ingredient because the total proportion is set to a maximum of $100 \%$. The ratio of ingredients is inter-dependent. A mixture experimental design is appropriate in this case which uses a different model than the usual factorial experiment. The design space is represented as a contained figure for more than two ingredients. Figure 2.2 represents the design space for a design with three ingredients.

The model used is a Scheffé polynomial model which has the same number of components as well as the same degree as the model from factorial experiments but a smaller number of coefficients. In the quadratic model for the mixture experiment, $X_{1} *$ $X_{2}$ cannot be considered an interaction effect because $X_{1}$ and $X_{2}$ are not independent of each other, that is one variable cannot be changed without having an effect on the other. This actually describes the nonlinear mixture effect of the two factors.

Models for the first and second degree Scheffé polynomials in the general form are shown below:

$$
\begin{aligned}
& \mathrm{Z}=\sum_{j=1}^{n} B_{j} X_{j} \text { (first-degree model) } \\
& \mathrm{Z}=\sum_{j=1}^{n} B_{j *} X_{j}+\sum_{j<k=2} B_{j k} * X_{j} X_{k} \text { (second-degree model) }
\end{aligned}
$$

The first-degree or linear model is the simplest in which case the assumption is that the recipe ingredients are additive in their effect on the response (index of quality) that is being measured. In practice it is usual that the index of quality from more complex 
Figure 2.2. Region in the simplex coordinate system for a three component mixture design with design points $1=$ constraint plane centroid (PlaneCent); $2=$ interior (Interior); $3=$ vertex (Vertex); 4=centre of edges (CentEdge).

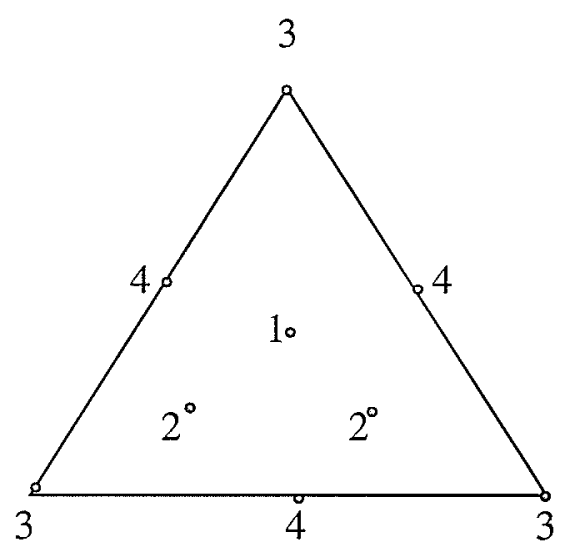

Source: Design-Expert Software (2000) 
formulations is better estimated by a polynomial model. Most often a second-degree or quadratic model is appropriate for describing the simplex design surface (Hu, 1999). 


\section{CHAPTER 3}

\section{MATERIALS AND METHODS}

\subsection{Materials}

\subsubsection{Micronized Flaked Lentils}

Processing was done at InfraReady Products (1998) Ltd., Saskatoon, SK. Eston lentils were tempered and held to equilibrate at room temperature in a 2 metric tonne tempering bin. A gas fired 2 ton capacity Micronizer Model No. MR20 was used for processing. Immediately after micronization, lentils were fed through a Turner Ipswich Flaker Model No. 460 with roller mill set to produce the desired thickness. Final moisture and temperature were recorded. Details regarding the processing parameters for four batches of lentils are found in Table 3.1.

\subsubsection{Ingredients}

Table 3.2 lists the product, manufacturer, ingredients, nutrient information and other details for components that were used to produce the experimental lentil bars. All products were purchased from retail supermarkets except for liquid honey which was obtained from the local honey cooperative.

\subsubsection{Commercial Samples}

Four commercial snack bars were purchased from retail supermarkets. Label information regarding manufacturer, ingredients and nutrient content are shown in Table 3.3A-D.

3.2 Methods

\subsubsection{Bar Formulation and Feasibility}


Table 3.1. Detailed processing parameters for micronized flaked lentils.

\begin{tabular}{|c|c|c|c|c|c|c|c|c|c|c|}
\hline Batch \# & Received & Lot \# & Grade & $\begin{array}{l}\text { Crop } \\
\text { Year }\end{array}$ & $\begin{array}{l}\text { Temp } \\
\%\end{array}$ & $\begin{array}{l}\text { ering } \\
\mathrm{hr}\end{array}$ & $\begin{array}{l}\text { Final } . \\
\text { Temperature } \\
{ }^{\circ} \mathrm{C}\end{array}$ & $\begin{array}{c}\text { Initial } \\
\text { Moisture } \\
\quad \%\end{array}$ & $\begin{array}{l}\text { Final } \\
\text { Moisture } \\
\quad \%\end{array}$ & $\begin{array}{c}\text { Flake } \\
\text { Thickness } \\
\text { mm }\end{array}$ \\
\hline 1 & July, 2000 & $20000 \mathrm{~T}$ & - & 1999 & - & - & - & - & - & $1.2-1.4$ \\
\hline 2 & May, 2001 & $12101^{1}$ & 1 & 2000 & 16.5 & 16 & 126 & 12.22 & 8.02 & $1.3-1.4$ \\
\hline 3 & May, 2002 & 14202 & 2 & 2001 & 15.14 & 16 & $120-125$ & 10.15 & 10.07 & $1.3-1.6$ \\
\hline $4^{2}$ & Sept., 2002 & - & 1 & 2001 & - & - & $115-117$ & 8.24 & - & $1.7-1.8$ \\
\hline
\end{tabular}

- unknown

${ }^{1}$ Foreign material was $0.1 \%$ wheat with $0.1 \%$ discoloured seed

${ }^{2}$ Sample not used due to high level of obviously visible foreign material 
Table 3.2. Product, manufacturer, ingredients, nutrient information and other comments for components of lentil snack bars.

\begin{tabular}{|c|c|c|c|}
\hline Product & Manufacturer & Ingredients & Nutrient Information and other comments \\
\hline $\begin{array}{l}\text { Low Fat Sweetened } \\
\text { Condensed Milk }\end{array}$ & $\begin{array}{l}\text { prepared for } \\
\text { Eagle Family Foods Inc. } \\
\text { Gahannia, OH } 43230 \\
\text { Bee-Maid }\end{array}$ & $\begin{array}{l}\text { concentrated partly } \\
\text { skimmed milk, liquid sugar } \\
\text { lactose }\end{array}$ & $\begin{array}{l}\text { per } 30 \mathrm{~mL} \text { serving ( } 2 \mathrm{Tbsp}) \\
\text { energy } 117 \mathrm{Cal} \\
\text { protein } 3.0 \mathrm{~g} \\
\text { fat } 1.5 \mathrm{~g} \\
\text { carbohydrate } 23 \mathrm{~g}\end{array}$ \\
\hline $\begin{array}{l}\text { Oats - Quick } \\
\text { cooks in } 3 \text { to } 5 \text { minutes } \\
\text { (rolled slightly finer than } \\
\text { large flake oats to allow } \\
\text { for a shorter cooking time) }\end{array}$ & $\begin{array}{l}\text { Quaker } \\
\text { The Quaker Oats } \\
\text { Company of Canada, } \\
\text { Peterborough, ON K9J 7B2 }\end{array}$ & $\begin{array}{l}100 \% \text { rolled oats, } \\
\text { naturally contains oat bran }\end{array}$ & $\begin{array}{l}\text { per } 30 \mathrm{~g} \text { serving }(1 / 3 \mathrm{cup}) \\
\text { energy } 114 \mathrm{Cal} \\
\text { protein } 4.2 \mathrm{~g} \\
\text { fat } 2.0 \mathrm{~g} \\
\text { carbohydrate } 20 \mathrm{~g} \\
\text { dietary fibre } 3 \mathrm{~g} \\
\text { no additives or preservatives - } 100 \% \text { whole } \\
\quad \text { grain- low fat }\end{array}$ \\
\hline Canola Oil & $\begin{array}{l}\text { Canbra Foods, } \\
\text { Lethbridge AB T1J } 3 \text { Y4 }\end{array}$ & & $\begin{array}{l}\text { per } 10 \mathrm{~mL} \text { serving ( } 2 \mathrm{tsp}) \\
\text { energy } 83 \mathrm{Cal} \\
\text { protein } 0 \mathrm{~g} \\
\text { fat } 9.2 \mathrm{~g} \\
\text { carbohydrate } 0 \mathrm{~g} \\
\text { lowest in saturated fat among vegetable oils }\end{array}$ \\
\hline
\end{tabular}


Table 3.2. Product, manufacturer, ingredients, nutrient information and other comments for components of lentil snack bars. (cont'd)

\begin{tabular}{|c|c|c|c|}
\hline Product & Manufacturer & Ingredients & Nutrient Information and other comments \\
\hline Dried Cranberries & $\begin{array}{l}\text { prepared for } \\
\text { Sunfresh Limited, } \\
\text { Toronto, ON M4T 2S8 } \\
\text { Montreal, QC H2M 2R9 }\end{array}$ & $\begin{array}{l}\text { cranberries, sugar, } \\
\text { sunflower oil }\end{array}$ & $\begin{array}{l}\text { Per } 40 \mathrm{~g} \text {. serving } \\
\text { energy } 119 \mathrm{Cal} \\
\text { protein } 0.1 \mathrm{~g} \\
\text { total fat } 0.6 \mathrm{~g} \\
\text { total carbohydrate } 33 \mathrm{~g} \\
\text { dietary fibre } 2.3 \mathrm{~g} \\
\text { sodium } 1 \mathrm{mg} \\
\text { potassium } 16 \mathrm{mg} \\
\text { calcium } 0 \% \\
\text { iron } 2 \% \\
\text { Vitamin A } 0 \% \\
\text { Vitamin C } 0 \% \\
\text { may contain traces of peanuts and/or other } \\
\text { nuts }\end{array}$ \\
\hline Olive Oil Pam & & $\begin{array}{l}\text { 100\% extra virgin olive oil, } \\
\text { grain alcohol, soya lecithin } \\
\text { and propellants isobutane } \\
\text { and propane }\end{array}$ & $\begin{array}{l}\text { per } 0.5 \mathrm{~g} 0.6 \text { second spray } \\
\text { energy } 4 \mathrm{Cal}^{*} \\
\text { protein } 0 \mathrm{~g} \\
\text { fat } 0.4 \mathrm{~g} \\
\text { carbohydrate } 0.1 \\
\text { *approx. } 2 \text { Cal are absorbed by food }\end{array}$ \\
\hline
\end{tabular}


Table 3.3. Manufacturer, ingredients and nutrient content for commercial snack bar samples.

\section{A. Low Fat Ginseng Blueberry Chewy Energy Bar}

Manufactured by: Sunny Crunch, Markham, Ontario. L3R 1G2

Ingredients: granola cereal, rolled oats, wheat flakes, brown sugar, soyabean oil, honey, whey powder, glycerine, sliced almonds, honey, soya lecithin, Canadian Ginseng, flavor enhancers (citric acid, malic acid, tartaric acid, natural and artificial flavors, may contain peanut traces

Nutrition Information: per $30 \mathrm{~g}$ (1 bar serving)

Energy $118 \mathrm{Cal}$

Protein $1.8 \mathrm{~g}$

Fat $2.2 \mathrm{~g}$

Carbohydrate $23 \mathrm{~g}$

Ginseng $50 \mathrm{mg}$

\section{B. Nature Valley Crunchy Granola Bar - Oats 'n' Honey - 100\% All Natural Ingredients}

Imported by: General Mills Canada, Inc. Mississauga, Ontario L4W 5K2

Ingredients: rolled oats, sugar, vegetable oil (canola), refiner's syrup, honey, salt, crisp rice ( rice flour, soy protein, sugar, malt, salt), soy lecithin. Contains soy ingredients. May contain traces of peanuts and/or other nuts.

Nutrition Information: per $23 \mathrm{~g}$ ( 1 bar serving)

Energy $106 \mathrm{Cal}$

Protein $1.9 \mathrm{~g}$

Fat $4.4 \mathrm{~g}$

Carbohydrate $69.6 \mathrm{~g}$

Sugars $6.0 \mathrm{~g}$

Starch $8.6 \mathrm{~g}$

Dietary Fibre $1.4 \mathrm{~g}$ 
Table 3.3. Manufacturer, ingredients and nutrient content for commercial snack bar samples. (cont'd)

\section{Quaker Granola Bar - Chewy - Honey Raisin with California raisins - CB1}

Manufactured by: The Quaker Oats Company of Canada Limited Peterborough, ON K9J 7B2

Ingredients: granola (Quaker rolled oats, rolled whole wheat, brown sugar, coconut oil, modified milk ingredients, dried unsweetened coconut, honey, almonds, natural flavor), glucose, raisins coated with hydrogenated cottonseed and/or soybean oil, corn flakes (milled corn, sugar, salt, barley malt, corn syrup), crisp rice (rice flour, sugar, malt extract, salt), glycerin, hydrogenated vegetable oil, shortening (soybean and/or cottonseed and/or modified palm oil), invert sugar, brown sugar, honey, sorbitol (less that $0.5 \mathrm{~g}$ per serving), salt, natural flavor (contains gluten), soy lecithin, BHA (a preservative), citric acid. May contain traces of peanuts and nuts.

Nutrition Information: per $26 \mathrm{~g}$ ( 1 bar serving)

Energy $106 \mathrm{cal}$

Protein $1.4 \mathrm{~g}$

Fat $2.6 \mathrm{~g}$

Carbohydrate $19 \mathrm{~g}$

Sugars $7.3 \mathrm{~g}$

Starch $11 \mathrm{~g}$

Dietary Fibre $1.0 \mathrm{~g}$ 
Table 3.3. Manufacturer, ingredients and nutrient content for commercial snack bar samples. (cont'd)

\section{Quaker Oatmeal to Go - Oats and Honey - CB2}

Manufactured by: QTG Canada Limited, Peterborough, ON K9J 7B2

Ingredients: instant quaker oatmeal (whole grain rolled oats with oat bran), icing sugar (may contain corn starch or wheat starch), salt, iron (coated with hydrogenated soybean oil), niacinamide, thiamine mononitrate (Vitamin B1), calcium pantothenate pyridoxine hydrochloride (Vitamin B6), folic acid, glucose, brown sugar, hydrogenated vegetable oil shortening (canola, palm and/or cottonseed, soybean), glycerin, invert sugar, coconut oil, sorbitol) less than $1.0 \mathrm{~g}$ per serving), honey, salt, soy lecithin, vanilla extract, natural and artificial flavours, BHA (preservative), citric acid Contains wheat, soy, coconut, and sulphite ingredients. May contain traces of peanuts and other nuts.

Nutrition Information: per $47 \mathrm{~g}$ (1 bar serving)

Energy $194 \mathrm{cal}$

Protein $3.2 \mathrm{~g}$

Fat $5.5 \mathrm{~g}$

Carbohydrate $33 \mathrm{~g}$

Sugars $13 \mathrm{~g}$

Starch $18 \mathrm{~g}$

Dietary Fibre $2.5 \mathrm{~g}$

\section{Additional Comments:}

Goodness on the Go:

All of the nutrition of a bowl of Quaker Oatmeal

$100 \%$ wholegrain Quaker oats

Source of dietary fibre 
A recipe was formulated based on percentage by weight of ingredients using published guidelines (Robbins, 1976) both with and without dried blueberries (Appendix 1A) from Lentil Batch \#1 (Table 3.1).

Sensory evaluation was conducted in two parts. A research group, consisting of four members, evaluated the bars to determine if the product was viable. A positive response warranted further testing with a small group of consumers to obtain quantitative data regarding acceptability and attribute analysis.

The consumers consisted of a group of students enrolled in a sensory evaluation class in the Faculty of Human Ecology at the University of Manitoba. Consent was obtained from ten consumers. Consumers evaluated the bars in individual booths equipped with fluorescent lights. Samples were placed in resealable plastic snack bags $(16.5 \times 8.25 \mathrm{~cm})$, assigned three-digit random number codes and presented in balanced order. The blueberry lentil bar was presented with a commercial sample (Table 3.3A).

The ten consumers evaluated both snack bars for overall acceptability on a 9 point scale from "like extremely" to "dislike extremely". Attribute analysis was performed to obtain opinions regarding the color, amount of blueberries, sweetness, blueberry flavor, thickness, firmness, chewiness and moistness. A ten point scale was used with 5-6 being "just right" and endpoints described as shown in Table 4.1.

\subsubsection{Quality Criteria}

\subsubsection{Lentil Quality}

As an indicator of the degree of lentil cooking by micronization and therefore softness, DSC was used to measure starch gelatinization following the method of 
Biliaderis et al., 1980. Instrumentation was a Dupont 9900 thermal analyzer with a 910 DSC cell base. Analysis, conducted by personnel in the Department of Food Science at the University of Manitoba, was run in duplicate for the four batches of lentils obtained from the processor (Table 3.1) as well as a raw sample of Eston lentils.

\subsubsection{Moisture Content}

The method for determining the percentage of total solids (\% total solids) was based on the two-stage AACC Method 44-15A (American Association of Cereal Chemists, 2000). Analysis was done in duplicate.

Lentil snack bar samples were held in double wrapped foil at room temperature for approximately 4 weeks before analysis. Commercial snack bars were removed from the original packaging just prior to analysis. A Fisher Isotemp Oven Model 655F was preheated to $130 \pm 2^{\circ} \mathrm{C}$. Fifteen to eighteen grams of representative crumbled sample were placed into moisture dishes and held on top of the oven for approximately 17 hours. Sample weight after drying in air was recorded.

The air dried sample was ground in a Proctor Silex Automatic Coffee Mill E1657 for 1 minute (samples with no cranberries) to 2 minutes (samples with cranberries) to a powder like consistency. Approximately 2 grams of the ground sample were placed in moisture dishes and dried in the oven at $130 \pm 2^{\circ} \mathrm{C}$ for 1 hour. Samples were held in a desiccator approximately 45 minutes before weighing.

\subsubsection{Water Activity}

Lentil snack bar samples were held in double wrapped foil at room temperature for approximately 3 weeks before analysis. Commercial snack bars were removed from 
the original packaging just prior to analysis.

Water activity $\left(\mathrm{a}_{\mathrm{w}}\right)$ was measured using the AWSprint - Novasina Swiss- made TH-500 instrument which was calibrated and set to $25^{\circ} \mathrm{C}$. Samples were crumbled and placed in the plastic sample dish $(4 \mathrm{~cm}$ diameter by $1 \mathrm{~cm}$ high) to the fill line (about $1 / 2$ full). Samples were tested randomly and duplicates performed. The next sample to be tested was prepared after the previous duplicate sample was placed in the machine. Samples were covered prior to testing to prevent moisture loss.

\subsubsection{Nutrient Content}

Weights for each ingredient for each lentil bar sample were entered into the Owl Software TechWizard Vers. 3 program (2003) which uses the USDA nutrient database. Note that the following substitutions were made as the actual ingredients used were not found in the database: regular fat sweetened condensed milk for low fat sweetened condensed milk, regular cranberries for dried, olive oil for canola oil and raw lentils for micronized flaked lentils. Nutrient content was based on a $30 \mathrm{~g}$ serving size for one snack bar (Canada Gazette, 2002). For comparison to a snack bar containing no lentils each sample was also analyzed substituting oats for all of the lentils.

\subsubsection{Consumer Focus Groups}

\subsubsection{Samples}

Revisions to formulations were based on the results from the preliminary work and appear in Appendix 1B and 1C. Dried fruit was changed from blueberry to cranberry due to its more appealing appearance and lower cost. Two commercial snack bars were also presented as described in Table 3.3B and C. Micronized flaked lentils from Batch 2 
were used (Table 3.1).

\subsubsection{Panelist Recruitment and Selection}

Procedures for panelist recruitment and selection were approved by the Ethical Review Board of the Faculty of Human Ecology, University of Manitoba. See Appendix 2A for the Approval Certificate.

Advertisements for volunteer tasters were placed in the Lance community newspaper for the Winnipeg South area for two consecutive weeks, in one issue of the University of Manitoba Bulletin, a bimonthly newspaper (once monthly during June, July, August and December), on the University of Manitoba web-site in the classified section, and in an e-memo which was distributed to all employees of the University of Manitoba with e-mail accounts. Respondents were sent the information letter, consent form and questionnaires (Appendix 3A). Of the 33 inquiries made approximately $36 \%$ participated. The consent form and questionnaires were completed and brought to the session. Four focus groups were conducted on four days, 2 at 19:00, 1 at 16:45 and 1 at 12:15, with three or four participants each for a total of 14 consumers.

\subsubsection{Methods}

The outline shown in Appendix 4 was followed for each focus group to elicit discussion. Four samples, one plain and one cranberry lentil bar plus two commercial snack bars were presented individually wrapped in resealable plastic snack bags $(16.5 \mathrm{x}$ $8.25 \mathrm{~cm}$ ) and labeled with a three-digit random number. Deionized water was available for rinsing as required. General comments were solicited regarding reasons for selecting snack bars, likes and dislikes, followed by sample observation ending with tasting of the 
samples. Sessions were audio recorded and lasted from 60 to 90 minutes.

\subsubsection{Mixture Design Experiment}

As noted by Greenhoff and MacFie (1994) at least eight products need to be assessed by both a descriptive panel and a consumer panel in order to obtain reliable data for internal preference mapping analysis. Samples need to be different enough so that consumers can provide preference ratings based on actual perceived attribute differences. A mixture design experiment was chosen as the method for selecting six lentil bar formulations. Two commercial snack bars representing different types of bars were used to complete the set of eight.

Steps in recipe design were followed according to $\mathrm{Hu}$ (1999) - ingredient screening, mixture experiment design, model building, model test and finally model application where optimization and predictions can be made based on the significant model.

All of the five ingredients were included in the design as they all have an effect on the flavor and texture of the product which ultimately affects the quality and acceptability of the snack bars. Minimum and maximum levels for each of the five ingredients were set based on the preliminary formulation trying to incorporate as many MFL as possible, having samples with and without dried cranberries, and increasing honey overall to compensate for increased overall dry ingredients that would result for some formulations (Table 3.4). For each of the 25 experimental runs the total of the proportions for the five ingredients was approximately 1 (Table 3.5).

A d-optimal mixture design experiment was selected using the computer program 
Table 3.4. Ingredient proportions used with corresponding percentages of preliminary formulation.

\begin{tabular}{lccccc}
\hline Ingredient & $\begin{array}{c}\text { Preliminary } \\
\text { Formulation } \\
(\mathrm{g})\end{array}$ & $\begin{array}{l}\text { Minimum } \\
\text { Proportion }\end{array}$ & $\begin{array}{l}\text { Percentage of } \\
\text { Preliminary } \\
\text { Formulation }\end{array}$ & $\begin{array}{l}\text { Maximum } \\
\text { Proportion }\end{array}$ & $\begin{array}{l}\text { Percentage of } \\
\text { Preliminary } \\
\text { Formulation }\end{array}$ \\
\hline $\begin{array}{l}\text { Sweetened } \\
\text { Condensed Milk }\end{array}$ & 220 & 0.28 & $18 \downarrow^{1}$ & 0.40 & $181^{2}$ \\
Honey & 30 & 0.06 & $33 \downarrow$ & 0.12 & $167 \uparrow$ \\
$\begin{array}{l}\text { Micronized } \\
\text { Flaked Lentils }\end{array}$ & 140 & 0.19 & $14 \downarrow$ & 0.37 & $71 \uparrow$ \\
Granola & 180 & 0.20 & $28 \downarrow$ & 0.40 & $44 \uparrow$ \\
Dried Cranberries & 80 & 0 & $100 \downarrow$ & 0.12 & 100 \\
\hline
\end{tabular}

${ }^{1}$ Indicates decrease from original proportion

${ }^{2}$ Indicates increase from original proportion 
Table 3.5. Proportions of ingredients used for 25 runs used in mixture design experiment.

\begin{tabular}{|c|c|c|c|c|c|c|c|}
\hline \multicolumn{2}{|c|}{$\begin{array}{l}\text { Standard Run Order } \\
\text { Order }\end{array}$} & \multirow{2}{*}{$\begin{array}{l}\text { Point Type }^{1} \\
\text { CentEdge }\end{array}$} & \multirow{2}{*}{$\begin{array}{l}\mathrm{SCM}^{2} \\
0.34^{4}\end{array}$} & \multirow{2}{*}{$\begin{array}{l}\text { Honey } \\
0.12^{4}\end{array}$} & \multirow{2}{*}{$\begin{array}{c}\mathrm{MFL}^{3} \\
0.19^{4}\end{array}$} & \multicolumn{2}{|c|}{$\begin{array}{l}\text { Granola Dried } \\
\text { Cranberries }\end{array}$} \\
\hline 19 & 1 & & & & & $0.34^{4}$ & $0.00^{4}$ \\
\hline 17 & 2 & CentEdge & 0.28 & 0.06 & 0.27 & 0.28 & 0.12 \\
\hline 18 & 3 & CentEdge & 0.40 & 0.12 & 0.19 & 0.25 & 0.05 \\
\hline 13 & 4 & Vertex & 0.37 & 0.12 & 0.19 & 0.20 & 0.12 \\
\hline 15 & 5 & PlaneCent & 0.35 & 0.09 & 0.29 & 0.20 & 0.07 \\
\hline 21 & $6^{5}$ & CentEdge & 0.28 & 0.09 & 0.19 & 0.32 & 0.12 \\
\hline 23 & $7^{5}$ & Vertex & 0.28 & 0.06 & 0.19 & 0.40 & 0.07 \\
\hline 6 & $8^{5}$ & CentEdge & 0.28 & 0.09 & 0.19 & 0.32 & 0.12 \\
\hline 22 & $9^{5}$ & CentEdge & 0.28 & 0.12 & 0.37 & 0.22 & 0.02 \\
\hline 25 & $10^{5}$ & CentEdge & 0.28 & 0.06 & 0.32 & 0.35 & 0.00 \\
\hline 1 & $11^{5}$ & CentEdge & 0.28 & 0.12 & 0.37 & 0.22 & 0.02 \\
\hline 7 & $12^{5}$ & Vertex & 0.28 & 0.06 & 0.19 & 0.40 & 0.07 \\
\hline 20 & 13 & CentEdge & 0.40 & 0.06 & 0.27 & 0.28 & 0.00 \\
\hline 11 & 14 & CentEdge & 0.34 & 0.06 & 0.19 & 0.29 & 0.12 \\
\hline 9 & $15^{5}$ & CentEdge & 0.28 & 0.06 & 0.32 & 0.35 & 0.00 \\
\hline 4 & 16 & Vertex & 0.40 & 0.06 & 0.22 & 0.20 & 0.12 \\
\hline 2 & 17 & Vertex & 0.28 & 0.12 & 0.28 & 0.20 & 0.12 \\
\hline 12 & 18 & Vertex & 0.40 & 0.12 & 0.28 & 0.20 & 0.00 \\
\hline 8 & $19^{5}$ & Vertex & 0.37 & 0.06 & 0.37 & 0.20 & 0.00 \\
\hline 3 & 20 & CentEdge & 0.28 & 0.12 & 0.19 & 0.35 & 0.07 \\
\hline 16 & 21 & Interior & 0.33 & 0.09 & 0.27 & 0.28 & 0.03 \\
\hline 24 & $22^{5}$ & Vertex & 0.37 & 0.06 & 0.37 & 0.20 & 0.00 \\
\hline 10 & 23 & Vertex & 0.28 & 0.06 & 0.37 & 0.20 & 0.09 \\
\hline 5 & 24 & Vertex & 0.40 & 0.06 & 0.19 & 0.35 & 0.00 \\
\hline 14 & 25 & Vertex & 0.28 & 0.12 & 0.20 & 0.40 & 0.00 \\
\hline
\end{tabular}

${ }^{1}$ Mixture design points defined in Figure 2.2

${ }^{2}$ Sweetened Condensed Milk

${ }^{3}$ Micronized Flaked Lentils

${ }^{4}$ Proportion of ingredient in total formulation where $\sum \mathrm{x} \approx 1$

${ }^{5}$ Replicated samples 
Design-Expert (Stat-Ease, 2000). The 25-run design was not blocked and contained 15 runs used to form the model, 5 to test for lack of fit and 5 which were replicates (Table 3.5).

\subsubsection{Sample Preparation}

The formulations for each of the 25 runs were determined using the proportion for each ingredient as noted in the design, multiplied by 650 which was the total weight in grams from the preliminary formulation including dried cranberries.

Baking was completed within a one week period. Five runs were baked on each day with duplicate runs 6 and 8;9 and 11;10 and 15; 7 and 12;19 and 22 baked on different days (Table 3.6).

Granola was made for all of the 25 batches on the same day in 5 lots and stored for approximately one week. The methods for granola and lentil bar preparation are given in Appendix 1B (plain bars) and Appendix 1C (cranberry bars). Micronized flaked lentils from Batch 3 were used (Table 3.1). Ingredients and sources are listed in Table 3.2.

Percent yield on a per batch basis for each of the twenty-five samples was calculated as: cooked weight $\div$ raw weight $\times 100$. Percent cooking loss $(\% \mathrm{CL})$ was 100 $\%$ Yield.

\subsubsection{Measurement of Response Variables}

An expert panel of seven members was recruited to evaluate the intensity of the flavor and texture attributes of the twenty-five lentil bar samples using a $15 \mathrm{~cm}$ line scale. These panelists had worked in the area of sensory evaluation and had evaluated many products to determine their flavor and textural characteristics using a variety of 


\section{Table 3.6. Baking schedule for mixture design experiment.}

\begin{tabular}{ll} 
Day & Run Number \\
\hline & \\
1 & $1,2,6,9,10$ \\
2 & $3,7,8,4,5$ \\
3 & $11,12,13,14,25$ \\
4 & $16,17,18,19,20$ \\
5 & $21,22,23,24,15$ \\
\hline
\end{tabular}


measurement methods.

\subsection{Part 1 - Development of Sensory Evaluation Method}

Panelists used the reference sample (Appendix 1D) to:

1. Determine the method to evaluate samples (Figures 3.1 and 3.2)

2. Determine attributes to evaluate, definitions, order for evaluation, endpoint descriptors (Table 3.7).

3. Determine intensity of the attributes for the reference sample (Table 3.7).

Samples were prepared for serving one day before the panel evaluation. Samples were removed from the freezer about 15 to 30 minutes before cutting. Approximately 0.5 $\mathrm{cm}$ was removed from the edges. Seven pieces were cut approximately $10 \mathrm{~cm} \times 4 \mathrm{~cm} \times 1$ $\mathrm{cm}$ thick. Each piece was placed individually in a resealable plastic snack bag ( $16.5 \mathrm{x}$ $8.25 \mathrm{~cm}$ ). A three-digit random number was assigned to each of the 25 runs. The reference sample was labeled REF. Panelists were each given two reference samples.

\subsection{Part 2 - Evaluation of 25 Samples}

Panelists were instructed to evaluate the reference sample first and then to evaluate the coded samples in relation to the reference sample, recording results in Figures 3.1 and 3.2. Filtered water was available for rinsing between samples.

A random order for evaluation of the 25 samples was selected for each panelist. A break was taken after every five samples with a longer break after the first 15 .

\subsubsection{Consumer Panel}

\subsubsection{Sample Preparation}

The six lentil snack bar formulations (LB1 to LB6) selected from the mixture 
Figure 3.1. Ballot used for flavor evaluation by expert panel in mixture design experiment.

Panelist No.

Date

\section{Method for Evaluation}

Thoroughly rinse your mouth with water. Take a bite about $1 \mathrm{~cm}$ wide from the end of the bar. Note: Chew carefully as the odd hard seed may be encountered.

\section{Instructions}

Place a vertical line across the horizontal line at the point that best represents the intensity of the attribute in the sample.

Evaluate the samples in the following order:

Sweetness

\begin{tabular}{lll} 
& REF & \\
\hline low & high
\end{tabular}

Oat Flavor

low \begin{tabular}{lll} 
REF & \\
\hline
\end{tabular}

Fruity

\begin{tabular}{lll} 
REF & \\
\hline low & high
\end{tabular}

Toasted

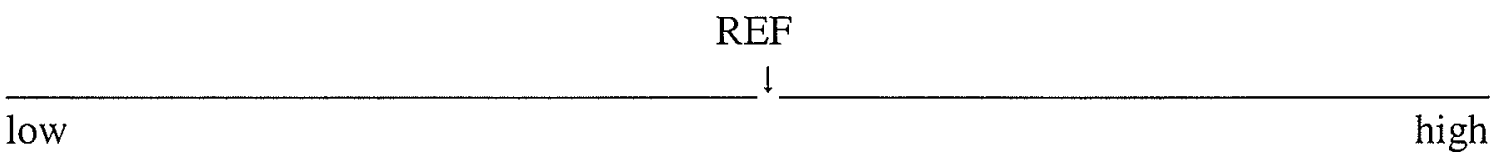

Stickiness to Touch

REF

low

high

Comments 
Figure 3.2. Ballot used for texture evaluation by expert panel in mixture design experiment.

Panelist No.

Date

\section{Method for Evaluation}

Thoroughly rinse your mouth with water. Take a bite about $1 \mathrm{~cm}$ wide from the end of the bar. Note: Chew carefully as the odd hard seed may be encountered.

\section{Instructions}

Place a vertical line across the horizontal line at the point that best represents the intensity of the attribute in the sample.

Evaluate the samples in the following order:

Initial Bite

\begin{tabular}{lll} 
& REF & \\
\hline soft & $\downarrow$ \\
& hard
\end{tabular}

Cohesiveness

\begin{tabular}{lll} 
& REF & \\
\hline low & & \\
$\downarrow$ & high
\end{tabular}

Moistness

$\begin{array}{lll}\text { REF } & \\ \text { dry } & \text { wet }\end{array}$

Chewiness

low $\quad$ REF

Toothpack

REF

low

high 
Table 3.7. Attribute definitions, reference point and endpoint descriptors used by expert panel $n=7$.

\begin{tabular}{|c|c|c|c|c|}
\hline \multicolumn{2}{|c|}{$\begin{array}{l}\text { Attribute Definition } \\
\text { (evaluated in order listed) }\end{array}$} & \multirow{2}{*}{$\begin{array}{l}\text { Marked } \\
\text { REF Point } \\
7.5\end{array}$} & \multirow{2}{*}{$\begin{array}{l}\text { Descriptor } \\
\text { For } 0 \mathrm{~cm}\end{array}$} & \multirow{2}{*}{$\begin{array}{l}\text { Descriptor } \\
\text { For } 15 \mathrm{~cm}\end{array}$} \\
\hline Sweetness & taste associated with sucrose & & & \\
\hline Oat Flavor & flavor of cooked oats & 7.5 & low & high \\
\hline Fruity & flavor of fruit & 2.0 & low & high \\
\hline Toasted Flavor & $\begin{array}{l}\text { perceived after oat flavor, } \\
\text { possibly a spicy note }\end{array}$ & 7.5 & low & high \\
\hline Stickiness to Touch & amount finger adheres to sample surface & 7.5 & low & high \\
\hline Initial Bite & $\begin{array}{l}\text { assessed by compressing } \\
\text { the sample with the front teeth }\end{array}$ & 7.5 & soft & hard \\
\hline Cohesiveness & $\begin{array}{l}\text { the amount the sample remains } \\
\text { together throughout chewing }\end{array}$ & 7.5 & low & high \\
\hline Moistness & $\begin{array}{l}\text { the amount of moisture } \\
\text { perceived during chewing }\end{array}$ & 7.5 & dry & wet \\
\hline Chewiness & $\begin{array}{l}\text { the amount of chewing required to } \\
\text { reduce the sample to a state ready to swallow }\end{array}$ & 7.5 & low & high \\
\hline Toothpack & $\begin{array}{l}\text { the amount of sample adhering in or } \\
\text { around the teeth after swallowing }\end{array}$ & 7.5 & low & high \\
\hline
\end{tabular}


design experiment (Table 4.15) were prepared using the standard method (Appendix 1B or 1C). Micronized flaked lentils from Batch 2 were used (Table 3.1). In order to produce enough samples three batches of lentil snack bars were made during two consecutive days. The six samples were prepared in a different random order for each of the three batches, one batch baked on one day and two batches the following day. Each batch was wrapped in two layers of aluminum foil and kept in the dark at room temperature from 9 to 13 days before evaluation.

Lentil snack bar samples for panel presentation were prepared approximately 24 hours prior to evaluation by trimming about $1 \mathrm{~cm}$ from the edges and cutting into pieces 5 $\mathrm{cm} \times 3 \mathrm{~cm}$. Each batch made 28 lentil bars each weighting approximately 19 grams each. Bars were placed in resealable plastic snack bags $(16.5 \times 8.25 \mathrm{~cm})$ and labeled with threedigit random numbers.

\subsubsection{Commercial Samples}

Two commercial snack bars (CB1 and CB2) (Table 3.3C and D respectively) were selected that demonstrated contrasting flavor and textural characteristics. These bars were held at room temperature and used within the recommended six month expiry period.

Samples of CB1 and CB2 were cut to a length of $5 \mathrm{~cm}$ and measured $2.5 \mathrm{~cm}$ and 4 $\mathrm{cm}$ in width respectively. $\mathrm{CB} 1$ samples each weighed approximately 13 grams. $\mathrm{CB} 2$ samples each weighed approximately 29 grams. The commercial snack bar samples were placed in resealable plastic snack bags in the same manner as for the lentil bars.

\subsubsection{Panelist Recruitment and Selection}


Ethical procedures were followed and approved according to the protocol outlined by the Joint Ethics Review Board at the University of Manitoba. (See Appendix 2B for Approval Certificate). A letter of invitation included a consent form, questionnaire regarding food likes/dislikes and allergies, and a questionnaire regarding personal information and consumption of snack bars. These were completed by consumers agreeing to participate on the panel (Appendix 3B). Women aged 18 to 50 were invited to participate based on the target group for the lentil bars. An e-mail was sent to members within the Faculty of Human Ecology and an announcement made in undergraduate and graduate foods courses as part of the recruitment process. Posters were also placed throughout the faculty. Sixty-two consumers agreed to participate. An honorarium was provided.

\subsubsection{Sensory Evaluation Methods}

Consumer testing was conducted over four days during one week with up to eight panelists evaluating the bars at one time. Panelists were instructed to perform the following tasks. The first part of the evaluation was to indicate how much the sample was liked and how often it would be purchased. The second part included a series of "just right" scales where panelists gave their opinions of the following attributes: stickiness to touch with your fingers, sweetness, cereal/grain flavor, cranberry flavor (if present), firmness, chewiness and moistness by checking the appropriate box on a 7 point scale with end points "not enough" and "too much" and mid point "just right". Ballots are shown in Figures 3.3 and 3.4.

All eight snack bar samples were presented at once in a Latin square design which 
Figure 3.3. Ballot used by consumer panel for overall acceptability and purchase behaviour.

\section{Instructions}

Panelist No.

Your task for each of the eight snack bar samples is to

1. Evaluate how much you like the bar.

2. Determine how often you would purchase it.

3. Tell us your opinion regarding the flavor and texture characteristics.

Evaluate the samples in the order that the questionnaires appear in this handout. Taste only as much sample as required to complete the three parts of the study.

Rinse with water before tasting each sample.

Part 1 -

Taste the sample and check the box beside the phrase which best describes how much you like it.

口 Like Extremely

Sample Number

口 Like Very Much

$\square$ Like Moderately

口 Like Slightly

$\square$ Neither Like Nor Dislike

口 Dislike Slightly

ㅁ Dislike Moderately

$\square$ Dislike Very Much

$\square$ Dislike Extremely

Part 2 -

How often would you purchase the bar given that the price is similar to bars found in the market place?

$\square$ Every Opportunity

$\square$ Very Often

$\square$ Frequently

$\square$ Sometimes

$\square$ Now and Then

$\square$ Not Very Often

$\square$ Never

Comments 
Figure 3.4. Ballot used by consumer panel for rating of attributes using "just right" scales.

Panelist No.

Part 3 - Check the box which best describes your opinion about each of the characteristics listed.

Stickiness to Touch With Your Fingers

Sample Number

\begin{tabular}{|c|c|c|c|c|c|c|}
\hline$\square$ & $\square$ & $\square$ & $\square$ & $\square$ & $\square$ & $\square$ \\
\hline Not Enough & & & Just Right & & & Too Much \\
\hline \multicolumn{7}{|l|}{ Sweetness } \\
\hline$\square$ & $\square$ & $\square$ & $\square$ & $\square$ & $\square$ & $\square$ \\
\hline Not Enough & & & Just Right & & & Too Much \\
\hline \multicolumn{7}{|c|}{ Cranberry Flavour } \\
\hline$\square$ & $\square$ & $\square$ & ㄷ & $\square$ & $\square$ & $\square$ \\
\hline Not Enough & & & Just Right & & & Too Much \\
\hline \multicolumn{7}{|c|}{ Cereal/Grain Flavour } \\
\hline$\square$ & $\square$ & $\square$ & $\square$ & $\square$ & $\square$ & $\square$ \\
\hline Not Enough & & & Just Right & & & Too Much \\
\hline \multicolumn{7}{|l|}{ Firmness } \\
\hline$\square$ & $\square$ & $\square$ & $\square$ & $\square$ & $\square$ & $\square$ \\
\hline Not Enough & & & Just Right & & & Too Much \\
\hline \multicolumn{7}{|l|}{ Chewiness } \\
\hline ㅁ & $\square$ & $\square$ & $\square$ & $\square$ & $\square$ & $\square$ \\
\hline Not Enough & & & Just Right & & & Too Much \\
\hline \multicolumn{7}{|l|}{ Moistness } \\
\hline$\square$ & $\square$ & $\square$ & $\square$ & $\square$ & $\square$ & $\square$ \\
\hline Not Enough & & & Just Right & & & Too Much \\
\hline
\end{tabular}


is recommended in order to eliminate carry over and adaptation effects (MacFie et al., 1989). Panelists sat in individual booths and evaluated samples under incandescent light. Filtered water at room temperature and crackers with unsalted tops were available for cleansing the palate before each sample. Damp cloths were provided to clean fingers after evaluating stickiness to touch.

\subsubsection{Descriptive Panel}

\subsubsection{Sample Preparation}

The six lentil snack bar samples selected from the mixture design experiment (Table 4.15) as well as the reference sample (Appendix 1D) were prepared using the standard method (Appendix 1B or 1C). Micronized flaked lentils from Batch 2 were used (Table 3.1). The seven samples were prepared in random order and baked during one day. Each batch was wrapped in two layers of aluminum foil and kept in the dark at room temperature from 8 to 10 days before evaluation.

Samples were prepared approximately 24 hours prior to evaluation by trimming about $1 \mathrm{~cm}$ from the edges and cutting into pieces $2 \mathrm{~cm} \times 2 \mathrm{~cm}$. Each batch made 100 pieces of approximately six grams each. Three pieces were placed in resealable plastic snack bags $(16.5 \times 8.25 \mathrm{~cm})$ and labeled with three-digit random numbers. Two sample bags (a total of six pieces) were presented for the reference sample.

\subsubsection{Commercial Samples}

The same commercial snack bar samples were used as for the consumer panel (Table 3.3C and D). Samples were cut to a length of $2 \mathrm{~cm}$ and three samples were placed in resealable plastic bags in the same manner as for the lentil bars. 


\subsubsection{Panelist Recruitment and Selection}

Ethical procedures were followed and approved according to the protocol outlined by the Joint Ethics Review Board at the University of Manitoba (See Appendix 2B for the Approval Certificate). A letter of invitation included a consent form and questionnaire regarding food likes/dislikes and allergies which were completed by potential participants (Appendix 3C). An e-mail was sent to members within the Faculty of Human Ecology and posters were placed throughout the Human Ecology building as part of the recruitment process. Eleven panelists were selected based on availability and interest in the project. An honorarium was provided.

\subsubsection{Sensory Evaluation Methods}

Descriptive analysis methods are suitable for applications in product development (Stone and Sidel, 1993). The Quantitative Descriptive Analysis method was selected with some modifications from the procedures given by Stone and Sidel (1993).

Training was conducted two to three times per week over a three-week period. Each session was approximately 45 minutes. The first session included an introduction of the overall research project and an orientation to sensory evaluation which included panelist and leader responsibilities as well as training and overall objectives. An exercise was completed to learn the use of the line scale where intensity was related to the proportion of a shaded circle (Appendix 5).

Training sessions were conducted with four objectives:

1) to agree as a group on the definition for each attribute, the technique for evaluating it and the standard samples and descriptors which corresponded to the 
endpoints for the $15 \mathrm{~cm}$ line scale (Tables 3.8 and 3.9).

2) to place the reference sample on the line scale for each attribute based on the average panel score (Figure 3.5).

3) to determine the appropriate order for attribute evaluation.

4) to practice evaluating samples in order to decrease individual and group variability.

The ballot shown in Figure 3.5 reflects the work that was accomplished as a result of the training sessions. Attributes were evaluated in the order they appear on the ballot. For flavor one half of the sample was used as the sample size. After evaluating hardness and cohesiveness resulting in half of the sample being in the mouth, this piece was used for cohesiveness of mass and moisture absorption which were both evaluated after about 10 chews. Chewiness and adhesiveness to teeth were evaluated on the other half of the sample. This left one piece for reevaluation of any of the attributes if necessary. Table 3.10 shows the range of standard deviations for four samples from the last training sessions. Flavor attributes generally produced higher standard deviations which is not unusual for a complex food product that panelists have not been previously exposed to. Sensory testing of the samples was replicated during two sessions one day apart. Sample order for each panelist was assigned based on an eight-sample Latin square design following the procedure of Bower and Whitten (2000). Samples were given three-digit random code numbers. Panelists sat in individual booths and evaluated samples under red light. Filtered water at room temperature and crackers with unsalted tops were available for cleansing the palate before each sample. 
Table 3.8. Flavor attribute definitions, endpoint descriptors with corresponding standard samples for descriptive panel $\mathbf{n = 1 1}$.

Standard Technique: Thoroughly rinse with water. Take a bite of one half of the sample (approximately $1 \mathrm{~cm}$ ). Rinse with water after sample.

\begin{tabular}{|c|c|c|c|}
\hline Attribute & Definition & 0 on line scale & 15 on line scale \\
\hline sweet & $\begin{array}{l}\text { the taste associated with } \\
\text { sucrose in solution }\end{array}$ & $\begin{array}{l}\text { low } \\
(2 \% \text { sucrose })^{1}\end{array}$ & $\begin{array}{c}\text { high } \\
\text { (10\% sucrose) }\end{array}$ \\
\hline sour/fruity flavor & $\begin{array}{l}\text { the taste associated with } \\
\text { the description of sour/fruity }\end{array}$ & $\begin{array}{l}\text { low } \\
\text { (dried cranberry - } \\
\text { mental reference) }\end{array}$ & $\begin{array}{l}\text { high } \\
\text { (dried cranberry - } \\
\text { mental reference) }\end{array}$ \\
\hline grainy & $\begin{array}{l}\text { the taste associated with the flavor } \\
\text { of granola (oat based product) }\end{array}$ & $\begin{array}{l}\text { low } \\
\text { (granola - mental } \\
\text { reference) }\end{array}$ & $\begin{array}{l}\text { high } \\
\text { (granola - mental } \\
\text { reference) }\end{array}$ \\
\hline lentil & $\begin{array}{l}\text { the taste associated with the flavor } \\
\text { of micronized flaked lentils (MFL); } \\
\text { appearing toward the end of } \\
\text { the evaluation }\end{array}$ & $\begin{array}{l}\text { low } \\
\text { (MFL - mental } \\
\text { reference) }\end{array}$ & $\begin{array}{l}\text { high } \\
\text { (MFL - mental } \\
\text { reference) }\end{array}$ \\
\hline
\end{tabular}

${ }^{1}$ Standard sample 
Table 3.9. Texture attribute definitions, endpoint descriptors with corresponding standard samples for descriptive panel $\mathrm{n}=11$.

\begin{tabular}{|c|c|c|c|c|}
\hline Attribute & Definition & Technique & 0 on line scale & 15 on line scale \\
\hline stickiness to touch & $\begin{array}{l}\text { the degree to which the } \\
\text { surface of the sample } \\
\text { adheres to the finger }\end{array}$ & $\begin{array}{l}\text { hold the sample }{ }^{1} \text { in one } \\
\text { hand and evaluate the top } \\
\text { of the sample with the } \\
\text { forefinger of the opposite } \\
\text { hand by pressing gently on } \\
\text { the sample for } 2 \text { seconds } \\
\text { and releasing }\end{array}$ & $\begin{array}{l}\text { low } \\
\left(\text { cracker }^{2}\right)^{3}\end{array}$ & $\begin{array}{l}\text { high } \\
\text { (lentil bar - \#2 July } \\
\text { 25/02) }\end{array}$ \\
\hline hardness & $\begin{array}{l}\text { the force required to bite } \\
\text { completely through a } \\
\text { sample placed between the } \\
\text { incisors }\end{array}$ & $\begin{array}{l}\text { place sample between the } \\
\text { incisor teeth and bite } \\
\text { down evenly at a rate of } 1 \\
\text { second, evaluating the } \\
\text { force required to compress } \\
\text { the food and bring incisors } \\
\text { together }\end{array}$ & $\begin{array}{l}\text { low } \\
\text { (hard cooked egg } \\
\text { white) }\end{array}$ & high (peanut) \\
\hline cohesiveness & $\begin{array}{l}\text { the amount of deformation } \\
\text { undergone by the material } \\
\text { before rupture when biting } \\
\text { completely through the } \\
\text { sample using the incisors }\end{array}$ & $\begin{array}{l}\text { place the sample between } \\
\text { the incisors and compress } \\
\text { fully }\end{array}$ & $\begin{array}{l}\text { low } \\
\text { (cornmeal muffin) }\end{array}$ & $\begin{array}{l}\text { high } \\
\text { (raisin) }\end{array}$ \\
\hline cohesiveness of mass & $\begin{array}{l}\text { the degree to which the } \\
\text { chewed sample holds } \\
\text { together in a mass }\end{array}$ & $\begin{array}{l}\text { chew the sample with the } \\
\text { molars for about } 10 \text { chews }\end{array}$ & $\begin{array}{l}\text { low } \\
\text { (carrot) }\end{array}$ & $\begin{array}{l}\text { high } \\
\text { (brownie) }\end{array}$ \\
\hline
\end{tabular}


Table 3.9. Texture attribute definitions, endpoint descriptors with corresponding standard samples for descriptive panel n=11. (cont'd)

\begin{tabular}{|l|l|l|l|l|}
\hline Attribute & Definition & Technique & on line scale & 15 on line scale \\
\hline moisture absorption & $\begin{array}{l}\text { the amount of saliva } \\
\text { absorbed by the sample } \\
\text { during mastication }\end{array}$ & $\begin{array}{l}\text { chew the sample for about } \\
10 \text { chews and evaluate the } \\
\text { amount of saliva absorbed }\end{array}$ & $\begin{array}{l}\text { low } \\
\text { (licorice })\end{array}$ & $\begin{array}{l}\text { high } \\
\text { (cracker) }\end{array}$ \\
\hline chewiness & $\begin{array}{l}\text { the length of time required } \\
\text { to masticate a sample at a } \\
\text { constant rate of force } \\
\text { application* to reduce it to } \\
\text { a consistency suitable for } \\
\text { swallowing } \\
\begin{array}{l}\text { Note: Rate of force } \\
\text { application is equal to that } \\
\text { required to penetrate a } \\
\text { gum drop in a } 1 / 2 \text { a second }\end{array}\end{array}$ & $\begin{array}{l}\text { lace sample in mouth and } \\
\text { masticate at 1 chew per } \\
\text { of chewiness as the } \\
\text { number of chews required } \\
\text { before the product is ready } \\
\text { for swallowing. }\end{array}$ & $\begin{array}{l}\text { low } \\
\text { (white bread) }\end{array}$ & $\begin{array}{l}\text { high } \\
\text { (1/2 a tootsie roll) }\end{array}$ \\
\hline adhesiveness to teeth & $\begin{array}{l}\text { the amount of sample } \\
\text { adhering on/in teeth after } \\
\text { mastication of the sample }\end{array}$ & $\begin{array}{l}\text { after the sample is } \\
\text { swallowed, feel the tooth } \\
\text { surfaces with the tongue }\end{array}$ & $\begin{array}{l}\text { low } \\
\text { (carrot) }\end{array}$ & $\begin{array}{l}\text { high } \\
\text { (jujube) }\end{array}$ \\
\hline
\end{tabular}

${ }^{1}$ Sample refers to $1 / 2$ of the $2 \mathrm{~cm}$ square piece presented

${ }^{2}$ Unsalted top saltine cracker

${ }^{3}$ Standard sample

${ }^{4}$ Twizzlers 
Figure 3.5. Ballot used by descriptive panel for rating of fiavor and texture attributes. (page 1 of 2)

Panelist No.

Date

\section{Overall Procedure}

Evaluate the reference (REF) sample first and note its position on the line scale indicating the intensity of the attribute. For the texture attributes use the technique provided for sample handling. Evaluate the first coded sample for all of the attributes on this page before continuing with the second sample. Place a vertical line across the horizontal line at the point which best describes the intensity of the attribute.

Coded sample order from left to right:

\section{Stickiness to Touch}

Technique Hold the sample in one hand and evaluate the top of the sample with the forefinger of the opposite hand by pressing gently on the sample for 2 seconds and releasing to determine the degree to which the surface of the sample adheres to the finger. REF

low $+$

cracker

high

Flavor -

Thoroughly rinse with water. Take a bite of one half of the sample (approximately $1 \mathrm{~cm}$ ). Rinse with water after each sample.

\section{Sweetness}

low

\section{Sour/Fruity}

\begin{tabular}{llll} 
& REF & \\
\hline low & & high
\end{tabular}

\section{Grainy}

low $\frac{\text { REF }}{\text { high }}$

Lentil

$\begin{array}{lll} & \text { REF } & \\ \text { low high } & \end{array}$


Figure 3.5. Ballot used by descriptive panel for rating of flavor and texture attributes. (page 2 of 2)

Panelist No.

Proceed with the following attributes once the first page for all of the samples is completed.

Coded sample order from left to right:

Texture -

Hardness

Technique Place sample at its midpoint between the incisor teeth and bite down evenly at a rate of 1 second, evaluating the force required to compress the food and bring incisors together.

\begin{tabular}{llr} 
& REF & \\
\hline low white & & $\begin{array}{r}\text { high } \\
\text { peanut }\end{array}$
\end{tabular}

\section{Cohesiveness}

Technique Place the sample at its midpoint between the incisors and compress fully, evaluating the amount of deformation undergone by the material before rupture.

\begin{tabular}{llr}
\multicolumn{2}{c}{ REF } & high \\
low & $: \quad r$ raisin
\end{tabular}

Cohesiveness of Mass

Technique Chew the sample with the molars for about 10 chews evaluating the degree to which the chewed sample holds together in a mass.

REF

low

high

carrot

brownie

Moisture Absorption

Technique Chew the sample for about 10 chews and evaluate the amount of saliva absorbed by the sample during mastication.

REF

$\begin{array}{ll}\text { low } & \text { high } \\ \text { licorice } & \text { cracker }\end{array}$

Chewiness

Technique Place approximately one half the sample in the mouth and masticate at 1 chew per second. Judge the degree of chewiness as the number of chews required before the product is ready for swallowing.

$\begin{array}{ll}\text { low } & \text { REF } \\ \text { White bread } & 1 / 2 \text { a tootsie roll }\end{array}$

Adhesiveness to Teeth

Technique After the sample is swallowed, feel the tooth surfaces with the tongue and evaluate the amount of sample adhering on/in the teeth.

REF

$\begin{array}{lr}\text { low } & \text { high } \\ \text { carrot } & \end{array}$


Table 3.10. Range of standard deviations for each attribute for four samples evaluated during the last training session.

Attribute

Range of Standard Deviation

Sweetness

1.8 to 2.7

Sour/Fruity Flavor

2.5 to 3.7

Grainy

1.6 to 2.7

Lentil

2.2 to 2.8

Stickiness to Touch

1.4 to 2.8

Hardness

1.2 to 2.0

Cohesiveness

2.1 to 2.4

Cohesiveness of Mass

1.7 to 2.8

Moisture Absorption

1.7 to 2.0

Chewiness

1.1 to 2.2

Adhesiveness to Teeth

1.3 to 2.8 


\subsubsection{Statistical Analyses}

All statistical analyses were performed using the Statistical Analysis System (SAS Institute Inc., 1999). Level of significance was set at $\mathrm{p}<0.05$ for all analysis of variance procedures and means comparisons tests. Tukey's test was used to test for mean differences in all cases except for the descriptive panel data where LSD (least significant difference) was performed.

\subsubsection{Bar Formulation and Feasibility}

Mean scores and standard deviations for the lentil snack bars and commercial snack bars were calculated. PROC GLM was performed to determine if the two samples differed in overall liking. Frequencies for each descriptor for the "just right" scales were tabulated.

\subsubsection{Quality Criteria}

PROC GLM was performed to determine if samples were significantly different for DSC gelatinization temperature and enthalpies and both moisture methods. Tukey's test was used for testing significant sample differences. PROC CORR was used to find Pearson correlation coefficients.

\subsubsection{Mixture Experiment}

For each sensory attribute measured, intensities marked on the $15 \mathrm{~cm}$ line scale were converted to numbers from 0 to 15 measuring the distance in centimeters from the left end of the scale. Mean values for each of the attributes were entered as dependent responses into the Design-Expert Program (Stat-Ease, 2000) for each of the 25 runs. 


\subsubsection{Consumer Panel}

Descriptors checked on the acceptance scales were converted to numbers as follows: 9 = "like extremely", 1 = "dislike extremely"; for the purchase behaviour scale, 7 = "purchase every opportunity", 1 = "purchase never" and for the "just right" scales, $1=$ "not enough", 4 = "just right", 7 = "too much".

Analyses of variance were performed on acceptance and purchase behaviour data using PROC GLM. Panelists and samples were used as main effects. The denominator for the $\mathrm{F}$ test for the main effects was the error mean square.

Frequencies for each category were tabulated for each of the attributes for the "just right" scales. Frequencies for categories 1 to 3 were combined into one category called "not enough", categories 5 to 7 were combined into one category called "too much".

Internal preference mapping was performed using PROC FACTOR and PROC PRINQUAL with the nonmetric MDPREF option to determine if consumers could be segmented based on their preferences for the snack bars. In this case the principal component analysis uses a matrix where the columns correspond to people and the rows to the objects which is the transpose of the type of matrix that is usually used in multivariate analysis. The bi-plot produced is the resulting transformed preference space that accounts for the most variance in the data. Vectors are represented by the consumers and points by the samples. The first principal component represented by the $\mathrm{X}$ axis is the overall preference. One end points in the most preferred direction by the consumers and 
the other end to the least preferred. Vectors pointing in roughly the same direction are those judges with similar preferences. Samples that are grouped tend to have similar patterns of preference across the consumers. Similar characteristics within this grouping might be an indicator of what consumers prefer. The second principal component is orthogonal to the first and is interpreted differently depending on the data being analyzed (SAS Institute Inc., 1999).

\subsubsection{Descriptive Panel}

Intensities marked on the line scales by each panelist for each attribute were measured as for the expert panel (Section 3.2.7.3). PROC GLM with the MANOVA option was used to test for differences between two or more samples using all eleven of the dependent variables at the same time. If a significant difference was found for samples, analysis of variance determined which attributes significantly differentiated the samples. A repeated measures two-factor analysis of variance was performed for each attribute with panelists, replications and samples as fixed effects as recommended by O'Mahony (1986). The main effects of panelist, replication and sample were tested as well as the two-way interactions of panelist and replication, panelist and sample, and replication and sample using PROC GLM. The denominator for the F test for the main effects and interactions was the error mean square. If the panelist by sample interaction was significant it was used as the error term to test the sample effect (Stone and Sidel, 1993).

PROC FACTOR was performed using the overall mean values for each of the 
attributes with correlation, principal component and no rotation selected as the options. Loadings were plotted to illustrate the relationship of the snack bar samples and the sensory attributes.

\subsubsection{External Preference Mapping}

Loadings (calculated by PROC IML (interactive matrix language) and weights for each factor including the mean values of the eleven sensory attributes ( $x$ variables predictor variables) and the mean values for consumer acceptance and purchase behaviour (y variables - response variables) were determined using PROC PLS (procedure partial least squares) with the details option. Loadings were plotted to give the relationships between the attributes and consumer acceptability/purchase behaviour. Regression coefficients, the product of loadings and weights, provided insight into the importance of the predictors in the model. The higher the coefficient the higher the importance. A prediction equation was developed from the predictors with higher coefficients. 


\section{CHAPTER 4}

\section{RESULTS AND DISCUSSION}

\subsection{Bar Formulation and Feasibility}

The majority of the ten consumers from the preliminary work on blueberry snack bars were females from 17 to 24 years of age who ate snack bars either at least once a week or a few times a year mostly as a daytime snack (Figure 4.1). Brands eaten included Kellogg's Nutri-grain, Nature Valley, Quaker, President's Choice, and Kellogg's Rice Krispies.

Mean scores and standard deviations for the bars were $6.7 \pm 1.3$ and $5.3 \pm 1.3$ for the lentil snack bar (Appendix 1A) and commercial snack bar (Table 3.3A) respectively which correspond to "like moderately" and "neither like nor dislike". Samples were significantly different $(p=0.025)$. For the lentil bar sample $90 \%$ of the responses fell in the "neither like nor dislike"category or higher (Figure 4.2). Panelists commented that the lentil snack bar contained fruits which added nicely to the taste, was rich in grains, had nice chewy mouthfeel, grainy feel was good, not too hard, texture was good, blueberry flavor was low, flavor and aftertaste were weird and very different, tasted like seeds, had more taste elements (than the commercial snack bar), bar fell apart while chewing so that marshmallow, honey or something to hold grains together was required.

For the commercial snack bar sample $40 \%$ of the responses fell in the "dislike slightly" category (Figure 4.2). Comments included not very "exciting" but okay flavor, texture was chewy which was okay, not too hard, soft and did not stick to teeth which was good, the flavoring was too heavy, taste was very unique but it had a kind of almond 
Figure 4.1. Consumer group for bar formulation and feasibility: age, gender and snack bar consumption patterns.
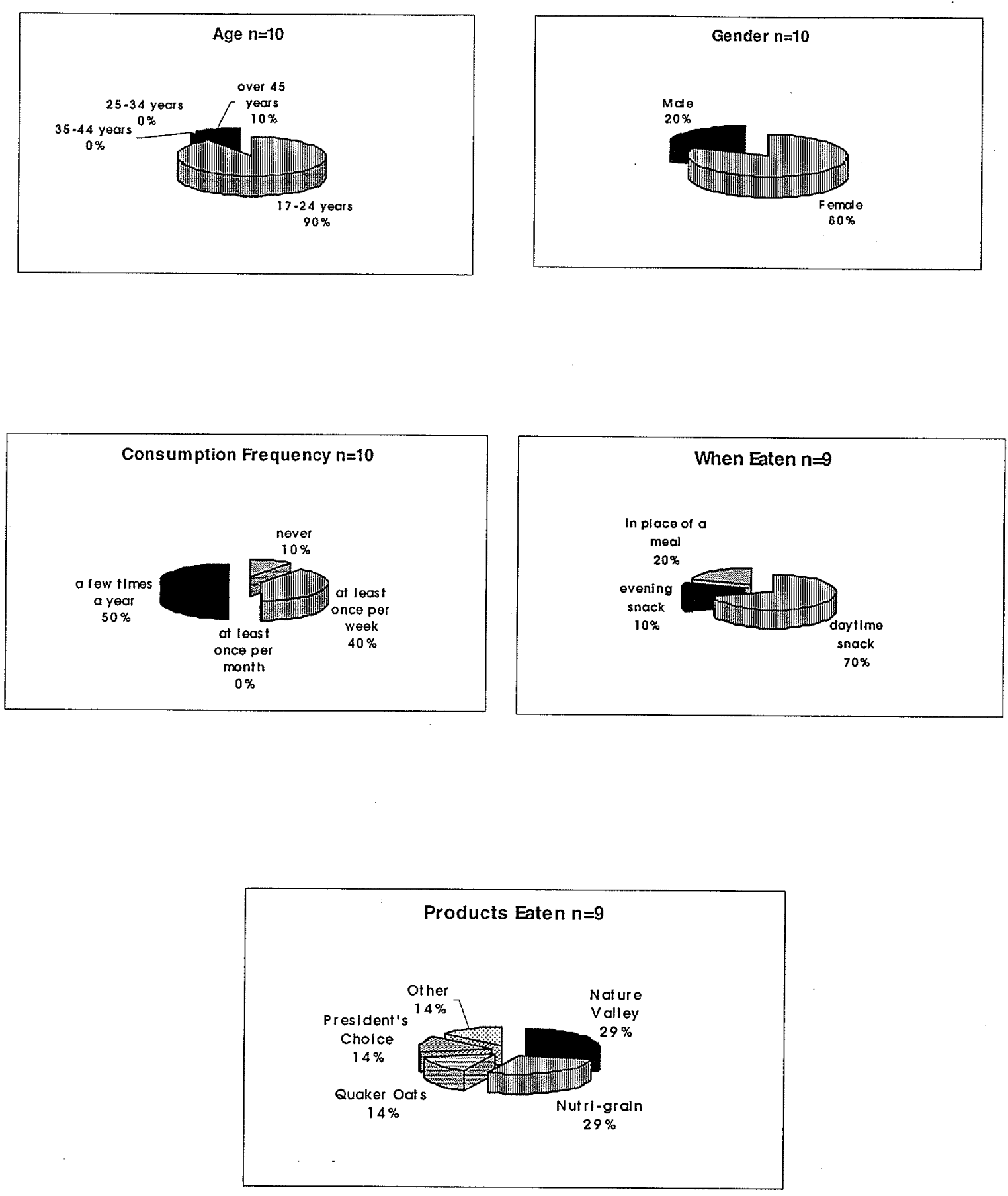
Figure 4.2. Percentage of responses for each hedonic category for experimental and commercial blueberry snack bars from preliminary consumer study $\mathbf{n = 1 0}$.

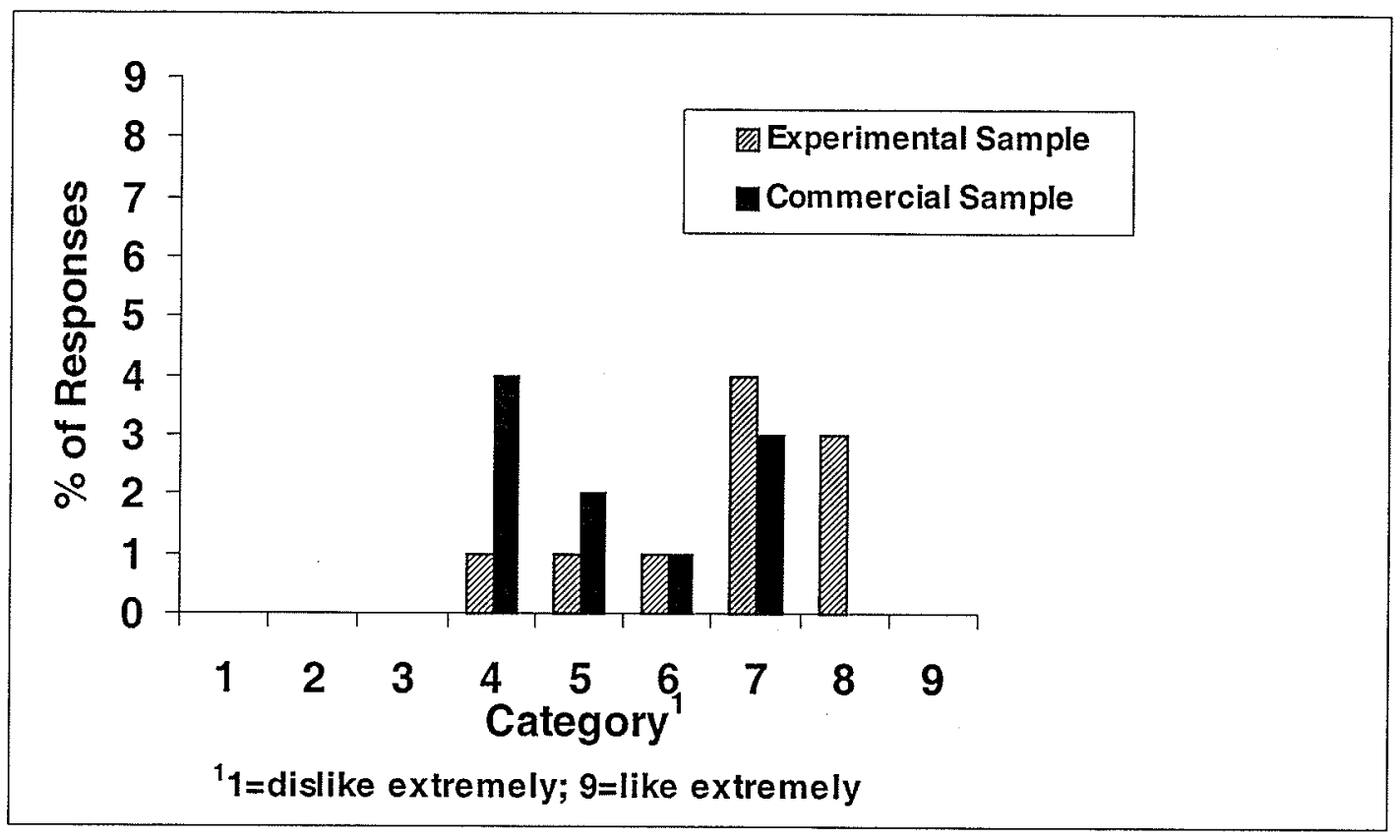


aftertaste which was too strong, had a cleaning agent taste, there was a strong flavor that seemed to mask any other flavor, blueberry taste was overbearing on sweetness and artificial like, initial bite was very tough.

Frequencies from the "just right" scales are shown in Table 4.1. For both the 5 and 6 scale values combined ("just right"), the experimental sample had a higher frequency for amount of blueberries ( 4 vs. 1 ), sweetness ( 8 vs. 4 ), firmness ( 8 vs. 6 ), with the same number for chewiness ( 7 vs. 7). The commercial sample had a higher frequency for color (4 vs. 3 ), blueberry flavor ( 4 vs. 2 ), thickness ( 9 vs. 3 ) and moistness (5 vs. 2 ). For the lentil sample the following attributes with their corresponding description are given for those attributes whose highest frequency did not fall in the "just right" zone: color - too dark, blueberries - too few (tied with 5-6), blueberry flavor - too little, thickness - too thin, moistness - too little.

From this preliminary work it was determined that further development could proceed as the lentil bar sample on average was "liked moderately". Improvements to be made included: lighten the color, increase the amount of blueberries and blueberry flavor, and increase the thickness and moisture level. The color and moisture problems could be rectified by decreasing the oven temperature from $350^{\circ} \mathrm{F}\left(180^{\circ} \mathrm{C}\right)$ to $300^{\circ} \mathrm{F}\left(150^{\circ} \mathrm{C}\right)$. Increasing the amount of blueberries would increase the flavor. Increasing the amount of total ingredients and keeping the pan size the same would increase the thickness. These aspects were incorporated into samples prepared for the consumer focus group study. It was determined that due to the high cost and restricted availability of dried blueberries, dried cranberries would be substituted. 
Table 4.1. Number of responses in each category for attributes from "just right" scales from preliminary consumer study $\mathrm{n}=10$.

\begin{tabular}{|c|c|c|c|c|c|c|c|c|c|c|c|c|c|c|c|c|}
\hline \multirow[t]{2}{*}{ Scale Value } & \multicolumn{2}{|c|}{ Color $^{1}$} & \multicolumn{2}{|c|}{$\begin{array}{l}\text { Amount of } \\
\text { Blueberries }^{2}\end{array}$} & \multicolumn{2}{|c|}{ Sweetness $^{3}$} & \multicolumn{2}{|c|}{$\begin{array}{l}\text { Blueberry } \\
\text { Flavor }^{4}\end{array}$} & \multicolumn{2}{|c|}{ Thickness $^{5}$} & \multicolumn{2}{|c|}{ Firmness $^{6}$} & \multicolumn{2}{|c|}{ Chewiness $^{7}$} & \multicolumn{2}{|c|}{ Moistness ${ }^{8}$} \\
\hline & $\mathrm{ES}^{9}$ & $\mathrm{CS}^{10}$ & $\mathrm{ES}$ & $\mathrm{CS}$ & ES & $\mathrm{CS}$ & $\mathrm{ES}$ & $\mathrm{CS}$ & ES & $\mathrm{CS}$ & $\mathrm{ES}$ & $\mathrm{CS}$ & ES & $\mathrm{CS}$ & ES & CS \\
\hline 1 & 0 & 0 & 0 & 3 & 0 & 0 & 1 & 1 & 0 & 0 & 0 & 0 & 0 & 0 & 0 & 0 \\
\hline 2 & 0 & 2 & 0 & 1 & 0 & 0 & 2 & 2 & 2 & 0 & 0 & 0 & 0 & 0 & 0 & 0 \\
\hline 3 & 0 & 1 & 0 & 1 & 1 & 1 & 3 & 1 & 3 & 0 & 1 & 1 & 0 & 1 & 1 & 0 \\
\hline 4 & 0 & 3 & 4 & 4 & 1 & 0 & 2 & 0 & 2 & 0 & 1 & 2 & 1 & 1 & 5 & 3 \\
\hline $5^{11}$ & 1 & 4 & 2 & 1 & 4 & 3 & 1 & 3 & 1 & 5 & 7 & 4 & 5 & 2 & 2 & 1 \\
\hline $6^{11}$ & 2 & 0 & 2 & 0 & 4 & 1 & 1 & 1 & 2 & 4 & 1 & 2 & 2 & 5 & 0 & 4 \\
\hline 7 & 5 & 0 & 1 & 0 & 0 & 3 & 0 & 1 & 0 & 0 & 0 & 0 & 1 & 1 & 1 & 2 \\
\hline 8 & 2 & 0 & 1 & 0 & 0 & 1 & 0 & 1 & 0 & 1 & 0 & 1 & 1 & 0 & 1 & 0 \\
\hline 9 & 0 & 0 & 0 & 0 & 0 & 1 & 0 & 0 & 0 & 0 & 0 & 0 & 0 & 0 & 0 & 0 \\
\hline 10 & 0 & 0 & 0 & 0 & 0 & 0 & 0 & 0 & 0 & 0 & 0 & 0 & 0 & 0 & 0 & 0 \\
\hline
\end{tabular}

${ }^{1} 1=$ too light $10=$ too dark

${ }^{2} 1=$ too few $10=$ too many

${ }^{3} 1=$ not enough $10=$ too much

${ }^{4} 1=$ too little $10=$ too much

${ }^{5} 1=$ too thin $10=$ too thick

${ }^{6} 1=$ too soft $10=$ too firm

${ }^{7} 1=$ too little $10=$ too much

${ }^{8} 1=$ too little $10=$ too much

${ }^{9}$ Experimental Sample

${ }^{10}$ Commercial Sample

$1{ }^{115} 6=$ = "just right" for all of the scales 
Costing of the lentil bars based on a single batch using retail prices determined that the product had market potential. More detailed financial information is presented Section 4.4.2.

\subsection{Quality Criteria}

\subsubsection{Lentil Quality}

Four batches of lentils obtained from the commercial processor resulted in differences in the textural quality of the snack bars. Batch 1 and 2 produced lentil bars with consistently soft lentils. Batch 3 produced a large percentage of lentils that were hard and definitely perceptible in the final product. Batch 4 had a high degree of foreign material and was not used. To determine if degree of starch gelatinization had an effect on the lentil hardness, DSC was done. A lower enthalpy value indicates a higher degree of starch gelatinization due to processing. The processed samples ranged from 2.2 to 4.6 $\mathrm{J} / \mathrm{g}$ (Table 4.2) which is in range of $3.2 \mathrm{~J} / \mathrm{g}$, the value found by Cenkowski and Sosulski (1997) for lentils micronized at $25.8 \%$ wet basis moisture content. Theoretically the raw sample should have a higher enthalpy value than the processed samples as no gelatinization would have taken place. This raw sample was taken from a different crop year than the processed samples and therefore comparison with the processed samples is difficult.

The samples with the lowest enthalpies, Batches 3 and 4, were not exhibiting the softest lentils therefore it may be concluded that starch gelatinization is not a good indicator of micronized lentil hardness in a snack bar. Other factors such as the "hard to cook" phenomenon which is influenced by growing conditions and storage may have had a 
Table 4.2. Raw and micronized flaked lentil (MFL) means $s^{\mathrm{a}}$ and standard deviations (SD) for lentil starch DSC, gelatinization temperature ${ }^{\mathrm{b}}$ and enthalpy change $\mathrm{e}^{\mathrm{c}}$.

\begin{tabular}{lll} 
Sample & Gelatinization Temperature & \\
& & Enthalpy $^{\mathrm{d}}$ \\
\hline & $70.5(1.6) \mathrm{ab}$ & \\
Raw & $73.1(0.0) \mathrm{a}$ & $2.60(0.01) \mathrm{ab}$ \\
MFL - Batch 1 - July '00 & $3.47(0.12) \mathrm{ab}$ \\
MFL - Batch 2 - May '01 & $71.8(1.9) \mathrm{ab}$ & $4.58(0.32) \mathrm{a}$ \\
MFL - Batch 3 - May '02 & $70.9(0.4) \mathrm{ab}$ & $3.28(0.37) \mathrm{ab}$ \\
MFL - Batch 4 - Sept '02 & $70.3(0.9) \mathrm{b}$ & $2.23(1.3) \mathrm{b}$
\end{tabular}

${ }^{a}$ Means are averages of duplicate samples

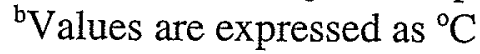

${ }^{\circ}$ Values are expressed in Joules per gram of sample as is

${ }^{\mathrm{d}}$ Values are mean and (SD); means with the same letter are not significantly different $(\mathrm{p}<0.05)$. 
larger effect than the micronization process. Batches with poor quality micronized lentils were grown in 2001 which was a very dry crop year producing lentils with initial moisture of 8 to $10 \%$ compared to $12 \%$ from the 2000 crop year (Table 3.1). Alterations in tempering parameters may be necessary to compensate for the lower moisture.

Development of a screening procedure for the raw product to predict micronized lentil softness suitable for inclusion in snack bars is advised.

\subsubsection{Moisture Content}

CB2 had a significantly higher \% total solids i.e. significantly lower moisture than all of the other samples (Table 4.3). CB1 had the second highest \% total solids and was not significantly different from LB3 and LB6.

Of the lentil bar samples LB1, LB3 and LB6 had significantly higher \% total solids than the other lentil bar samples ranging from 90 to $91 \%$. LB4 had least $\%$ total solids which was significantly lower than the other lentil bars except for the reference snack bar and LB2. Moisture levels found for LB3 and LB6 and the commercial snack bars were within the same range as the walnut/cereal bars made by Estevez et al., (1995) which was 7.7 to $9.4 \%$. These levels were lower than the $32 \%$ found in the fibre bars made by Azlyn and colleagues (1989).

\subsubsection{Water Activity}

Water activity ranged from 0.454 for $\mathrm{CB} 1$ to 0.622 for LB2 (Table 4.4). According to Troller (1989) foods with an $\mathrm{a}_{\mathrm{w}}$ of below 0.78 to 0.80 should not promote growth and toxin production. Yeasts and molds are more tolerant of lower water activities as noted in Troller and Christian (1978) some existing as low as 6.1 to 6.2. While $\mathrm{a}_{\mathrm{w}}$ can be an 
Table 4.3. Snack bar sample means ${ }^{\mathrm{a}}$ and standard deviations (SD) for $\%$ total solids.

\begin{tabular}{ll} 
Sample & \% Total Solids \\
\hline CB2 & $92.04(0.10) \mathrm{a}$ \\
CB1 & $91.13(0.34) \mathrm{b}$ \\
LB3 & $90.90(0.11) \mathrm{bc}$ \\
LB6 & $90.77(0.07) \mathrm{bc}$ \\
LB1 & $90.18(0.26) \mathrm{c}$ \\
LB5 & $88.50(0.03) \mathrm{d}$ \\
REF & $88.10(0.01) \mathrm{de}$ \\
LB2 & $87.98(0.12) \mathrm{de}$ \\
LB4 & $87.43(0.40) \mathrm{e}$
\end{tabular}

aMeans are averages of duplicate samples

${ }^{b}$ Values are mean and (SD); means with the same letter are not significantly different $(\mathrm{p}<0.05)$ 
Table 4.4. Snack bar sample means $\mathrm{s}^{\mathrm{a}}$ and standard deviations (SD) for $\mathrm{a}_{\mathrm{w}}$.

Sample $\quad a_{w}{ }^{b}$

$\begin{array}{ll}\text { CB2 } & 0.457(0.001) \mathrm{a} \\ \text { CB1 } & 0.454(0.004) \mathrm{a} \\ \text { LB3 } & 0.533(0.000) \mathrm{c} \\ \text { LB6 } & 0.523(0.002) \mathrm{c} \\ \text { LB1 } & 0.510(0.004) \mathrm{b} \\ \text { LB5 } & 0.588(0.002) \mathrm{d} \\ \text { REF } & 0.579(0.003) \mathrm{d} \\ \text { LB2 } & 0.622(0.000) \mathrm{e} \\ \text { LB4 } & 0.586(0.001) \mathrm{d}\end{array}$

${ }^{a}$ Means are averages of duplicate samples

balues are mean and (SD); means with the same letter are not significantly different $(\mathrm{p}<0.05)$ 
indicator of possible microbial growth it is important to be aware of other possible factors such as $\mathrm{pH}$, salt, sugar and honey that can also provide preservative effects either alone or in combination (Troller, 1987).

LB2 had water activity which was significantly higher than all of the other samples. It had the highest level of sweetened condensed milk. The other samples were grouped as follows: LB5, LB4 and the reference sample were significantly higher than LB3 and LB6 which were significantly higher than LB1 which was in turn significantly higher than both $\mathrm{CB} 2$ and $\mathrm{CB} 1$. LB1 had the lowest amount of sweetened condensed milk. Comparing the water activity levels for bars in this study to those of Estevez and colleagues (1995) showed three lentil bars within the range of 0.50 to 0.56, LB1, LB3 and LB6. The commercial samples were lower than those from the Estevez study. Water activity of bars made by Maurer et al., (2002) and Sipahioglu et al., (2002) was 0.28 and 0.97 respectively indicating that a wide range of water activities can be found for these products.

A correlation of -0.91 was found between $\%$ total solids and water activity with an associated $p$ value of 0.0006 which is expected (Baker et al., 1988). No significant correlation was found between these two physical moisture measurements and the mean moisture scores from the descriptive panel.

\subsubsection{Nutrient Content}

LB3 contained the highest amounts of calories and total carbohydrate and lowest amounts for dietary fibre, protein, iron and folate (Table 4.5). This could be because it had the highest level of granola which contains canola oil and lowest level of lentils (Table 
Table 4.5. Major nutrients in lentil bars ( $30 \mathrm{~g}$ serving size).

\begin{tabular}{|c|c|c|c|c|c|c|c|c|c|c|c|c|c|c|}
\hline \multirow[t]{2}{*}{ Sampl } & \multicolumn{2}{|c|}{$\begin{array}{l}\text { Energy } \\
\text { (kcal) }\end{array}$} & \multicolumn{2}{|c|}{$\begin{array}{l}\text { Total } \\
\text { Fat } \\
(\mathrm{g})\end{array}$} & \multicolumn{2}{|c|}{$\begin{array}{c}\text { Total } \\
\text { Carbohydrate } \\
\text { (g) }\end{array}$} & \multicolumn{2}{|c|}{$\begin{array}{l}\text { Dietary } \\
\text { Fibre } \\
\text { (g) }\end{array}$} & \multicolumn{2}{|c|}{$\begin{array}{l}\text { Protein } \\
(\mathrm{g})\end{array}$} & \multicolumn{2}{|c|}{$\begin{array}{l}\text { Iron } \\
(\mathrm{mg})\end{array}$} & \multicolumn{2}{|c|}{$\begin{array}{l}\text { Folate } \\
\qquad(\mu \mathrm{g})\end{array}$} \\
\hline & $\mathrm{L} / \mathrm{O}^{1}$ & $\mathrm{O}^{2}$ & L/O & $\mathrm{O}$ & $\mathrm{L} / \mathrm{O}$ & $\mathrm{O}$ & $\mathrm{L} / \mathrm{O}$ & $\mathrm{O}$ & $\mathrm{L} / \mathrm{O}$ & $\mathrm{O}$ & $\mathrm{L} / \mathrm{O}$ & $\mathrm{O}$ & $\mathrm{L} / \mathrm{O}$ & $\mathrm{O}$ \\
\hline LB1 & 87 & 91 & 2.3 & 2.7 & 13.2 & 13.9 & 3.1 & 1.6 & 4.1 & 3.2 & 1.0 & 0.6 & 34.8 & 4.6 \\
\hline LB2 & 84 & 88 & 2.1 & 2.5 & 12.4 & 13.2 & 3.0 & 1.5 & 4.4 & 3.5 & 1.0 & 0.6 & 36.2 & 4.5 \\
\hline LB3 & 98 & 101 & 3.1 & 3.4 & 14.3 & 14.9 & 2.8 & 1.6 & 4.0 & 3.2 & 1.0 & 0.7 & 29.3 & 4.8 \\
\hline LB4 & 77 & 80 & 1.6 & 2.1 & 12.0 & 12.8 & 3.2 & 1.5 & 4.1 & 3.1 & 1.0 & 0.6 & 38.6 & 4.3 \\
\hline LB5 & 82 & 86 & 1.6 & 2.1 & 12.9 & 13.8 & 3.4 & 1.5 & 4.5 & 3.3 & 1.0 & 0.6 & 42.8 & 4.6 \\
\hline LB6 & 94 & 97 & 3.0 & 3.3 & 13.3 & 13.9 & 2.9 & 1.6 & 4.2 & 3.4 & 1.0 & 0.7 & 30.4 & 4.8 \\
\hline
\end{tabular}

${ }^{1}$ Nutrient content of bars containing lentils and oats

${ }^{2}$ Nutrient content of bars replacing lentils with oats

Source: Owl Software TechWizard Vers. 3 (2003) 
4.6). LB4 contained the lowest amounts for calories, total fat, total carbohydrate.

Compared to LB3 it had half the granola and $38 \%$ more lentils. LB5 contained the highest amount of dietary fibre, protein, iron and folate. This sample had the highest amount of lentils. LB6 contained the highest amount of fat. It had almost the same level of granola as LB3 and higher sweetened condensed milk. One lentil bar (30 g) would provide from 8 to $10 \%$ of the daily adult recommended intake of $400 \mu \mathrm{g}$ for folate.

Calories, carbohydrate, fat and protein levels for lentil bars generally fit the definition of a bar classified as carbohydrate/energy and endurance (Deis, 2000). According to Deis (2000) these bars contain between 160 to 250 calories and are high in carbohydrate suited to replenish energy lost during exercise and to aid in muscle recovery. Generally a 200 calorie lentil bar contained 25 to 30 grams of carbohydrate, 5 to 15 grams of protein and 2 to 6 grams of fat (Table 4.5 ).

Snack bars with oats only, provided more calories, fat and carbohydrate and less dietary fibre, protein, iron and folate than those containing lentils (Table 4.5). This is to be expected based on the nutrient contribution of the lentils (Table 2.2). Inclusion of lentils provided 6 to 9 times more folate compared to a bar containing only oats (Table 4.5). According to Health Canada's Nutrient Content Claims (Canada Gazette, 2002) all lentil bars would provide a source of dietary fibre, non-heme iron and folate. LB1, LB2, LB4 and LB5 would provide a good source of folate.

\subsection{Consumer Focus Groups}

\subsubsection{Consumer Profiles}

Most of the 14 consumers participating in the focus groups ate snack bars 
Table 4.6. Lentil bar ingredients in grams for one batch.

\begin{tabular}{lllllll}
\hline Sample & $\begin{array}{l}\text { Sweetened } \\
\text { Condensed } \\
\text { Milk }\end{array}$ & Honey & $\begin{array}{l}\text { Micronized } \\
\text { Flaked } \\
\text { Lentils }\end{array}$ & Granola & $\begin{array}{l}\text { Dried } \\
\text { Cranberries }\end{array}$ & $\begin{array}{l}\text { Total } \\
\text { Weight }\end{array}$ \\
\hline LB1 & 189 & 59 & 169 & 195 & 47 & 659 \\
LB2 & 260 & 39 & 176 & 176 & 0 & 651 \\
LB3 & 182 & 72 & 137 & 260 & 0 & 651 \\
LB4 & 208 & 46 & 189 & 130 & 78 & 651 \\
LB5 & 221 & 59 & 208 & 130 & 26 & 644 \\
LB6 & 215 & 39 & 143 & 254 & 0 & 651 \\
\hline
\end{tabular}

${ }^{1}$ One batch 
occasionally with equal numbers represented from the other categories (Figure 4.3). These consumers met the criteria of having eaten snack bars at least once. One-half of the group were 35 to 45 years old and one-half were 45 to 55 years old. About half the group ate bars sometimes, most often to replace breakfast. The majority of respondents (87\%) ate bars as a snack, most often in the afternoon. Granola and nutri-grain bars of various brands were the type eaten most often with most selections coming from the fruit and nut groups.

\subsubsection{Consumer Responses}

Development of the new product should include properties that consumers look for in snack bars. They need to be nutritious, contain natural products, be low in fat and taste good (Table 4.7). Comments about the cereal bars currently found in the market can be used to guide the development of the bar. It was found that consumers desired sweetness at the appropriate level, flavor that is evident and not off, and texture that is not too hard, too gummy, too crumbly or too sticky. Addition of fruit and nuts could add to the appeal of the bar (Table 4.8).

Suggestions to improve the flavor of the plain and cranberry lentil bars included: - add other ingredients such as finely ground nuts (perhaps almonds), raisins, currants, strawberries, dates, oranges, coconut, cinnamon, vanilla, dried lemon, dried pineapple

- decrease sweetness in the cranberry bar so that the fruit flavor comes out - increase the amount of cranberries, use less lentils and more oatmeal The suggestion to improve texture was to compress the bar more like the Nature Valley sample (Table 4.9). 
Figure 4.3. Consumer focus groups: age and snack bar consumption patterns.
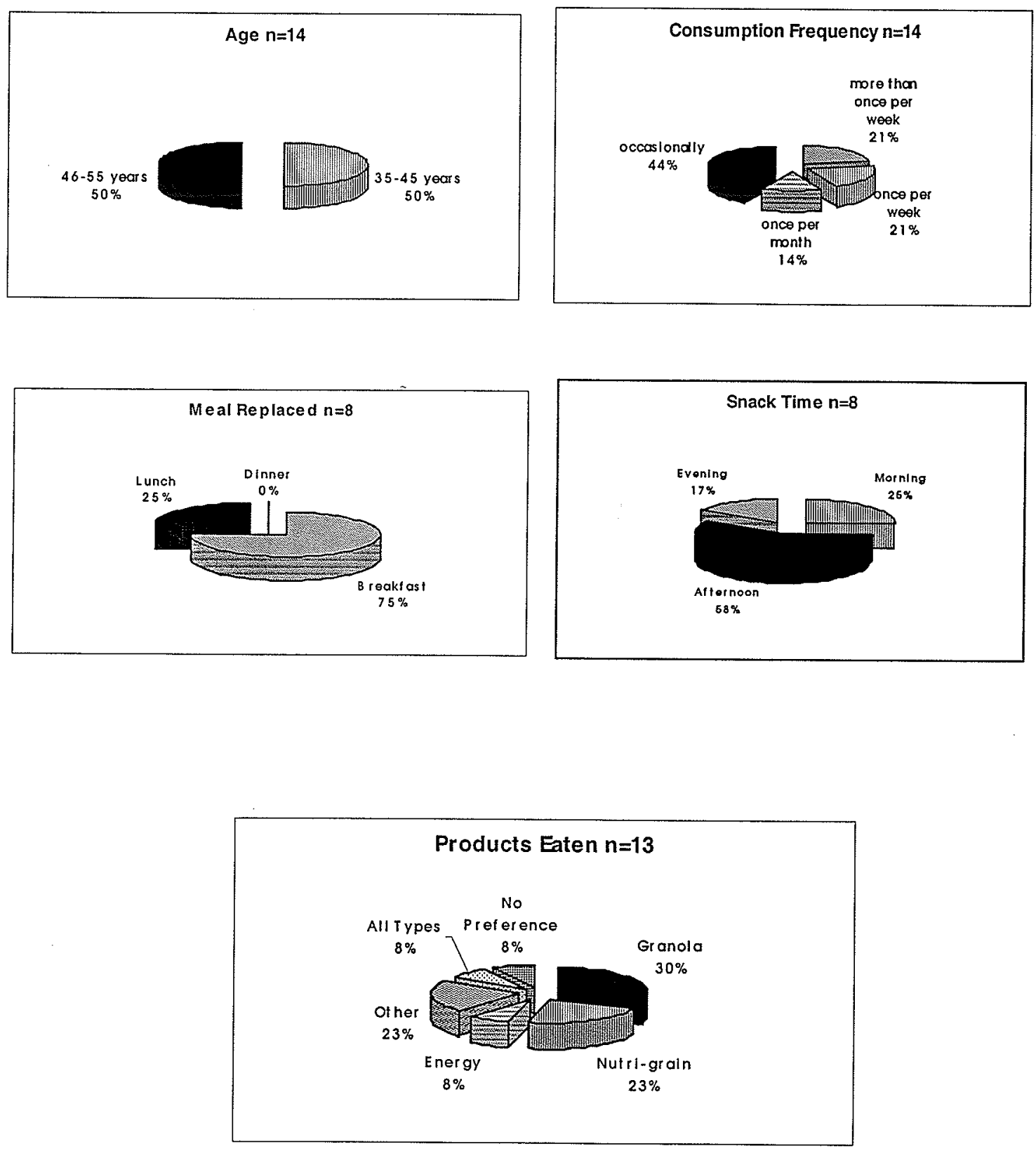
Table 4.7. Comments from four focus groups ${ }^{1}$ regarding what consumers look for in snack bars.

\section{Attributes Comments}

Flavor specific flavor such as apple cinnamon variety of flavors to satisfy all family members taste/good flavor

Texture chewier

harder, crunchier not crumbly

Nutrition low fat (compared to chocolate bar)

low calorie

balance between carbohydrate and protein healthy

Ingredients honey vs sugar, fruit, not aspartame or other additives, calcium, no refined sugar, oatmeal, nuts, raisins, protein

Price brand names and specials vs no name

Other nice packaging

${ }^{1} 3$ to 4 participants per group; $n=14$ 
Table 4.8. Comments from four focus groups ${ }^{1}$ regarding commercial snack bars.

\begin{tabular}{|c|c|c|c|c|}
\hline \multicolumn{3}{|c|}{ Nature Valley - Oats and Honey } & \multicolumn{2}{|c|}{ Quaker Oats - Honey and Raisin } \\
\hline Attributes & Positive Comments & Negative Comments & Positive Comments & Negative Comments \\
\hline Flavor & $\begin{array}{l}\text { sweet enough } \\
\text { nutty taste } \\
\text { tasty } \\
\text { tastes like high fibre, high pr }\end{array}$ & $\begin{array}{l}\text { need something like raisins } \\
\text { or cinnamon } \\
\text { not appetizing/appealing }\end{array}$ & $\begin{array}{l}\text { smells good, stronger, sweet } \\
\text { tastes good, high fat } \\
\text { marshmallow taste }\end{array}$ & $\begin{array}{l}\text { buttery taste } \\
\text { stale? } \\
\text { some flavor I don't } \\
\text { like } \\
\text { too sweet }\end{array}$ \\
\hline Texture & $\begin{array}{l}\text { not sticky } \\
\text { like texture a little hard } \\
\text { not too chewy } \\
\text { not too hard } \\
\text { not too gummy } \\
\text { light flaky } \\
\text { doesn't break apart } \\
\text { crunchy }\end{array}$ & $\begin{array}{l}\text { dry texture needs raisins } \\
\text { or currants to improve } \\
\text { initial bite not so good } \\
\text { sticks to teeth a bit but } \\
\text { can get it off }\end{array}$ & $\begin{array}{l}\text { like rice crispy cake } \\
\text { softer }\end{array}$ & $\begin{array}{l}\text { prefer drier texture } \\
\text { greasy and sticky on } \\
\text { holding } \\
\text { breaks apart in mouth } \\
\text { soft and falls apart } \\
\text { sticky texture sticks to teeth } \\
\text { too flexible }\end{array}$ \\
\hline Nutrition & $\begin{array}{l}\text { looks nutritious/healthy } \\
\text { due to oatmeal, granola, } \\
\text { and other grains }\end{array}$ & $\begin{array}{l}\text { more like a healthy cookie } \\
\text { not as sweet }\end{array}$ & raisins sound healthier & $\begin{array}{l}\text { tastes sweeter, too } \\
\text { unhealthy } \\
\text { like a dessert bar, } \\
\text { cookie or treat }\end{array}$ \\
\hline Appearance & $\begin{array}{l}\text { high in fibre } \\
\text { hard/looks too hard } \\
\text { drier, crispy, crunchy } \\
\text { cookie-like, nice color, plain } \\
\text { oily, easy to break }\end{array}$ & & $\begin{array}{l}\text { like rice crispy cake } \\
\text { lots of different colors/ } \\
\text { looks inviting } \\
\text { airy not as compressed } \\
\text { moist }\end{array}$ & $\begin{array}{l}\text { too light in color } \\
\text { like white flour product } \\
\text { too narrow } \\
\text { sticky }\end{array}$ \\
\hline
\end{tabular}

${ }^{1} 3$ to 4 participants per group; $n=14$ 
Table 4.9. Comments from four focus groups ${ }^{1}$ regarding micronized flaked lentil bars.

\begin{tabular}{|c|c|c|c|c|}
\hline & \multicolumn{2}{|c|}{ Plain } & \multicolumn{2}{|c|}{ Cranberry } \\
\hline Attributes & Positive Comments & Negative Comments & Positive Comments & Negative Comments \\
\hline Flavor & aftertaste okay & $\begin{array}{l}\text { a little sweet } \\
\text { not a lot of flavor } \\
\text { bland, not enough zip } \\
\text { unappealing pepper taste } \\
\text { on initial chewing } \\
\text { uncooked flavor }\end{array}$ & $\begin{array}{l}\text { fruit gives nice sharp taste } \\
\text { not too sweet } \\
\text { like fruit }\end{array}$ & $\begin{array}{l}\text { fruit not necessary to increase } \\
\text { sweetness } \\
\text { fruit not fresh } \\
\text { a little too much fruit }\end{array}$ \\
\hline Texture & $\begin{array}{l}\text { not sticky but still chewy } \\
\text { doesn't melt in mouth } \\
\text { not too hard and } \\
\text { not too soft } \\
\text { a bit of moisture } \\
\text { stays together } \\
\text { not sticky } \\
\text { doesn't break }\end{array}$ & $\begin{array}{l}\text { could be more compressed } \\
\text { a little sticky on bottom } \\
\text { dry }\end{array}$ & & a bit too sticky \\
\hline Nutrition & $\begin{array}{l}\text { seems like it would have } \\
\text { good nutrition based } \\
\text { on tasting it }\end{array}$ & & fruit adds to servings for $\mathrm{f}$ & \\
\hline
\end{tabular}


Table 4.9. Comments from four focus groups ${ }^{1}$ regarding micronized flaked lentil bars. (cont'd)

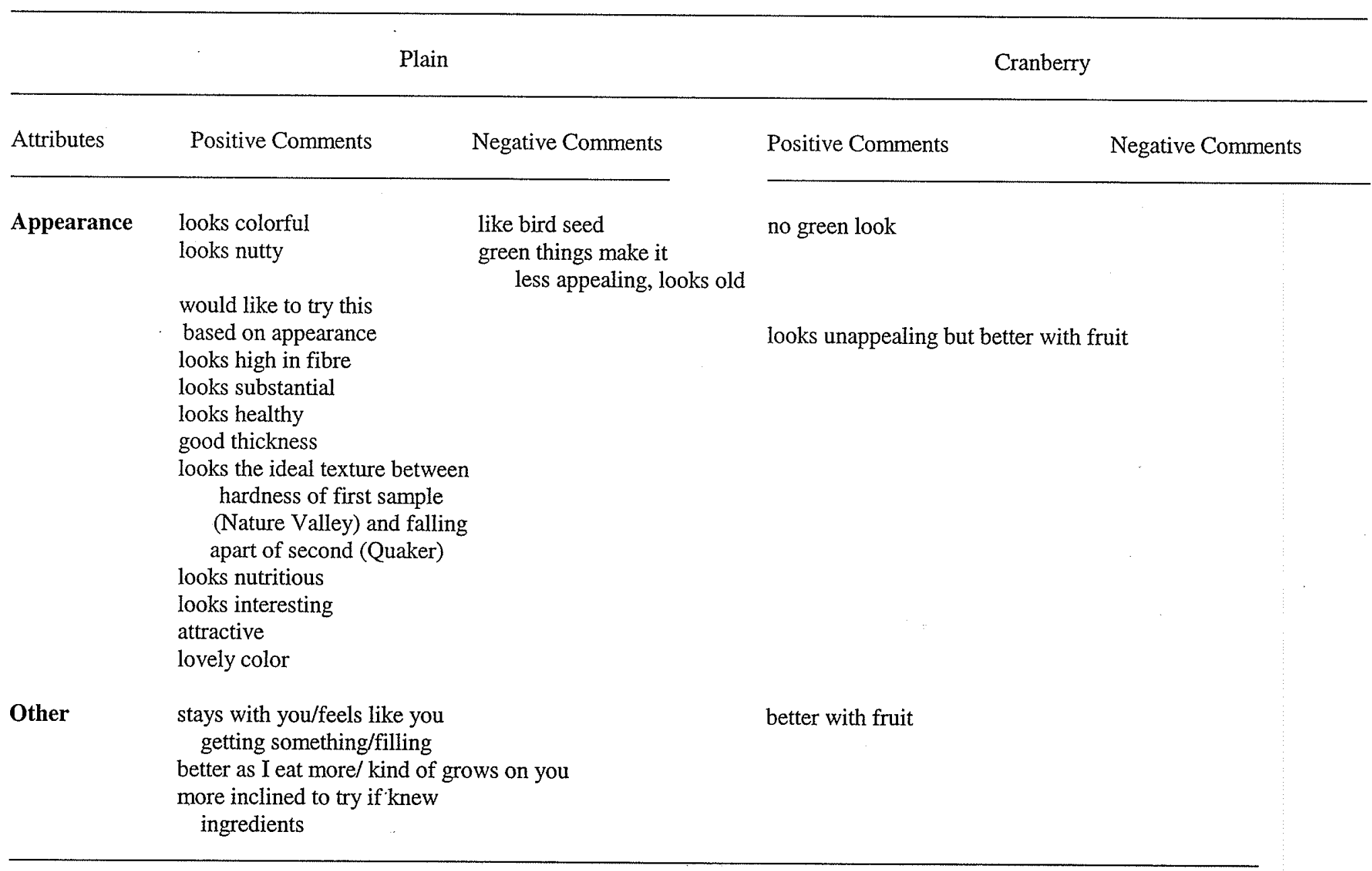

${ }^{1} 3$ to 4 participants per group; $n=14$ 
It appeared that these consumers were focused on flavor more than texture when it came to making improvements in the bar reinforcing the fact that taste is important when developing products (Katz, 1999). Comments were made about the texture but few improvements were noted either due to its desirability, its comparability to existing products or its reduced importance in acceptability criteria. Attributes used by the consumers to describe the flavor and texture of the product included sweet, bland, fruit amount, sticky, hard, soft, chewy and dry. The lentil bars in general were perceived as nutritious and filling. Generally the appearance was favorable although negative comments included like bird seed, green things made it look less appealing and looked old (Table 4.9).

Results from these focus groups provided input for the next stages of development. Comments provided direction for setting the constraints for the ingredients in the mixture design experiment. The lentils generally were not as well liked as granola so that varying the ratio of lentil to granola would likely provide a range in acceptability. The sweetness level could be varied and would also produce a range in acceptability. Dried cranberries for the most part seemed to improve the bar so that including formulations with cranberries is important with perhaps a lower amount of sugar to compensate for their inherent sweetness. Excluding cranberries in some formulations would be necessary for consumers that do not like cranberries. Hardness/softness could be adjusted with different liquid to dry ingredient ratios.

Data from these focus groups were also used for recruitment in the quantitative study. Since the aspect of "nutritious" was noted it was used as a description of the bar as 
well as the fact that lentils were a component. This would appeal to those that like to try new products and that liked lentils eliminating the "guesswork" that was part of the assessment procedure during the focus groups. Attributes provided by the group were included in the attribute analysis (i.e. "just right" scales).

\subsection{Mixture Design Experiment}

\subsubsection{Yield}

Percent yield for one batch of each of the twenty-five lentil bar formulations ranged from 94.76 to 98.38 with corresponding cooking losses from 5.24 to $1.62 \%$ (Table 4.10 ). No trend was noted for relating yields to ingredient amounts.

\subsubsection{Cost of Production Estimate}

An estimate of the costs of production for the cranberry lentil bar was made based on the formulations and work completed for the mixture design experiment. The material cost for a 30 gram bar was $\$ 0.195$ (Table 4.11A). The major input was sweetened condensed milk representing about $50 \%$ of the total cost with dried cranberries and honey the next highest at about $12 \%$ each of the total. Micronized flaked lentils and canola oil were the lowest cost ingredients at $3.4 \%$ each of the total. Lentils were a slightly lower cost than the oats.

Adding packaging, labor and overhead increased the cost by approximately $34 \%$ to $\$ 0.294$ per bar (Table 4.11B). It should be noted that material prices are retail, labor is set at $\$ 12.00$ per hour with overhead estimated at twice the labor cost. An estimated 720 bars would be made in one hour in an automated commercial scale facility. The estimated retail price of a $30 \mathrm{~g}$ cranberry lentil bar would be lower than four of seven nutritious 
Table 4.10. Cooked yield of one batch of lentil bars for 25 formulations from the mixture design experiment.

Ingredients

\begin{tabular}{|c|c|c|c|c|c|c|c|}
\hline $\begin{array}{l}\text { Run } \\
\text { Order }\end{array}$ & $\mathrm{SCM}^{1}$ & Honey & $\mathrm{MFL}^{2}$ & Granola & $\begin{array}{l}\text { Dried } \\
\text { Cranberry }\end{array}$ & $\begin{array}{l}\text { Yield } \\
(\%)\end{array}$ & $\begin{array}{l}\text { Cooking } \\
\text { Loss (\%) }\end{array}$ \\
\hline 1 & $0.34^{3}$ & $0.12^{3}$ & $0.19^{3}$ & $0.34^{3}$ & $0.00^{3}$ & 94.76 & 5.24 \\
\hline 2 & 0.28 & 0.06 & 0.27 & 0.28 & 0.12 & 96.55 & 3.45 \\
\hline 3 & 0.40 & 0.12 & 0.19 & 0.25 & 0.05 & 97.28 & 2.72 \\
\hline 4 & 0.37 & 0.12 & 0.19 & 0.20 & 0.12 & 97.20 & 2.80 \\
\hline 5 & 0.35 & 0.09 & 0.29 & 0.20 & 0.07 & 96.00 & 4.00 \\
\hline 6 & 0.28 & 0.09 & 0.19 & 0.32 & 0.12 & 96.54 & 3.46 \\
\hline 7 & 0.28 & 0.06 & 0.19 & 0.40 & 0.07 & 96.20 & 3.80 \\
\hline 8 & 0.28 & 0.09 & 0.19 & 0.32 & 0.12 & 97.58 & 2.42 \\
\hline 9 & 0.28 & 0.12 & 0.37 & 0.22 & 0.02 & 96.95 & 3.05 \\
\hline 10 & 0.28 & 0.06 & 0.32 & 0.35 & 0.00 & 95.71 & 4.29 \\
\hline 11 & 0.28 & 0.12 & 0.37 & 0.22 & 0.02 & 96.23 & 3.77 \\
\hline 12 & 0.28 & 0.06 & 0.19 & 0.40 & 0.07 & 95.99 & 4.01 \\
\hline 13 & 0.40 & 0.06 & 0.27 & 0.28 & 0.00 & 95.90 & 4.10 \\
\hline 14 & 0.34 & 0.06 & 0.19 & 0.29 & 0.12 & 97.32 & 2.68 \\
\hline 15 & 0.28 & 0.06 & 0.32 & 0.35 & 0.00 & 98.38 & 1.62 \\
\hline 16 & 0.40 & 0.06 & 0.22 & 0.20 & 0.12 & 97.62 & 2.38 \\
\hline 17 & 0.28 & 0.12 & 0.28 & 0.20 & 0.12 & 97.15 & 2.85 \\
\hline 18 & 0.40 & 0.12 & 0.28 & 0.20 & 0.00 & 95.51 & 4.49 \\
\hline 19 & 0.37 & 0.06 & 0.37 & 0.20 & 0.00 & 97.66 & 2.34 \\
\hline 20 & 0.28 & 0.12 & 0.19 & 0.35 & 0.07 & 95.54 & 4.46 \\
\hline 21 & 0.33 & 0.09 & 0.27 & 0.28 & 0.03 & 96.94 & 3.06 \\
\hline 22 & 0.37 & 0.06 & 0.37 & 0.20 & 0.00 & 97.12 & 2.88 \\
\hline 23 & 0.28 & 0.06 & 0.37 & 0.20 & 0.09 & 96.45 & 3.55 \\
\hline 24 & 0.40 & 0.06 & 0.19 & 0.35 & 0.00 & 96.75 & 3.25 \\
\hline 25 & 0.28 & 0.12 & 0.20 & 0.40 & 0.00 & 96.25 & 3.75 \\
\hline
\end{tabular}

${ }^{1}$ Sweetened Condensed Milk

${ }^{2}$ Micronized Flaked Lentils

${ }^{3}$ Proportion of ingredient in total formulation where $\sum \mathrm{x} \sim 1$ 
Table 4.11. Cost estimate and market pricing comparison for 30 gram micronized flaked lentil bar.

\section{A. Material Cost}

\begin{tabular}{|c|c|c|c|c|}
\hline Materials & $\begin{array}{l}\text { ost for } 25 \text { runs } \\
\text { (\$) }\end{array}$ & $\begin{array}{c}\text { Cost for } 1 \text { run } \\
(\$)\end{array}$ & $\begin{array}{c}\text { Cost for } 1 \text { bar } \\
(\$)\end{array}$ & $\begin{array}{r}\% \text { of } \\
\text { Total Cost }\end{array}$ \\
\hline $\mathrm{MFL}^{1}$ & 3.01 & 0.12 & 0.006 & 3.4 \\
\hline $\mathrm{SCM}^{2}$ & 44.42 & 1.78 & 0.099 & 50.6 \\
\hline Oatmeal & 5.11 & 0.20 & 0.011 & 5.8 \\
\hline Dried Cranberries & s $\quad 10.48$ & 0.42 & 0.023 & 11.9 \\
\hline Cooking Spray & 6.98 & 0.28 & 0.016 & 8.0 \\
\hline Canola Oil & 2.99 & 0.12 & 0.007 & 3.4 \\
\hline Honey & 10.64 & 0.43 & 0.024 & 12.1 \\
\hline Aluminum Foil & 4.17 & 0.17 & $\underline{0.009}$ & 4.7 \\
\hline \multicolumn{3}{|c|}{ Total Material Cost for Bar: } & 0.195 & \\
\hline
\end{tabular}

${ }^{1}$ Micronized Flaked Lentils

${ }^{2}$ Sweetened Condensed Milk

\section{B. Retail Price}

Total Cost Before Retail Markup of 50\%:

$\begin{array}{lll}\text { Material Cost for Bar (above) } & \$ & 0.195 \\ \text { Package } & & 0.050 \\ \text { Labor } & & 0.016 \\ \text { Overhead (2x Labor) } & & \underline{0.033} \\ & \$ \quad \underline{0.294}\end{array}$

Retail Price: $\quad \$ \quad \underline{0.59}$ 
Table 4.11. Cost estimate and market pricing comparison for 30 gram micronized flaked lentil bar. (cont'd)

\section{Price Comparison}

\begin{tabular}{llcl}
\hline Sample & Manufacturer & Retail Price/30 grams & $\begin{array}{l}\text { Lentil Bar } \\
\text { Retail Price } \\
\text { Compared to } \\
\text { Competitors } \\
\$\end{array}$ \\
\hline A & $\$$ & \\
$\mathrm{~B}$ & Quaker Honey Raisin & 0.51 & 0.08 higher \\
$\mathrm{C}$ & Adams Body Smarts & 0.89 & 0.30 lower \\
$\mathrm{D}$ & Clif Luna Bar for Women & 1.24 & 0.65 lower \\
$\mathrm{E}$ & Quaker Trail Mix & 0.71 & 0.12 lower \\
$\mathrm{F}$ & Quaker Oatmeal to Go & 0.47 & 0.12 higher \\
$\mathrm{G}$ & Kelloggs' Vector Bar & 0.61 & 0.02 higher \\
& Power Bar & 0.95 & 0.36 lower \\
\hline
\end{tabular}


snack bars currently found in supermarkets (Table 4.11C). It is unlikely that this bar would be able to compete for snack bar market share with large multinational companies but would be financially viable in a specialized market.

\subsubsection{Expert Panel}

Mean values for each of the sensory attributes for each of the 25 formulations were used to construct models for each attribute (Table 4.12). A linear model was appropriate for all of the responses except toasted. A quadratic model was suggested for toasted and was reduced to having combinations of sweetened condensed milk (SCM) and granola and SCM and dried cranberries in the model as significant effects. Toasted had an outlier at 3.513 which was only .013 above the recommended limit and leverage at 0.6018 which should not be close to 1 . All of the other responses fell within the recommended limits. Square root transformation was necessary for fruit flavor. All of the other responses required no transformation.

Significant models were used to predict formulations for six lentil bars. Sensory characteristics for these six samples were based on comments from the consumer focus groups. These characteristics were identified by the groups and comments were provided as to whether they did or did not like these particular characteristics. High and low combinations of the characteristics would result in lentil bars displaying a range of flavor and textural attributes with a corresponding range in acceptability as follows:

1. low sweetness with high fruit flavor

2. high sweetness, no fruit flavor

3. high oat, no fruit flavor 
Table 4.12. Mean values for sensory attributes evaluated by the expert panel used to construct models for all of the attributes.

\begin{tabular}{|c|c|c|c|c|c|c|c|c|c|c|c|c|c|c|c|c|}
\hline \multirow[b]{2}{*}{$\begin{array}{l}\text { Run } \\
\text { Order }\end{array}$} & \multirow[b]{2}{*}{ Point Type } & \multicolumn{4}{|c|}{ Proportion of Ingredients } & \multirow[b]{2}{*}{$\begin{array}{l}\text { Dried } \\
\text { Cran- } \\
\text { berry }\end{array}$} & \multicolumn{10}{|c|}{ Mean Values $n=7$} \\
\hline & & $\mathrm{SCM}^{2}$ & Honey & $\mathrm{MFL}^{3}$ & Granola & & sweet $^{4}$ & $\begin{array}{l}\text { oat } \\
\text { flavor }\end{array}$ & fruity $^{4}$ & toasted ${ }^{4}$ & sticky $^{4}$ & initial bite $^{5}$ & cohesive $^{4}$ & moistness ${ }^{6}$ & chewiness ${ }^{4}$ & toothpack ${ }^{4}$ \\
\hline 1 & CentEdge & 0.34 & 0.12 & 0.19 & 0.34 & 0.00 & 7.4 & 7.8 & 0.1 & 9.2 & 9.0 & 6.8 & 7.4 & 7.0 & 8.6 & 9.9 \\
\hline 2 & CentEdge & 0.28 & 0.06 & 0.27 & 0.27 & 0.12 & 7.5 & 5.2 & 5.2 & 7.2 & 6.2 & 9.5 & 8.3 & 6.2 & 9.0 & 7.0 \\
\hline 3 & CentEdge & 0.40 & 0.12 & 0.19 & 0.25 & 0.04 & 9.8 & 5.6. & 1.7 & 6.7 & 9.5 & 5.1 & 6.9 & 8.5 & 6.9 & 8.1 \\
\hline 4 & Vertex & 0.37 & 0.12 & 0.19 & 0.20 & 0.12 & 9.3 & 5.9 & 5.3 & 6.4 & 10.7 & 5.3 & 7.2 & 9.9 & 6.7 & 8.2 \\
\hline 5 & PlaneCent & 0.35 & 0.09 & 0.29 & 0.20 & 0.07 & 8.3 & 6.3 & 3.2 & 8.4 & 7.0 & 5.9 & 7.2 & 7.9 & 8.1 & 8.6 \\
\hline 6 & CentEdge & 0.28 & 0.09 & 0.19 & 0.32 & 0.12 & 6.9 & 6.0 & 4.4 & 5.8 & 6.5 & 7.3 & 7.5 & 6.9 & 8.3 & 8.6 \\
\hline 7 & Vertex & 0.28 & 0.06 & 0.19 & 0.40 & 0.07 & 6.1 & 6.2 & 1.7 & 7.7 & 6.9 & 9.7 & 9.7 & 5.5 & 9.0 & 6.2 \\
\hline 8 & CentEdge & 0.28 & 0.09 & 0.19 . & 0.32 & 0.12 & 7.9 & 7.4 & 5.4 & 6.6 & 5.8 & 7.7 & 8.3 & 7.6 & 6.7 & 7.2 \\
\hline 9 & CentEdge & 0.28 & 0.12 & 0.37 & 0.22 & 0.01 & 7.3 & 7.2 & 0.8 & 9.8 & 7.8 & 7.0 & 5.7 & 6.7 & 9.6 & 8.7 \\
\hline 10 & CentEdge & 0.28 & 0.06 & 0.31 & 0.34 & 0.00 & 5.4 & 8.7 & 0.2 & 9.3 & 4.7 & 8.7 & 8.1 & 4.9 & 8.6 & 8.0 \\
\hline 11 & CentEdge & 0.28 & 0.12 & 0.37 & 0.22 & 0.01 & 6.6 & 8.7 & 1.5 & 9.0 & 8.6 & 6.2 & 5.5 & 6.4 & 10.2 & 10.0 \\
\hline 12 & Vertex & 0.28 & 0.06 & 0.19 & 0.40 & 0.07 & 6.6 & 6.2 & 4.5 & 6.9 & 5.1 & 8.8 & 7.6 & 5.2 & 8.4 & 7.7 \\
\hline 13 & CentEdge & 0.40 & 0.06 & 0.26 & 0.27 & 0.00 & 8.0 & 7.8 & 0.3 & 7.7 & 7.6 & 6.9 & 6.6 & 6.6 & 8.1 & 8.6 \\
\hline 14 & CentEdge & 0.34 & 0.06 & 0.19 & 0.29 & 0.12 & 7.2 & 6.2 & 5.0 & 7.5 & 5.7 & 7.7 & 8.5 & 6.5 & 7.6 & 6.7 \\
\hline 15 & CentEdge & 0.28 & 0.06 & 0.31 & 0.34 & 0.00 & 5.7 & 9.0 & 0.2 & 9.1 & 5.6 & 8.3 & 8.5 & 6.3 & 8.3 & 8.2 \\
\hline 16 & Vertex & 0.40 & 0.06 & 0.22 & 0.20 & 0.12 & 9.2 & 5.5 & 6.0 & 6.9 & 7.7 & 6.7 & 6.4 & 7.3 & 7.3 & 8.0 \\
\hline 17 & Vertex & 0.28 & 0.12 & 0.28 & 0.20 & 0.12 & 8.1 & 7.2 & 5.3 & 7.7 & 6.9 & 6.4 & 7.9 & 8.4 & 7.8 & 7.5 \\
\hline 18 & Vertex & 0.40 & 0.12 & 0.28 & 0.20 & 0.00 & 9.7 & 6.6 & 0.2 & 7.5 & 10.2 & 6.2 & 6.0 & 8.1 & 7.8 & 7.1 \\
\hline 19 & Vertex & 0.37 & 0.06 & 0.37 & 0.20 & 0.00 & 6.4 & 8.3 & 0.1 & 8.5 & 5.9 & 7.4 & 6.7 & 5.7 & 10.1 & 9.2 \\
\hline 20 & CentEdge & 0.28 & 0.12 & 0.19 & 0.34 & 0.06 & 8.6 & 7.8 & 3.9 & 6.2 & 7.4 & 6.6 & 6.7 & 7.2 & 8.2 & 8.6 \\
\hline 21 & Interior & 0.33 & 0.09 & 0.27 & 0.28 & 0.03 & 6.2 & 8.4 & 2.0 & 8.6 & 7.8 & 6.1 & 6.3 & 6.7 & 7.9 & 8.0 \\
\hline 22 & Vertex & 0.37 & 0.06 & 0.37 & 0.20 & 0.00 & 6.1 & 5.6 & 0.1 & 8.6 & 6.7 & 7.1 & 6.4 & 5.5 & 8.9 & 9.2 \\
\hline 23 & Vertex & 0.28 & 0.06 & 0.37 & 0.20 & 0.09 & 6.0 & 7.4 & 3.2 & 8.7 & 5.8 & 7.7 & 7.1 & 6.5 & 10.0 & 8.4 \\
\hline 24 & Vertex & 0.4 & 0.06 & 0.19 & 0.35 & 0.00 & 6.8 & 8.1 & 0.3 & 7.6 & 9.7 & 6.6 & 6.5 & 7.6 & 7.9 & 7.8 \\
\hline 25 & Vertex & 0.28 & 0.12 & 0.20 & 0.40 & 0.00 & 7.0 & 9.1 & 0.1 & 7.6 & 6.7 & 6.8 & 7.0 & 6.4 & 7.9 & 8.5 \\
\hline
\end{tabular}

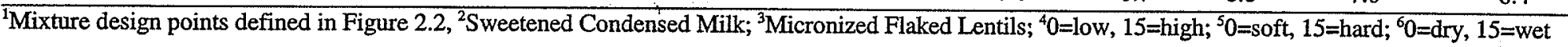


4. low oat, high fruit flavor

5. soft, chewy, moist, moderate fruit flavor

6. not as soft, less chewy, drier, no fruit flavor

Note: Stickiness to touch and toothpack were kept as low as possible for all of the samples.

The numerical optimization option in the Design-Expert Program was used to set minimums, maximums and targets for each of the sensory characteristics depending on each of the six bar characteristics listed above (Table 4.13). Formulations were selected based on the solution with the highest desirability score, optimizing the amount of lentils where possible and minimizing toothpacking and stickiness to touch (Table 4.14). The six bar formulations shown in Table 4.15 were selected for further study.

\subsection{Consumer Panel}

\subsubsection{Demographic Data}

The majority of the 62 consumers $(86 \%)$ were 18 to 29 years of age with almost equal numbers making up the other two age groups 30 to 39 and 40 to 49 (Figure 4.4). Fifty-five percent ate snack bars at least once per week with $31 \%$ of respondents eating them at least once per month. Of the 48 consumers making a single response as to when the bars were eaten, "as a snack" was the response chosen by $83 \%$. Nature Valley and Quaker brands were each chosen by $21 \%$ of the consumers as the brand most often purchased.

\subsubsection{Acceptability and Purchase Behaviour}

$\mathrm{CB} 1$ and $\mathrm{CB} 2$ were highest in acceptability with mean values 7.1 and 6.5 
Table 4.13 Criteria entered into the Design-Expert numerical optimization option for selection of six lentil bar samples.

\begin{tabular}{|c|c|c|c|c|c|c|}
\hline Sensory Attribute & $\begin{array}{l}\text { Bar } 1 \\
\text { low sweet; } \\
\text { high fruit }\end{array}$ & $\begin{array}{l}\text { Bar } 2 \\
\text { high sweet; } \\
\text { no fruit }\end{array}$ & $\begin{array}{l}\text { Bar } 3 \\
\text { high oat; } \\
\text { low toasted; } \\
\text { no fruit }\end{array}$ & $\begin{array}{l}\text { Bar } 4 \\
\text { low oat; } \\
\text { high toasted; } \\
\text { high fruit }\end{array}$ & $\begin{array}{l}\text { Bar } 5 \\
\text { soft; } \\
\text { chewy; } \\
\text { moist; } \\
\text { moderate fruit }\end{array}$ & $\begin{array}{l}\text { Bar } 6 \\
\text { less soft; } \\
\text { less chewy; } \\
\text { less moist; } \\
\text { no fruit }\end{array}$ \\
\hline sweetness & minimum & maximum & target $=7.6$ & target $=7.6$ & target $=7.6$ & target $=7.6$ \\
\hline oat flavor & target $=7.2$ & target $=7.2$ & maximum & minimum & target $=7.2$ & target $=7.2$ \\
\hline fruity & maximum & minimum & minimum & maximum & target $=1.4$ & minimum \\
\hline toasted & target $=7.8$ & target $=7.8$ & minimum & maximum & target $=7.8$ & target $=7.8$ \\
\hline sticky to touch & minimum & minimum & minimum & minimum & minimum & minimum \\
\hline initial bite & target $=7.4$ & target $=7.4$ & target $=7.4$ & target $=7.4$ & minimum & maximum \\
\hline cohesiveness & target $=7.6$ & target $=7.6$ & target $=7.6$ & target $=7.6$ & minimum & maximum \\
\hline moistness & target $=7.4$ & target $=7.4$ & target $=7.4$ & target $=7.4$ & maximum & minimum \\
\hline chewiness & target $=8.5$ & target $=8.5$ & target $=8.5$ & target $=8.5$ & maximum & minimum \\
\hline toothpack & minimum & minimum & minimum & minimum & minimum & minimum \\
\hline
\end{tabular}


Table 4.14. Solutions (Sol) for six lentil bar samples generated from the Design-Expert numerical optimization option.

Ingredients

$\begin{array}{llllllllllllllllll}\text { Bar \# } & \text { Sol \# } & \mathrm{SCM}^{1} & \mathrm{HO}^{2} & \mathrm{MFL}^{3} & \mathrm{GR}^{4} & \mathrm{DC}^{5} & \mathrm{SW}^{6} & \mathrm{OF}^{7} & \mathrm{FR}^{8} & \mathrm{TO}^{9} & \mathrm{ST}^{10} & \mathrm{IB}^{11} & \mathrm{CO}^{12} & \mathrm{MO}^{13} & \mathrm{CH}^{14} & \mathrm{TP}^{15} & \mathrm{DE}^{16}\end{array}$

\begin{tabular}{|c|c|c|c|c|c|c|c|c|c|c|c|c|c|c|c|c|c|}
\hline 1 & 1 & 0.29 & 0.09 & 0.26 & 0.30 & 0.07 & 7.0 & 7.2 & 2.6 & 7.8 & 6.6 & 7.6 & 7.6 & 6.6 & 8.5 & 8.0 & 0.826 \\
\hline \multirow[t]{3}{*}{2} & 1 & 0.38 & 0.06 & 0.21 & 0.34 & 0.02 & 7.2 & 7.2 & 0.5 & 8.2 & 7.5 & 7.4 & 7.4 & 6.4 & 7.9 & 7.9 & 0.703 \\
\hline & 2 & 0.36 & 0.07 & 0.20 & 0.34 & 0.03 & 7.3 & 7.2 & 0.8 & 8.1 & 7.5 & 7.4 & 7.5 & 6.5 & 7.8 & 7.9 & 0.702 \\
\hline & 3 & 0.40 & 0.06 & 0.26 & 0.27 & 0.01 & 7.3 & 7.0 & 0.4 & 8.0 & 7.8 & 7.0 & 6.8 & 6.6 & 8.2 & 8.2 & 0.690 \\
\hline \multirow[t]{7}{*}{3} & 1 & 0.28 & 0.11 & 0.19 & 0.40 & 0.02 & 6.9 & 8.3 & 0.8 & 7.6 & 7.3 & 7.4 & 7.5 & 6.5 & 8.1 & 8.2 & 0.702 \\
\hline & 2 & 0.28 & 0.11 & 0.20 & 0.40 & 0.01 & 6.9 & 8.5 & 0.5 & 7.8 & 7.5 & 7.3 & 7.4 & 6.5 & 8.2 & 8.4 & 0.699 \\
\hline & 3 & 0.29 & 0.10 & 0.19 & 0.40 & 0.02 & 7.0 & 8.2 & 0.7 & 7.7 & 7.4 & 7.4 & 7.5 & 6.5 & 8.1 & 8.2 & 0.699 \\
\hline & 4 & 0.28 & 0.11 & 0.21 & 0.40 & 0.00 & 6.8 & 8.6 & 0.4 & 8.0 & 7.3 & 7.4 & 7.4 & 6.4 & 8.3 & 8.4 & 0.696 \\
\hline & 5 & 0.31 & 0.10 & 0.19 & 0.40 & 0.01 & 6.9 & 8.2 & 0.4 & 8.0 & 7.5 & 7.4 & 7.5 & 6.4 & 8.0 & 8.2 & 0.694 \\
\hline & 6 & 0.28 & 0.11 & 0.21 & 0.39 & 0.01 & 6.8 & 8.5 & 0.5 & 8.0 & 7.3 & 7.4 & 7.4 & 6.4 & 8.4 & 8.4 & 0.693 \\
\hline & 7 & 0.32 & 0.09 & 0.19 & 0.39 & 0.01 & 7.0 & 8.1 & 0.5 & 8.0 & 7.5 & 7.4 & 7.5 & 6.4 & 8.0 & 8.2 & 0.689 \\
\hline \multirow[t]{2}{*}{4} & 1 & 0.32 & 0.07 & 0.29 & 0.20 & 0.12 & 7.6 & 5.9 & 5.5 & 7.6 & 6.5 & 7.4 & 7.5 & 7.1 & 8.4 & 7.8 & 0.814 \\
\hline & 2 & 0.31 & 0.08 & 0.28 & 0.21 & 0.12 & 7.6 & 6.1 & 5.6 & 7.5 & 6.5 & 7.4 & 7.5 & 7.2 & 8.4 & 7.8 & 0.807 \\
\hline \multirow[t]{4}{*}{5} & 1 & 0.34 & 0.09 & 0.32 & 0.20 & 0.04 & 7.6 & 7.1 & 1.4 & 8.3 & 7.7 & 6.5 & 6.5 & 7.1 & 8.7 & 8.6 & 0.671 \\
\hline & 2 & 0.34 & 0.10 & 0.31 & 0.22 & 0.04 & 7.6 & 7.2 & 1.4 & 8.3 & 7.8 & 6.5 & 6.6 & 7.1 & 8.6 & 8.6 & 0.670 \\
\hline & 3 & 0.37 & 0.08 & 0.31 & 0.20 & 0.04 & 7.6 & 6.8 & 1.4 & 8.0 & 7.6 & 6.7 & 6.6 & 7.0 & 8.5 & 8.4 & 0.666 \\
\hline & 4 & 0.34 & 0.11 & 0.31 & 0.20 & 0.04 & 8.1 & 7.2 & 1.4 & 8.1 & 8.5 & 6.0 & 6.3 & 7.6 & 8.5 & 8.8 & 0.659 \\
\hline
\end{tabular}


Table 4.14. Solutions (Sol) for six lentil bar samples generated from the Design-Expert numerical optimization option. (cont'd)

\begin{tabular}{|c|c|c|c|c|c|c|c|c|c|c|c|c|c|c|c|c|c|}
\hline \multirow[b]{2}{*}{ Bar \# } & \multirow[b]{2}{*}{ Sol \# } & \multicolumn{5}{|c|}{ Ingredients } & \multicolumn{10}{|c|}{ Mean values $n=7$} & \multirow[b]{2}{*}{$\mathrm{DE}^{16}$} \\
\hline & & $\mathrm{SCM}^{\mathrm{l}}$ & $\mathrm{HO}^{2}$ & $\mathrm{MFL}^{3}$ & $\mathrm{GR}^{4}$ & $\mathrm{DC}^{5}$ & $\mathrm{SW}^{6}$ & $\mathrm{OF}^{7}$ & $\mathrm{FR}^{8}$ & $\mathrm{TO}^{9}$ & $S T^{10}$ & $\mathbb{I B}^{11}$ & $\mathrm{CO}^{12}$ & $\mathrm{MO}^{13}$ & $\mathrm{CH}^{14}$ & $\mathrm{TP}^{15}$ & \\
\hline \multirow[t]{5}{*}{6} & 1 & 0.36 & 0.06 & 0.19 & 0.36 & 0.03 & 7.0 & 7.2 & 0.8 & 8.1 & 7.1 & 7.8 & 7.7 & 6.3 & 7.8 & 7.7 & 0.683 \\
\hline & 2 & 0.35 & 0.06 & 0.19 & 0.37 & 0.03 & 6.9 & 7.3 & 0.9 & 8.1 & 7.0 & 7.9 & 7.8 & 6.2 & 7.9 & 7.7 & 0.683 \\
\hline & 3 & 0.33 & 0.06 & 0.19 & 0.38 & 0.03 & 6.7 & 7.4 & 0.9 & 8.0 & 6.7 & 8.1 & 7.9 & 6.0 & 8.0 & 7.7 & 0.682 \\
\hline & 4 & 0.33 & 0.06 & 0.19 & 0.39 & 0.03 & 6.5 & 7.5 & 0.9 & 8.0 & 6.5 & 8.2 & 8.0 & 5.9 & 8.0 & 7.7 & 0.679 \\
\hline & 5 & 0.40 & 0.06 & 0.20 & 0.33 & 0.01 & 7.4 & 7.2 & 0.3 & 8.1 & 8.0 & 7.2 & 7.2 & 6.5 & 7.7 & 8.0 & 0.665 \\
\hline
\end{tabular}

${ }^{1}$ Sweetened condensed milk

${ }^{2}$ Honey

${ }^{3}$ Micronized Flaked Lentils

${ }^{4}$ Granola

${ }^{5}$ Dried cranberries

${ }^{6}$ Sweetness

${ }^{7}$ Oat flavor

${ }^{8}$ Fruity

${ }^{9}$ Toasted

${ }^{10}$ Sticky to touch

${ }^{11}$ initial bite

${ }^{12}$ Cohesiveness

${ }^{13}$ moistness

${ }^{14}$ Chewiness

${ }^{15}$ Tooth pack

${ }^{16}$ Desirability value based on criteria entered into the Design-Expert numerical optimization option 
Table 4.15. Bar formulations selected from the Design-Expert numerical optimization option for presenting to consumer and descriptive panels.

\begin{tabular}{|c|c|c|c|c|c|c|c|c|}
\hline Sample & Description $S$ & $\begin{array}{l}\text { Solution \# } \\
\text { Selected }^{1}\end{array}$ & Rationale & $\mathrm{SCM}^{2}$ & Honey & $\mathrm{MFL}^{2}$ & Granola & $\begin{array}{l}\text { Dried } \\
\text { Cranberries }\end{array}$ \\
\hline LB1 & $\begin{array}{l}\text { low sweet } \\
\text { high fruit }\end{array}$ & 1 & $\begin{array}{l}\text { only solution } \\
\text { provided }\end{array}$ & 0.29 & 0.09 & 0.26 & 0.30 & 0.07 \\
\hline LB2 & $\begin{array}{l}\text { high sweet } \\
\text { no fruit flavor }\end{array}$ & 3 & $\begin{array}{l}\text { maximize } \\
\text { lentils }\end{array}$ & 0.40 & 0.06 & 0.27 & 0.27 & $0.01^{*}$ \\
\hline LB3 & $\begin{array}{l}\text { low toasted } \\
\text { no fruit flavor }\end{array}$ & 1 & $\begin{array}{l}\text { highest } \\
\text { desirability }\end{array}$ & 0.28 & 0.11 & 0.19 & 0.40 & $0.02 *$ \\
\hline LB4 & $\begin{array}{l}\text { high toasted } \\
\text { high fruit }\end{array}$ & 1 & $\begin{array}{l}\text { highest } \\
\text { desirability }\end{array}$ & 0.32 & 0.07 & 0.29 & 0.20 & 0.12 \\
\hline LB5 & $\begin{array}{l}\text { soft } \\
\text { chewy } \\
\text { moist } \\
\text { mod fruit }\end{array}$ & 1 & $\begin{array}{l}\text { highest } \\
\text { desirability }\end{array}$ & 0.34 & 0.09 & 0.32 & 0.20 & 0.04 \\
\hline LB6 & $\begin{array}{l}\text { less soft } \\
\text { less chewy } \\
\text { less moist } \\
\text { no fruit flavor }\end{array}$ & 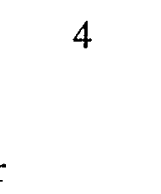 & $\begin{array}{l}\text { lowest SCM } \\
\text { lowest sticky }\end{array}$ & 0.33 & 0.06 & 0.19 & 0.39 & $0.03 *$ \\
\hline
\end{tabular}

* add to lentil proportion

${ }^{1}$ Solution \# selected from options presented in Table 4.14 generated by the numerical optimization procedure

${ }^{2}$ Sweetemed Condensed Milk; ${ }^{3}$ Micronized Flaked Lentils 
Figure 4.4 Consumer panel: age and snack bar consumption patterns.
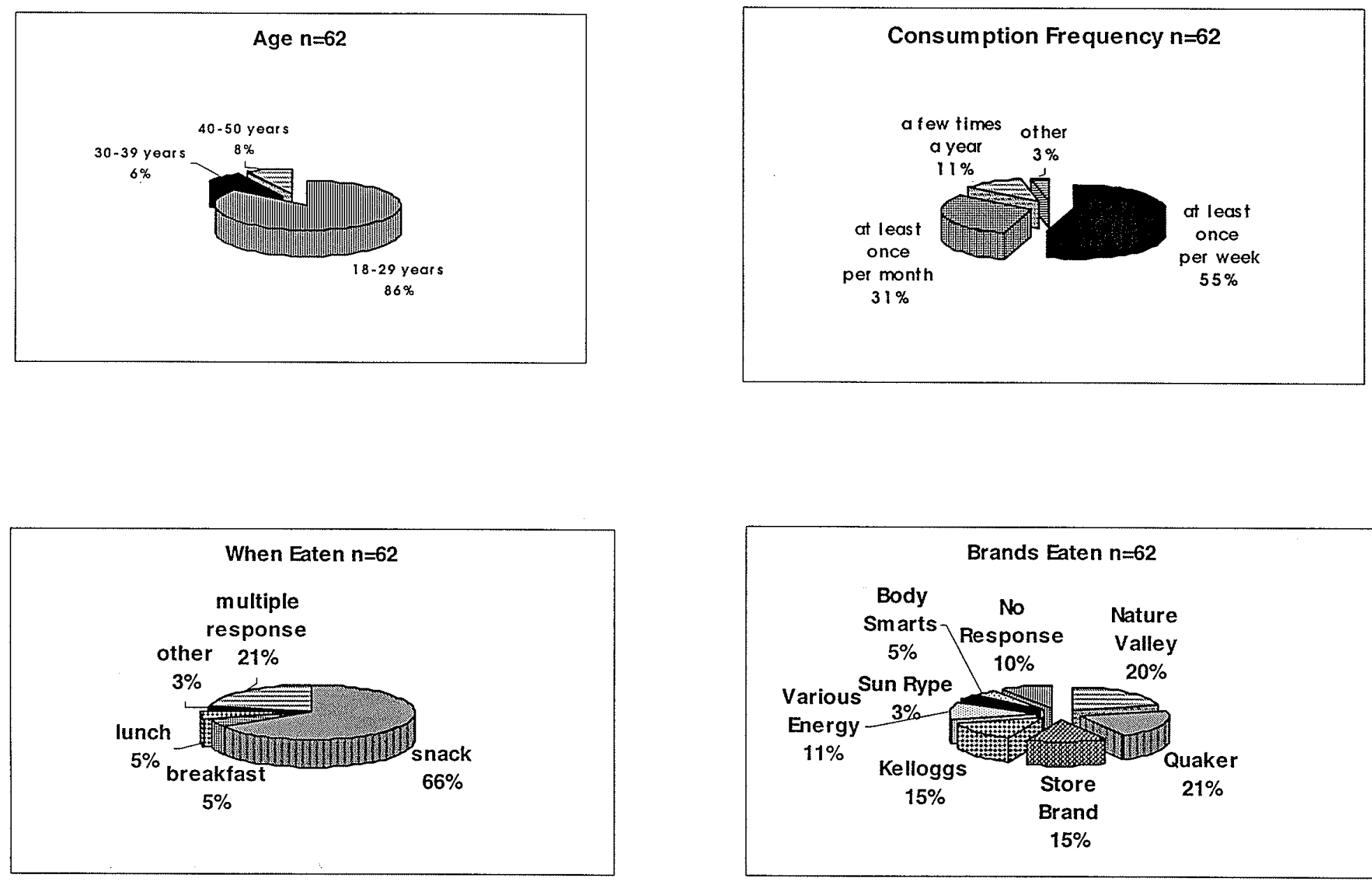

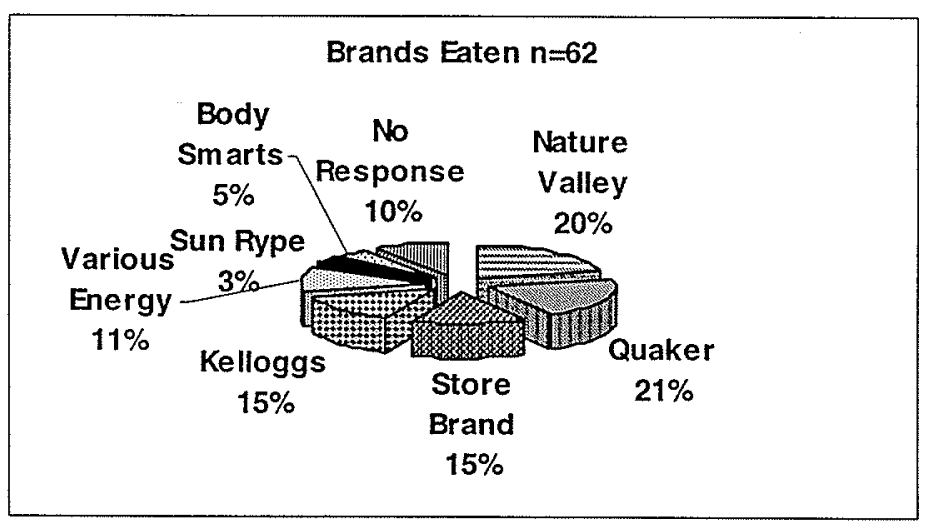


respectively corresponding to "like moderately" (Figure 4.5). LB1, LB3 and LB6 with mean values of 5.9, 6.0 and 6.0 respectively were not significantly different from CB2 although the mean score corresponded to "like slightly". LB2, LB4 and LB5 were liked significantly less than both the commercial bars with mean values of $5.6,5.6$ and 5.2 respectively which corresponded to "like slightly" for LB2 and LB4 and "neither like nor dislike" for LB5. No significant difference in liking was found between any of the lentil bars although LB5 had the lowest mean score corresponding to "neither like nor dislike". Selecting a wider range of constraints for the mixture design experiment may have helped to separate the lentil bars so that a wider range of acceptability could be found. The initial intent was to include a relatively high percentage of lentils in the snack bars in order to maximize their nutritional benefit and increase lentil consumption. On the other hand lowering the lentil level may increase demand for the snack bars so that increased consumption would offset the decreased amount used.

Samples with the highest purchase behaviour scores followed the same trend as those with the highest acceptability scores agreeing with Moskowitz (1994). The mean purchase behaviour scores for CB1 and CB2 (4.1 and 3.6 respectively) corresponded to "would purchase sometimes" (Figure 4.5). As for acceptability, LB1, LB3 and LB6 were not significantly different from the two commercial snack bars. Purchase behaviour mean values for LB2, LB4 and LB5 indicated that these samples would be purchased significantly less often than the two commercial samples. All lentil snack bars had mean values that showed no significant differences corresponding to "would purchase now and then". Moskowitz (1994) suggests that determining the proportion of the responses for the 
Figure 4.5. Snack bar sample means ${ }^{a}$ for acceptability and purchase behaviour from consumer panel $n=62$.

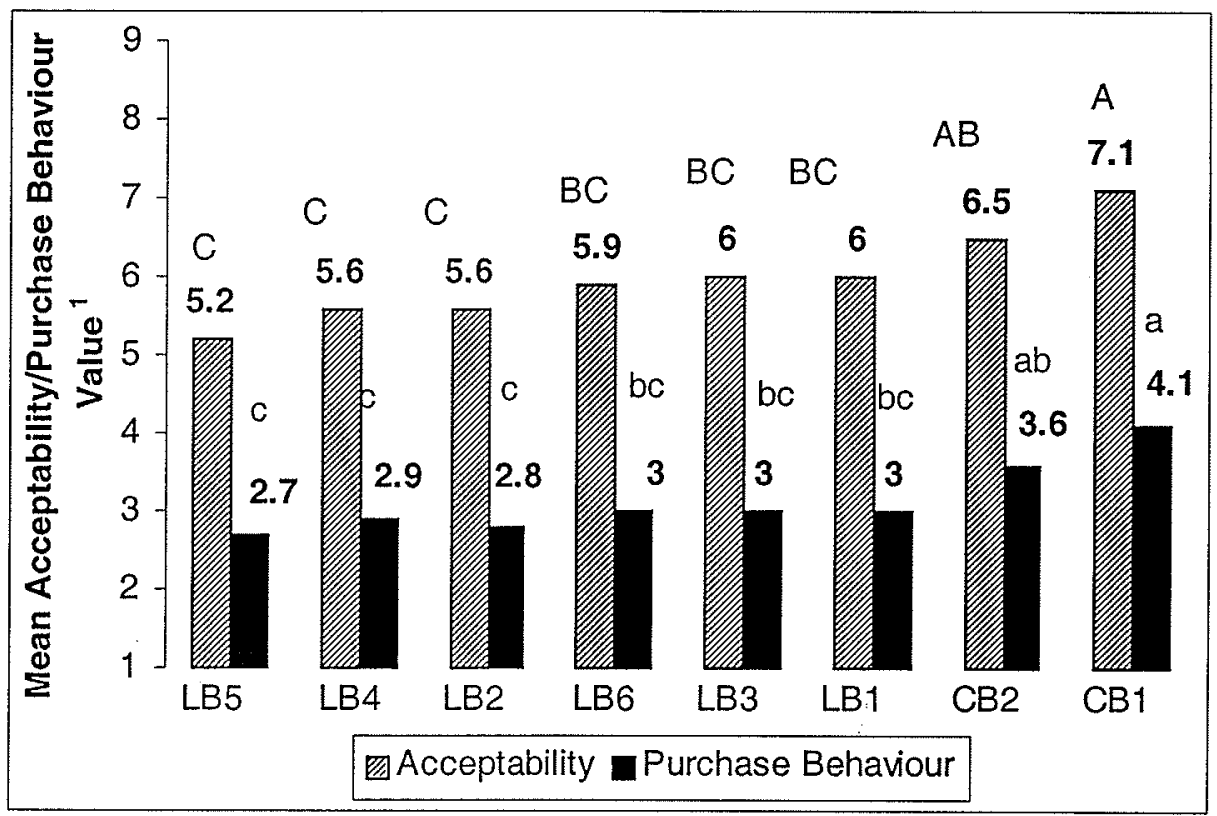

${ }^{a}$ Means are the averages of 62 panelists; mean values with the same uppercase letter within the attribute "acceptability" are not significantly different $(\mathrm{p}<0.05)$; mean values with the same lower case letter within the attribute "purchase behaviour" are not significantly different $(\mathrm{p}<0.05)$

${ }^{1}$ Acceptability: $1=$ dislike extremely 5 = neither like nor dislike $9=$ like extremely; Purchase Behaviour: $1=$ never 4 = sometimes 7 = every opportunity 
top two categories may be a more appropriate indicator of purchase behaviour. For the first two categories, "every opportunity" and "very often", LB1 had the highest number of responses for the lentil bar samples at $10 \%$ which is slightly higher than CB2 at $8 \%$ (Figure 4.6). Not surprising the most liked bar, CB1, had the highest frequency at $23 \%$ of the responses falling in both the "every opportunity" and "very often" categories. Even though consumers were asked their opinions regarding purchase behaviour given that the price would be similar to bars found in the marketplace different prices would be used depending on the consumers' usual purchasing patterns. More reliable purchase behaviour data may be obtained by using the price the consumer is accustomed to paying.

To determine the distribution of the data for each of the samples, frequencies for each category were plotted. Categories with the highest frequencies corresponded to the mean value for LB2, LB3 and CB1 (Figure 4.7B, C and G). Categories where the highest frequencies were lower than the mean value were found for LB4 and LB5 (Figure 4.7D and E) and categories where the highest frequencies were higher than the mean value were found for LB1, LB6 and CB2 (Figure 4.7A, F and H). Therefore, the data showed normal, skewed and in the case of LB5 possibly a bivariate distribution.

Figure 4.8 shows the percentage of responses that are at 5 (neither like nor dislike) or higher using the guideline of Polizzoto et al., (1983) who stated that an acceptable product was one which was rated at the half way point or better on an acceptance scale. Even though the mean scores were the same for LB2 and LB4 the frequency scores infer that LB4 was less acceptable as there were only $68 \%$ responses with scores over 5 compared to $82 \%$ for LB2. 
Figure 4.6. Percentage of responses for each category for purchase behaviour ${ }^{\mathrm{a}}$ of snack bars from consumer panel $n=62$.

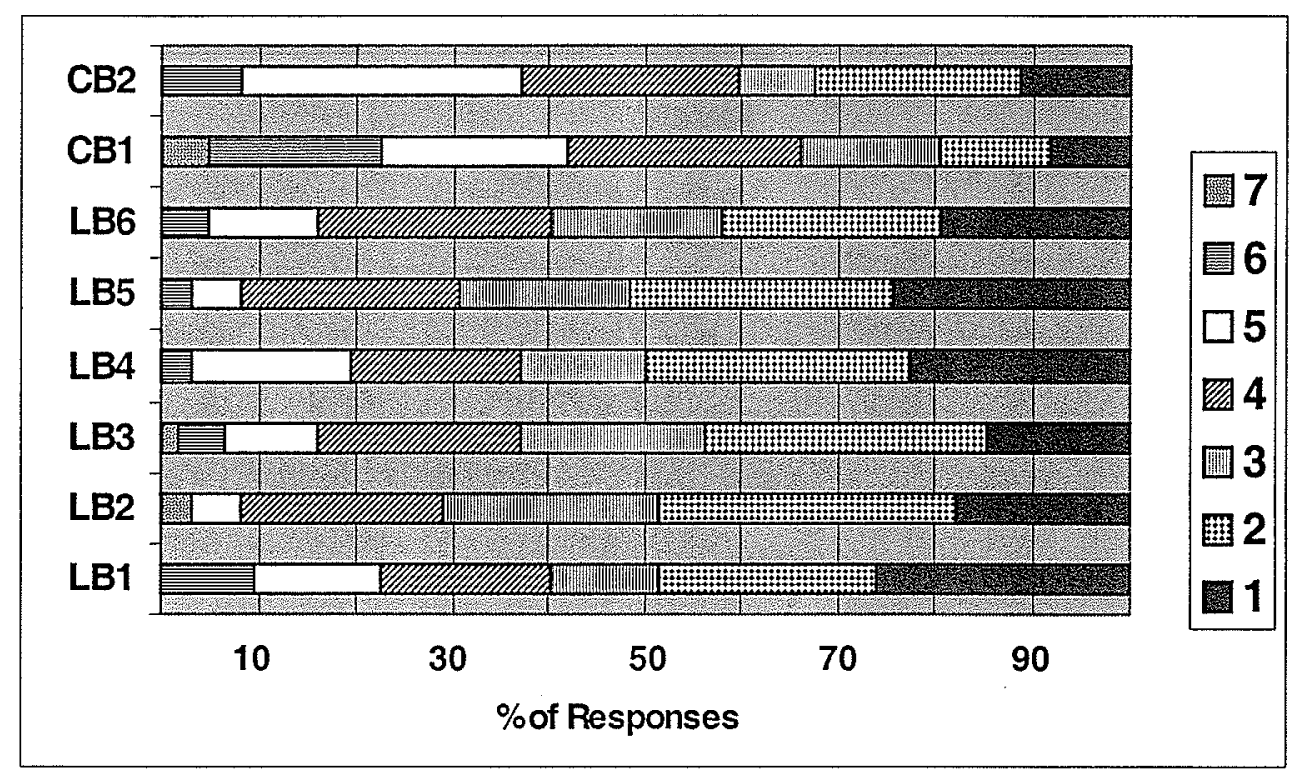

${ }^{\mathrm{a}} 1=$ =never; $2=$ not very often; $3=$ now and then; $4=$ sometimes; $5=$ frequently; $6=$ very often; $7=$ every opportunity 
Figure 4.7. Number of responses for each category for acceptability of snack bars by the consumer panel $n=62$.
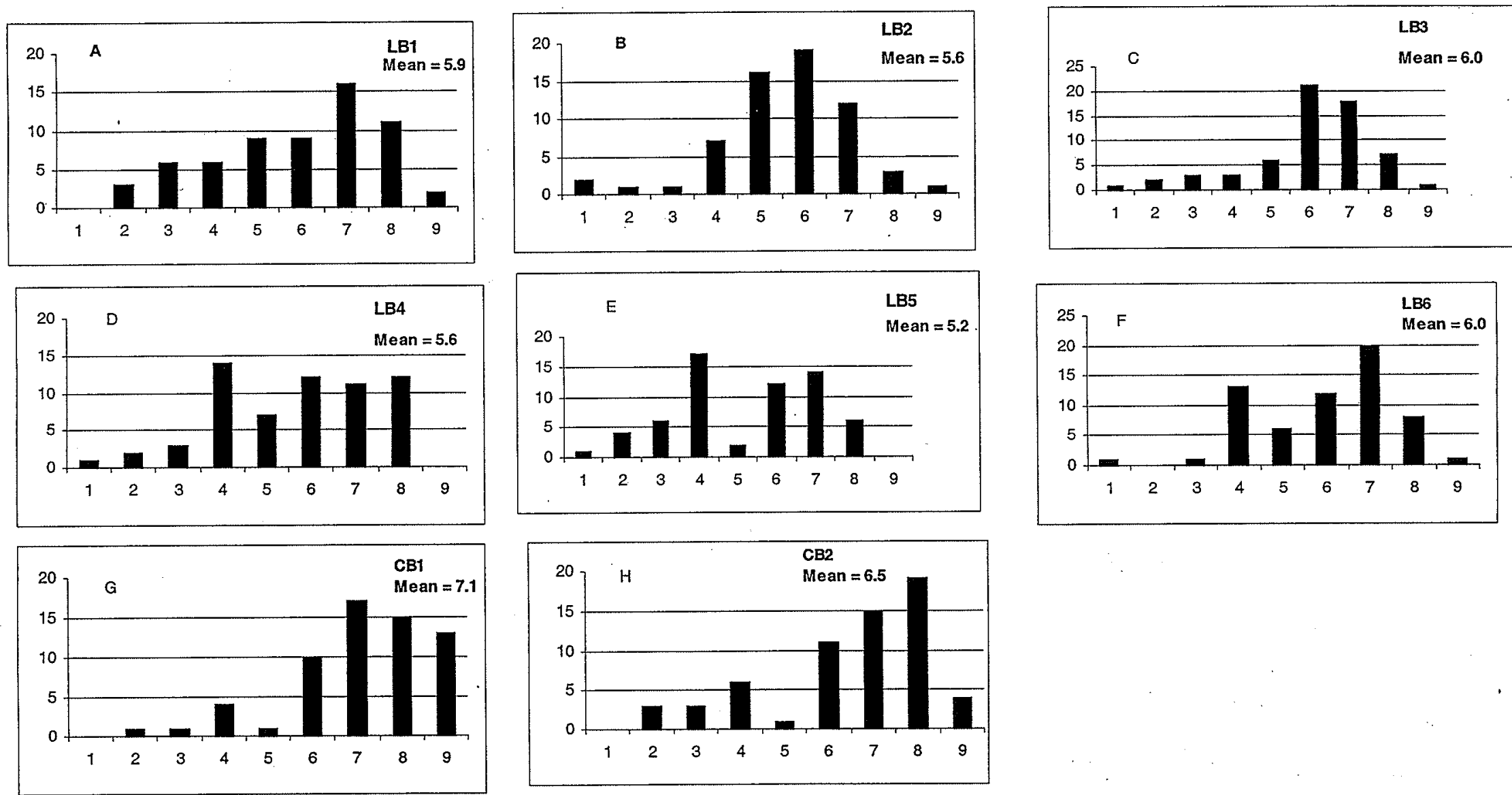
Figure 4.8. Percentage of responses for each category for acceptability ${ }^{\mathrm{a}}$ of snack bars from consumer panel $n=62$.

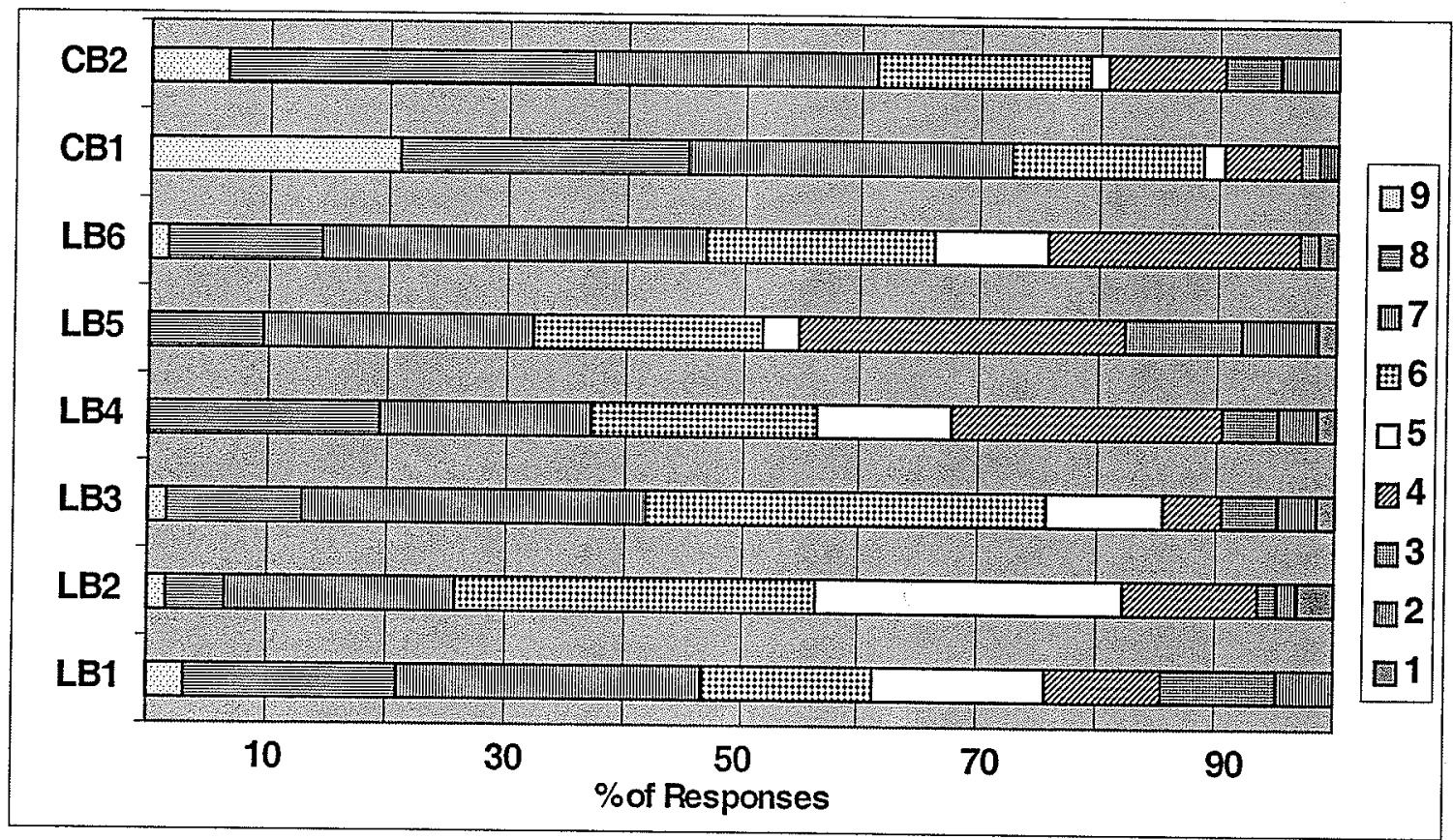

${ }^{\mathrm{a}}$ 1=dislike extremely; 2=dislike very much; $3=$ dislike moderately; 4=dislike slightly; 5=neither like nor dislike; $6=$ like slightly; $7=$ like moderately; $8=$ like very much; $9=$ like extremely 


\subsubsection{Attribute Appropriateness}

"Just right" scales are often used to determine the optimum level of an ingredient based on consumer opinion of the appropriate level for an attribute and therefore may provide insight for product development (Vickers, 1988).

For sweetness of the lentil bar samples, of the three categories, "not enough", "just right" and "too much", LB1, LB4 had the highest frequency in the "just right" category (Figure 4.9A). LB2 had equal frequency for "just right" and "not enough". LB3, LB5 and LB6 had the highest frequency in "not enough". For the commercial samples CB1 had equal frequency for "just right" and "too much" and CB2 had the highest frequency in the “just right” category.

For cranberry flavor, of the three lentil bars that contained cranberries, LB4 had the highest frequency in the "just right" category while both LB1 and LB5 had "not enough" cranberry flavor (Figure 4.9B). Amount of cranberry in the sample reflected the frequency as LB5, the sample with the least cranberries, had the highest frequency in the "not enough" category (74\%), LB1 (mid level cranberry) the next highest (57\%) and LB4 (most cranberry) the lowest frequency for "not enough" (39\%) only slightly lower than the frequency for "just right" (40\%).

LB6 was the lentil bar sample with the highest frequency in the "just right" category for cereal/grain flavor (Figure 4.9C). All of the other lentil bar samples had the highest frequency in the "too much" category with LB4 the highest at 50\%. The lentil:granola ratio for LB6 and LB4 was 1:1.77 and 1:0.69 respectively suggesting more granola than lentil was thought to be "better" by these consumers. Both the commercial 
Figure 4.9. Frequencies (\%) in for "not enough", "just right" and "too much" categories for all attributes from "just right" scales from consumer panel n=6
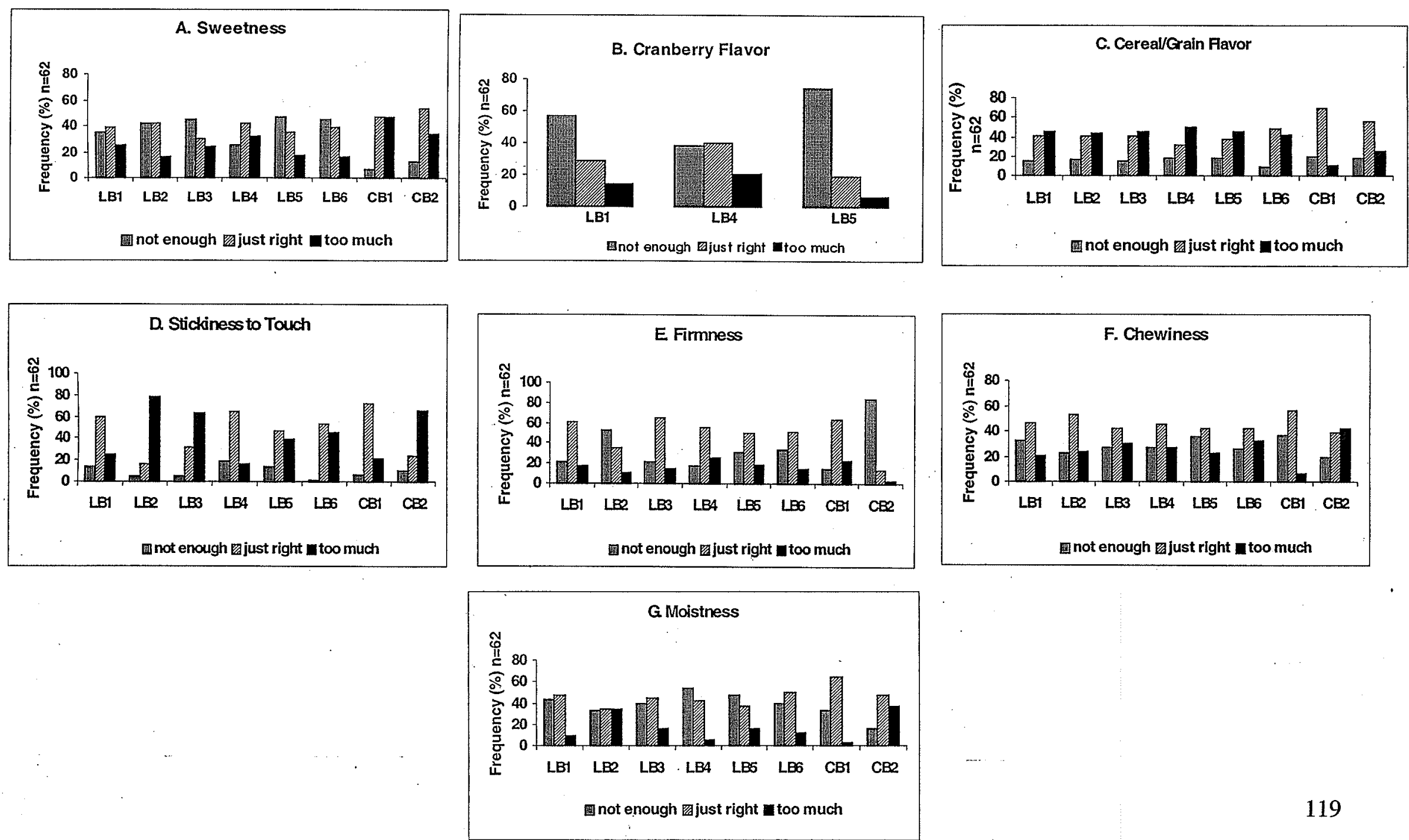
samples had highest frequencies in the "just right" category for cereal/grain.

LB1, LB4, LB5 and LB6 had the highest frequency in the "just right" category (Figure 4.9D) for stickiness to touch. Both LB2 and LB3 had 79\% and 63\% respectively in the "too much" category. LB2 contained the highest amount of sweetened condensed milk and LB3 contained the highest amount of honey. CB1 had over $73 \%$ of the responses in the "just right" category and CB2 had $66 \%$ in the "too much" category.

LB1, LB3, LB4, LB5 and LB6 all had highest frequencies (at least 50\%) in the "just right" category for firmness (Figure 4.9E). LB2 had the highest frequency (53\%) in the "not enough" category. It was the only sample that contained an equal amount of lentils and granola and had the highest level of sweetened condensed milk. CB1 had 63\% of the responses in the "just right" category and CB2 had 84\% in the "not enough" category.

For chewiness, all of the lentil bar samples had the highest frequency in the "just right" category from 53\% for LB2 to $42 \%$ for LB3, LB5 and LB6 (Figure 4.9F). CB1 had the highest frequency in the" just right" category while CB2 hand the highest frequency of responses in the "too much" category.

For moistness, LB1, LB3 and LB6 had the highest frequency in the "just right" category (Figure 4.9G). Frequencies for LB2 were similar for all three categories. Frequencies were highest in the "not enough" category for LB4 and LB5 (53\% and 47\% respectively). These two samples had the lowest amount of granola with the top two levels of lentils. Both the commercial samples had the highest frequency in the "just right" category. 
A higher percentage of attributes that have the majority of responses in the "just right" category may be an indication of a more acceptable product. Product improvements would be based on which category the majority of responses fell. For example, if the highest frequency of responses was in the "too much" category then less of that attribute would be desirable. If the highest frequency was in the "not enough" category then more of that attribute would be desirable. Of all of the lentil bars LB6 had the highest percentage of attributes with the majority of responses in the "just right" category (83\%) which was the same as CB1 (Table 4.16). Increasing sweetness by increasing honey and/or sweetened condensed milk would improve LB6. LB2 had the lowest percentage of attributes in the "just right" category with all attributes needing improvement except chewiness.

\subsubsection{Internal Preference Mapping}

From principal components analysis it was determined that the first two components accounted for $50 \%$ of the variation (Figure 4.10). The first component, illustrated along the x-axis, differentiated the acceptability levels of the commercial snack bar samples from the lentil samples. The second component, illustrated along the $y$-axis, differentiated the lentil bars containing the cranberries, which is found in the top section, from the plain lentil bars in the bottom section. Each arrowed line represents a consumer with longer lines showing a higher acceptability. Therefore, the further from the origin the more acceptable the product. These results confirmed that $\mathrm{CB} 1$ was highest in acceptability due to its distance from the origin. Of the lentil bars containing cranberries LB4, the sample containing the most cranberries had the highest acceptability with LB5, 
Table 4.16. Percentage of attributes in "just right" category and suggested improvements for snack bars.

Sample

$\%$ attributes with majority

of responses in JR category

Suggested improvements

$\mathrm{CB} 1$

$83 \% \mathrm{n}=6$

$83 \% \mathrm{n}=6$

$71 \% \mathrm{n}=7$

LB1

$71 \% \mathrm{n}=7$

LB4

$50 \% \mathrm{n}=6$

LB3

$50 \% \mathrm{n}=6$

LB5

$43 \% \mathrm{n}=7$

LB2

$17 \% \mathrm{n}=6$

$\downarrow$ sweetness ${ }^{1}$

$\uparrow$ sweetness

$\downarrow$ cereal/grain; $\uparrow$ cranberry flavor

$\downarrow$ cereal/grain; $\uparrow$ moistness

istickiness to touch; †firmness;

$\downarrow$ chewiness

$\downarrow$ cereal/grain; † sweetness;

$\downarrow$ stickiness to touch

$\downarrow$ cereal/grain; $\uparrow$ sweetness;

$\uparrow$ cranberry flavor; $\uparrow$ moistness

$\downarrow$ cereal/grain; † sweetness ${ }^{2}$;

$\downarrow$ stickiness to touch; †firmness;

$\downarrow$ moistness $^{2}$

${ }^{1} \mathrm{~J}$ frequency $=$ "not enough" frequency

${ }^{2} \mathrm{JR}$ frequency = "too much" frequency 
Figure 4.10. Groupings of consumers based on acceptability of snack bars using loadings from the first two principal components $n=62$.

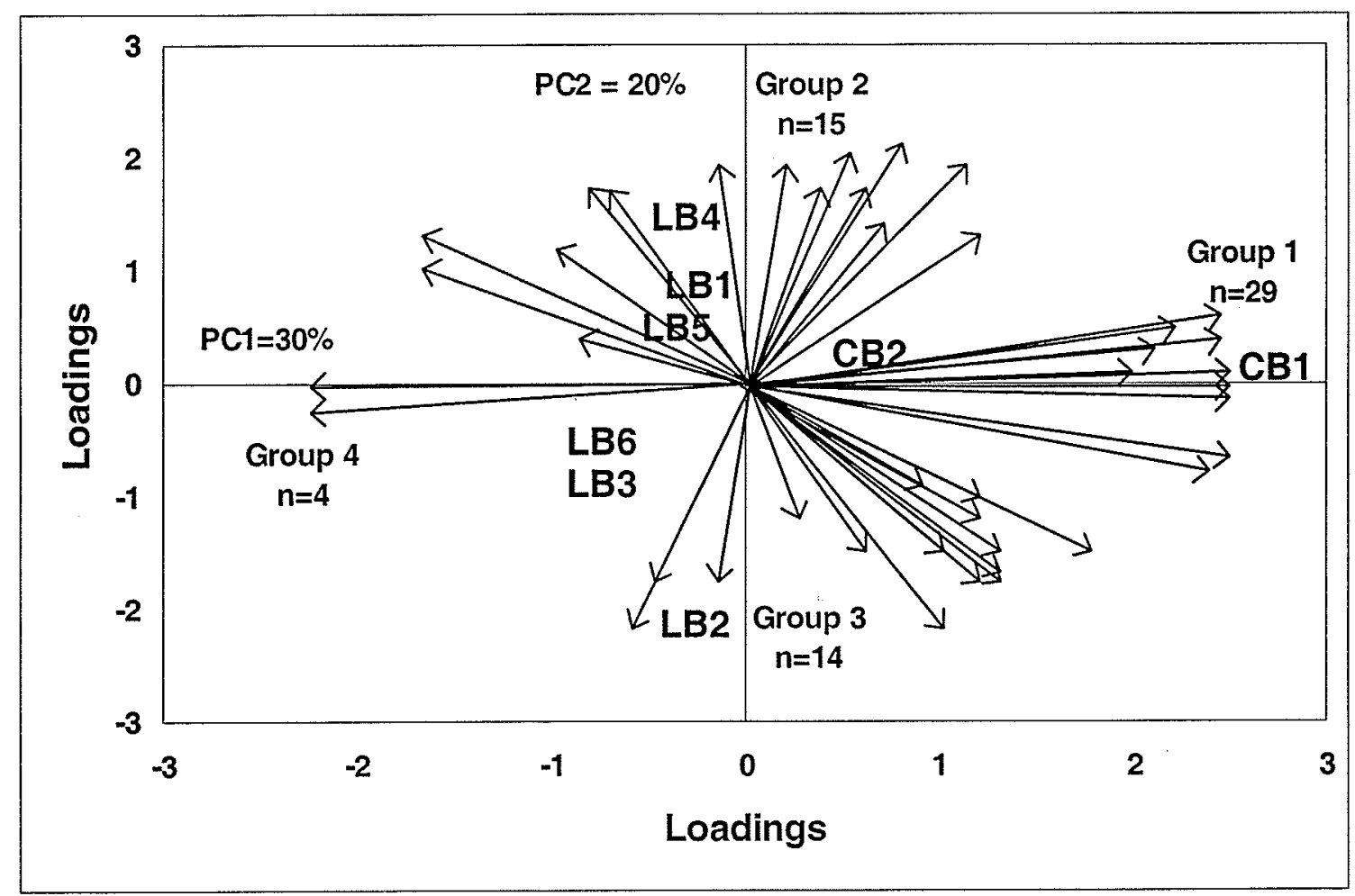


the sample containing the fewest cranberries showing the lowest acceptability. Within the plain lentil bar group LB2 showed the highest acceptability with LB3 and LB6 lower and similar in acceptability due to their close proximity.

Four consumer groupings for acceptability of snack bars were shown. Those who found the commercial samples most acceptable were found in group 1 which contained the largest number of consumers (Figure 4.10). This information indicates that development of a product similar to these commercial samples would be most likely to succeed. Fifteen consumers found cranberry lentil bars more acceptable while fourteen found the plain lentil bars more acceptable. Even though fruit was mentioned by the focus group members as being a positive ingredient the consumer panel did not seem to have a preference for the lentil bars with fruit or without fruit. Developing the product with or without cranberries would appear to have no marketing benefit. Four consumers found none of the eight samples acceptable suggesting that there could be a market for some other type of bar for this consumer group perhaps bars substituting savory ingredients for sweet.

To determine if a marketing segmentation advantage was apparent consumers from within each of these groupings were compared to their demographic characteristics of age, frequency, time of eating, brand and flavor of bar eaten. No trends were noted (Appendix 6). Using a larger more diverse consumer group may have yielded valuable information regarding specific target groups for the lentil bars.

\subsection{Descriptive Panel}

\subsubsection{Multivariate Analysis of Variance}


A significant Wilks' lambda value of 0.0722 with $\mathrm{F}=6.35$ and $\mathrm{p}<0.0001$ was found for the samples indicating that the attributes evaluated contributed to differences among the samples.

\subsubsection{Analysis of Variance}

All of the models for each of the sensory attributes were significant indicating that sources of variability included the effects that were used in the analysis (Table 4.17 and Appendix 7- Tables A to K). Significant interaction was found for sample by replication for stickiness to touch. This is plotted in Figure 4.11 showing that LB2 was less sticky for the second replication and LB3 was more sticky. This may have been the result of exposure to air caused by time variations when preparing samples.

Significant panelist by replication interactions for grainy, lentil, cohesiveness of mass and chewiness are shown in Figure 4.12A to D. It appeared that for grainy and lentil flavors and cohesiveness of mass, panelist 7 found replication one to be higher in intensity than replication two. This same trend was found for panelist 9 for grainy and lentil flavors and for panelist 4 for chewiness. Panelist 6 found replication 1 lower in intensity than replication 2 for chewiness. Since the replications were performed on different days there may have been some factors which varied for these panelists from day to day such as stress and concentration levels which can affect sensory ability.

Significant panelist by sample interactions were shown for stickiness to touch, sweetness, sour/fruity flavor, grainy flavor, lentil flavor, hardness and cohesiveness of mass and are plotted in Figure 4.13A to G. A crossover interaction occurs when one or more panelists scores the product opposite to the panel as a whole. For example panelist 7 
Table 4.17 - Summary of probabilities for main effects and two-way interactions of attributes for eight lentil bar measured by descriptive panel $n=11$.

Attributes

\begin{tabular}{|c|c|c|c|c|c|c|c|c|c|c|c|c|}
\hline Fixed Effects & $\mathrm{df}$ & $\begin{array}{l}\text { Sticki- } \\
\text { ness } \\
\text { To Touch }\end{array}$ & Sweetness & $\begin{array}{l}\text { Sour/ } \\
\text { fruity } \\
\text { Flavor }\end{array}$ & $\begin{array}{l}\text { Grainy } \\
\text { Flavor }\end{array}$ & $\begin{array}{l}\text { Lentil } \\
\text { Flavor }\end{array}$ & $\begin{array}{l}\text { Hard- } \\
\text { ness }\end{array}$ & $\begin{array}{l}\text { Cohes- } \\
\text { iveness }\end{array}$ & $\begin{array}{l}\text { Cohes- } \\
\text { iveness }\end{array}$ & $\begin{array}{l}\text { Moist- } \\
\text { ness }\end{array}$ & $\begin{array}{l}\text { Chew } \\
\text { ness }\end{array}$ & $\begin{array}{l}\text { Adhesive- } \\
\text { ness to } \\
\text { Teeth }\end{array}$ \\
\hline model & 105 & $<0.0001$ & $<0.0001$ & $<0.0001$ & $<0.0001$ & $<0.0001$ & $<0.0001$ & 0.0171 & 0.0028 & 0.0021 & 0.0162 & 0.0014 \\
\hline panelist (p) & 10 & $<0.0001$ & $<0.0001$ & $<0.0001$ & $<0.0001$ & $<0.0001$ & 0.0221 & 0.0476 & 0.2588 & 0.0057 & 0.0258 & $<0.0001$ \\
\hline replication $(\mathrm{r})$ & 2 & 0.1801 & 0.4933 & 0.1271 & 0.0073 & 0.3240 & 0.8494 & 0.2360 & 0.0429 & 0.4483 & 0.0467 & 0.6467 \\
\hline sample (s) & 7 & $<0.0001$ & $<0.0001$ & $<0.0001$ & $<0.0001$ & $<0.0001$ & $<0.0001$ & 0.0009 & 0.0247 & $<0.0001$ & 0.0386 & 0.0164 \\
\hline $\mathrm{p} * \mathrm{r}$ & 10 & 0.0558 & 0.2417 & 0.1966 & 0.0062 & 0.0040 & 0.8443 & 0.5327 & 0.0007 & 0.0828 & 0.0290 & 0.5047 \\
\hline $\mathrm{p} * \mathrm{~s}$ & 70 & $<0.0001$ & $<0.0001$ & 0.0287 & 0.0006 & 0.0052 & 0.0006 & 0.0922 & 0.0094 & 0.1404 & 0.0854 & 0.7015 \\
\hline$s * r$ & 7 & 0.0067 & 0.2777 & 0.3715 & 0.2433 & 0.5272 & 0.0628 & 0.0676 & 0.9245 & 0.1241 & 0.3052 & 0.3475 \\
\hline
\end{tabular}


Figure 4.11. Plot of sample*replication interaction for stickiness to touch from descriptive panel $n=11$.

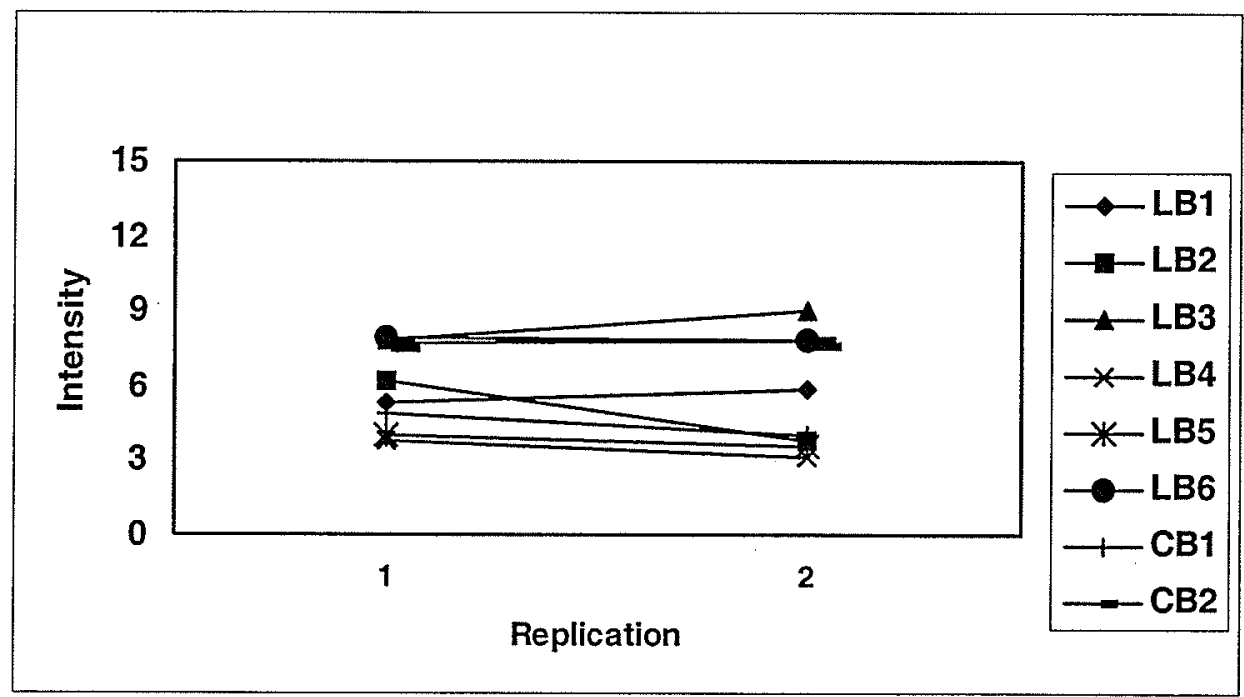


Figure 4.12. Plots of panelist*replication interaction for grainy flavor, lentil flavor, cohesiveness of mass and chewiness from descriptive panel $n=11$.
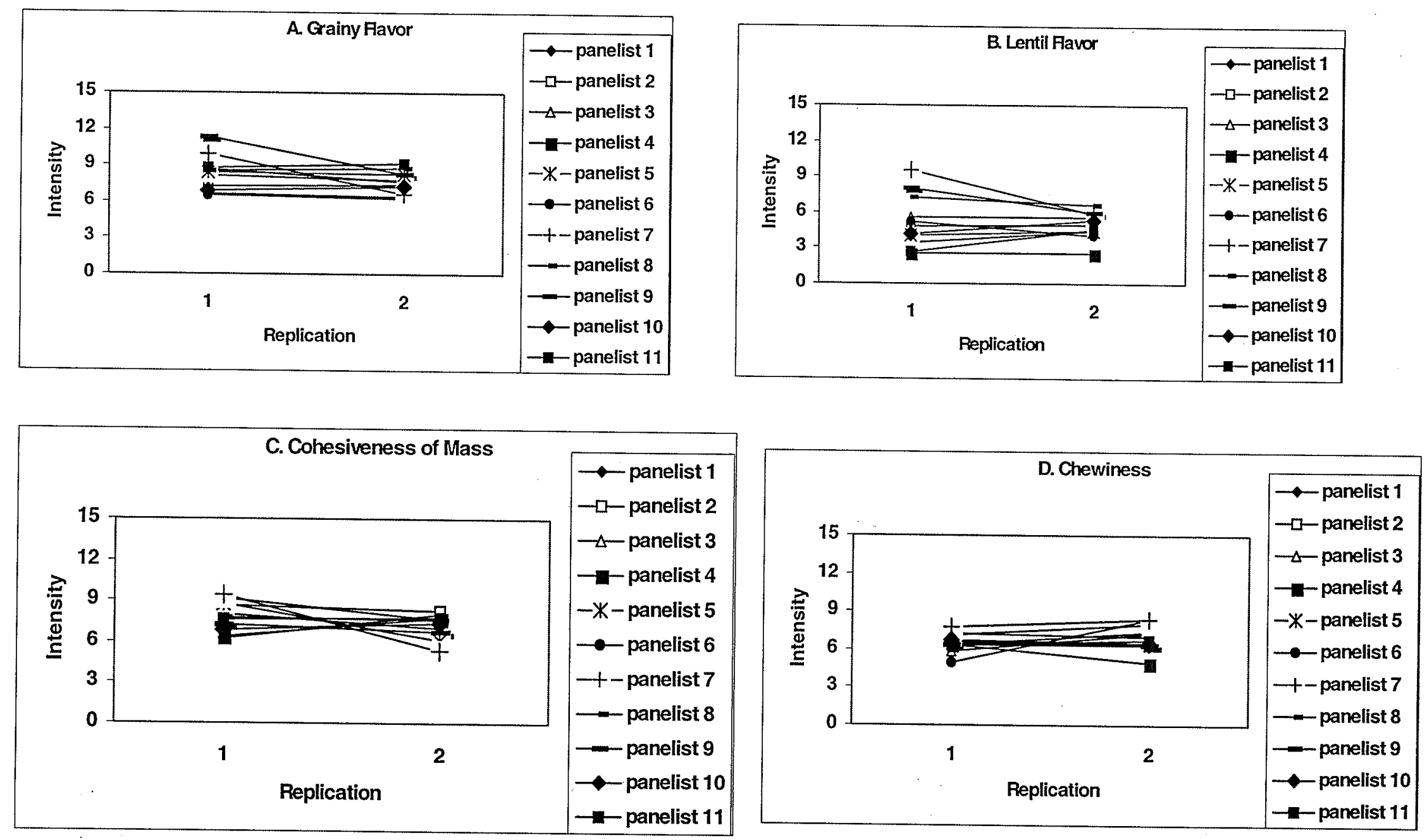
Figure 4.13. Plots of panelist*sample interaction for stickiness to touch, sweetness, sour/fruity flavor, grainy flavor, lentil flavor, hardness and cohesiveness of mass from descriptive panel $n=11$.
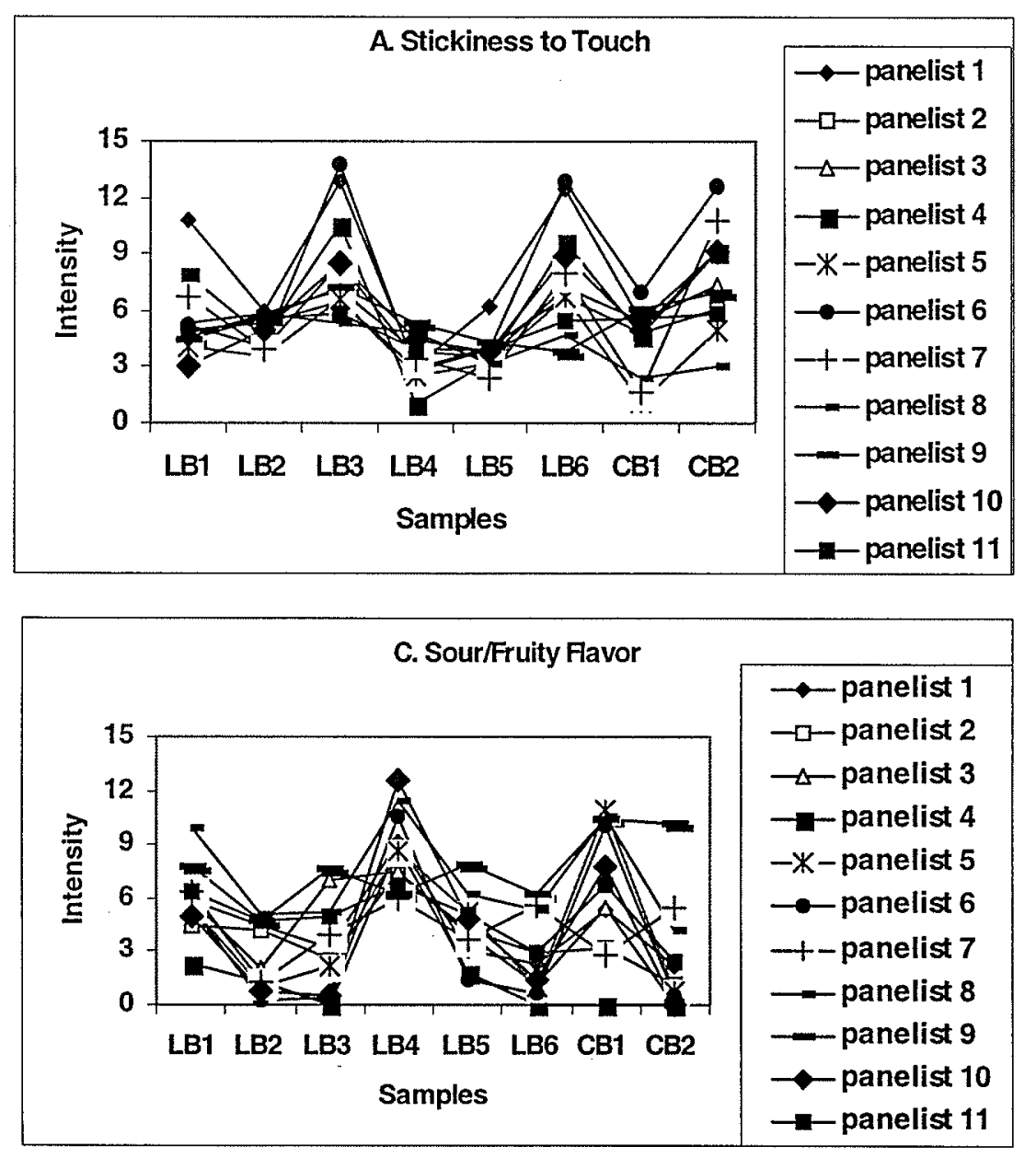
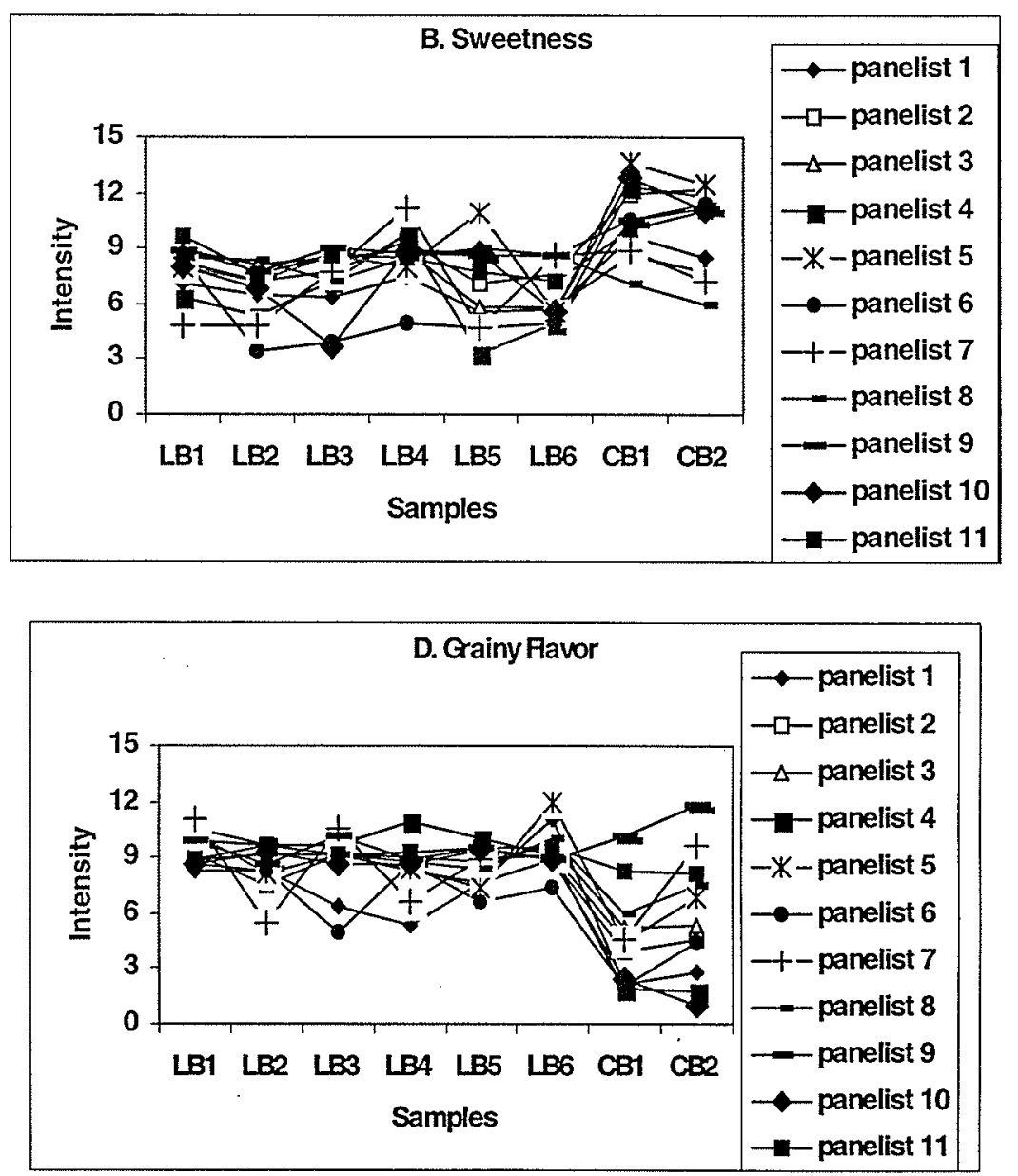
Figure 4.13. Plots of panelist*sample interaction for stickiness to touch, sweetness, sour/fruity flavor, grainy flavor, lentil flavor, hardness and cohesiveness of mass from descriptive panel $n=11$. (cont'd)
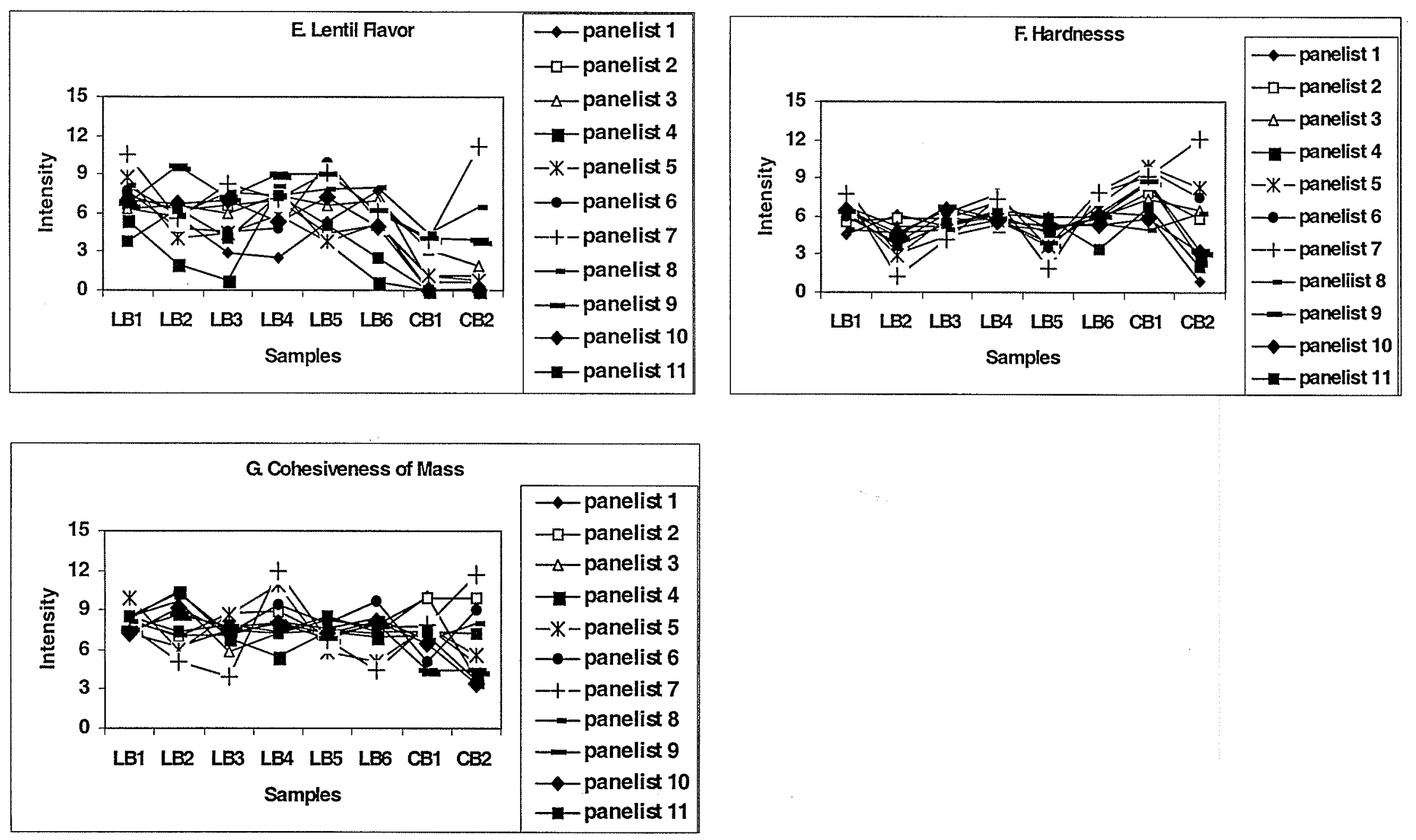
rated CB2 highest of all of the samples in lentil flavor whereas for the majority it is one of the lowest samples for lentil flavor (Figure 4.13E). This type of interaction can be caused by a true difference in perception. Perhaps inadequate rinsing between samples caused residual flavors to remain. It could also be caused by confusion on the part of the panelist regarding the definition of the attributes or the endpoints on the line scale (Stone and Sidel, 1993). A less serious consequence of significant interaction is a magnitude interaction. This is found when panelists are not scoring the samples at the same relative attribute intensity which may be due to differences by panelists in use of the line scale as shown for stickiness to touch (Figure 4.13A). Knowing about these interactions leads to further understanding regarding panelist performance. The use of reference samples and training reduces interaction but due to the nature of sensory evaluation and inherent panelist variability interactions are not unexpected. Re-testing the sample effect using the panelist by sample interaction as the error term resulted in no significant sample effect for cohesiveness of mass (Appendix 7). All of the other attributes showed significant differences between the samples. Mean values for each attribute for all of the samples with results from the least significant difference test are shown in Table 4.18.

LB3, LB6 and CB2 were significantly more sticky to touch than the other samples (Table 4.18). LB4 and LB5 were less sticky than LB1 and LB2. LB3 and LB6 had the lowest ratio of sweetener to dry ingredients. These samples had the highest level of granola perhaps indicating that granola resists absorption of the sweetener to a greater degree than the lentils. The granola was prepared by mixing oil and honey into the oats and heating so that perhaps the oil acted as a barrier. 
Table 4.18. Snack bars sample means ${ }^{1}$ and standard deviations (SD) for sensory attributes.

\begin{tabular}{|c|c|c|c|c|c|c|c|c|}
\hline & $\mathrm{LB}^{\mathrm{b}}$ & LB2 & LB3 & LB4 & LB5 & LB6 & $\mathrm{CB} 1$ & $\mathrm{CB} 2$ \\
\hline $\begin{array}{l}\text { Stickiness to } \\
\text { Touch }\end{array}$ & $5.6(2.5) b$ & $5.0(1.8) b c$ & $8.4(3.0) \mathrm{a}$ & $8.4(3.0) \mathrm{a}$ & $3.8(1.5) \mathrm{de}$ & $7.8(3.0) \mathrm{a}$ & $4.5(2.2) \mathrm{cd}$ & $7.7(2.8) \mathrm{a}$ \\
\hline Sweetness & $7.9(1.7) b c$ & $6.6(2.0) \mathrm{d}$ & $7.1(2.1) \mathrm{cd}$ & $8.6(1.7) b$ & $6.9(2.4) \mathrm{d}$ & $6.7(1.9) \mathrm{d}$ & $10.5(2.2) \mathrm{a}$ & $10.0(2.4) \mathrm{a}$ \\
\hline Sour/Fruity & & & & & & & & \\
\hline Flavor & $5.9(2.2) b$ & $2.7(2.0) \mathrm{d}$ & $3.4(3.0) \mathrm{cd}$ & $8.6(3.5) \mathrm{a}$ & $4.3(2.4) c$ & $2.6(2.4) \mathrm{d}$ & $6.7(4.3) b$ & $2.4(3.3) d$ \\
\hline Grainy Flavor & $9.5(1.3) \mathrm{ab}$ & $8.5(2.1) \mathrm{c}$ & $8.7(1.8) a b c$ & $8.4(2.2) \mathrm{c}$ & $8.5(1.5) b c$ & $9.5(1.5) \mathrm{a}$ & $4.6(3.0) \mathrm{e}$ & $5.7(3.6) d$ \\
\hline Lentil Flavor & $7.1(2.4) \mathrm{a}$ & $5.8(2.4) b c$ & $5.4(2.5) c$ & $6.5(2.8) a b$ & $6.5(2.8) \mathrm{ab}$ & $5.3(2.5) c$ & $1.7(1.9) \mathrm{d}$ & $2.4(3.6) \mathrm{d}$ \\
\hline Hardness & $6.3(1.2) b$ & $4.2(1.5) \mathrm{e}$ & $5.5(1.3) b c$ & $6.3(1.9) \mathrm{b}$ & $4.5(1.3) \mathrm{de}$ & $6.1(1.8) b c$ & $7.7(1.9) \mathrm{a}$ & $5.3(3.5) \mathrm{cd}$ \\
\hline Cohesiveness & $6.5(1.8) \mathrm{a}$ & $6.0(2.4) \mathrm{a}$ & $6.4(2.2) \mathrm{a}$ & $6.3(2.2) \mathrm{a}$ & $6.1(2.1) \mathrm{a}$ & $6.2(1.5) \mathrm{a}$ & $6.4(2.6) \mathrm{a}$ & $3.9(2.8) b$ \\
\hline $\begin{array}{l}\text { Cohesiveness } \\
\text { of Mass }\end{array}$ & $8.2(1.8) \mathrm{a}$ & $7.9(2.3) \mathrm{a}$ & $7.1(2.0) \mathrm{a}$ & $8.4(2.1) \mathrm{a}$ & $7.3(1.5) \mathrm{a}$ & $7.4(2.2) \mathrm{a}$ & $7.3(1.9) \mathrm{a}$ & $6.5(3.4) \mathrm{a}$ \\
\hline Moistness & $7.7(1.6) \mathrm{a}$ & $7.4(1.6) \mathrm{a}$ & $7.5(1.6) \mathrm{a}$ & $6.7(2.0) \mathrm{ab}$ & $7.4(1.4) \mathrm{a}$ & $7.3(2.1) \mathrm{a}$ & $6.4(2.0) \mathrm{b}$ & $4.9(2.1) \mathrm{c}$ \\
\hline Chewiness & $7.2(1.8) \mathrm{a}$ & $5.8(1.7) \mathrm{c}$ & $6.8(1.4) a b c$ & $7.3(1.9) \mathrm{a}$ & $6.7(2.2) \mathrm{abc}$ & $6.9(1.9) \mathrm{ab}$ & $6.0(2.1) b c$ & $7.2(2.7) \mathrm{a}$ \\
\hline $\begin{array}{l}\text { Adhesiveness } \\
\text { to Teeth }\end{array}$ & $4.1(1.7) a b c$ & $3.9(2.1) a b c$ & $4.4(2.3) a b$ & $4.9(2.4) \mathrm{a}$ & $4.8(2.6) \mathrm{a}$ & $4.5(2.5) a b$ & $3.1(1.4) c$ & $3.6(2.1) b c$ \\
\hline
\end{tabular}

${ }^{a}$ Means are averages of 11 panelists

balues are mean and (SD): means with the same letter within the same row are not significantly different $(\mathrm{p}<0.05)$ 
For sweetness $\mathrm{CB} 1$ and $\mathrm{CB} 2$ were significantly sweeter than all of the lentil bar samples. Of the lentil bar samples LB4 was significantly sweeter than LB2, LB3, LB5 and LB6 (Table 4.18). The ratio of sweetener to dry ingredients was mid range for this sample. LB2 was the sample with the highest ratio of sweetener to dry ingredients and had the lowest level of sweetness indicating that the equal proportions of lentil and granola may have had a masking effect on sweetness.

LB4, the sample with the highest cranberry level, had significantly more sour/fruity flavor than all of the other samples (Table 4.18). CB1 was not significantly different from LB1 which contained the next highest level of cranberries. LB5 contained the lowest level of cranberries and was found to be not significantly different from LB3, a plain sample, perhaps indicating the level was not high enough to yield a perceptible difference from the samples containing no fruit. Analysis from the just right scales determined that $74 \%$ of the consumers felt the level of cranberry flavor in LB5 was not enough. As expected other plain samples showed low levels for sour/fruity that were not significantly different from one another.

The commercial snack bars had significantly less grainy flavor than all of the lentil bars with $\mathrm{CB} 1$ having significantly less grainy flavor than $\mathrm{CB} 2$ perhaps due to its raisin component (Table 4.18). LB6 had significantly more grainy flavor than LB2, LB4 and LB5 again likely due to the low lentil:granola ratio.

All of the lentil bars had significantly higher lentil flavor than the commercial snack bars (Table 4.18). LB4 and LB5 had the highest ratio of lentil to granola, 1.45:1 and 1.6:1 respectively, and showed significantly higher lentil flavor than LB3 and LB6 which 
had the lowest ratio of lentil to granola $0.53: 1$ and $0.56: 1$ respectively.

For hardness, CB1 was significantly harder than all of the other samples (Table

4.18). LB2 and LB5 were significantly less hard than all of the samples except CB2.

For cohesiveness $\mathrm{CB} 2$ was significantly less cohesive than all of the other samples

(Table 4.18). Honey, an ingredient used for binding snack bar components, is quite low on the list of ingredients (Table 3.3D) which may account for the low cohesiveness found in $\mathrm{CB} 2$. This may also contribute to $\mathrm{CB} 2$ being significantly less moist than all of the other samples. None of the lentil bars were significantly different from one another. Ratios of dry to liquid ingredients of the lentil bars ranged from 1.17 to 1.56 which may not be large enough to produce differences in moisture perception although significant differences in the physical moisture measurements were noted (Section 4.2.2).

LB1, LB4 and CB2 were significantly more chewy than CB1 and LB2 (Table 4.18). Inclusion of the cranberries may have contributed to the significantly higher chewiness for LB4 and LB1.

CB1 showed significantly less adhesiveness to teeth than LB3, LB4, LB5 and LB6 with no significant differences shown between CB2, LB2 and LB1 (Table 4.18). LB4 and LB5, samples with the highest mean value have the second and third highest sweetener to dry ingredient ratios ( 0.79 and 0.83 respectively) and they also contain cranberries.

\subsubsection{Principal Components Analysis (PCA)}

Selection of the appropriate number of components or factors to be retained for interpretation can be based on a number of criteria (Lawless and Heymann, 1998):

1) Eigenvalues $(\lambda)$ are equal to the variances of the components. An eigenvalue 
should be greater than 1 as that indicates that more variance is explained than with a single variable.

2) The scatter plot of eigenvalue vs. principal component number shows a quick decline and then a point where the curve levels off. The start of the leveling portion indicates the appropriate number of principal components. This is also referred to as a scree test.

3) The number of principal components correspond to a preset level of the percentage of the variance explained which may be 70,80 or $85 \%$ for example.

4) Use common sense so that the variables contributing to the principal component should have a similar meaning and those contributing to different principal components should have different meanings.

Three factors were selected in this study. All of these factors had an eigenvalue greater than 1 (Table 4.19), a breakpoint shown by the scree plot (Figure 4.14) and $86 \%$ of the variability was explained with these three factors. The fourth factor was not included as its eigenvalue was only one, it explained only $9 \%$ more of the variability and was not adding information regarding importance of the attributes.

Interpretation of the principal components is key in describing the relationship between each of the attributes as well as how they relate to the principal components that are formed. Loadings are calculated by determining the correlations between the original variables, in this case the attributes, and the new variables, those transformed by PCA. Attributes that are heavily loaded (positively or negatively) on a particular factor or principal component would have the largest influence on that factor. To interpret the 
Table 4.19. Variance, eigenvalues and loadings for sensory attributes measured by the descriptive panel determined by principal component analysis.

\begin{tabular}{|c|c|c|c|}
\hline Parameter & $\mathrm{PC}^{1} 1$ & PC2 & PC3 \\
\hline $\begin{array}{l}\text { Percentage Variance } \\
\text { Cumulative Percentage }\end{array}$ & 45.7 & 26.0 & 14.6 \\
\hline Variance & 45.7 & 71.7 & 86.3 \\
\hline Eigenvalue $(\lambda)$ & 5.0 & 2.9 & 1.6 \\
\hline
\end{tabular}

Loadings

$\begin{array}{lccc}\text { Stickiness to Touch } & -0.25 & \mathbf{- 0 . 7 1}^{\mathbf{b}} & 0.10 \\ \text { Sweetness } & \mathbf{- 0 . 8 3} & \mathbf{0 . 4 9} & 0.24 \\ \text { Sour/Fruity Flavor } & 0.15 & \mathbf{0 . 9 4} & 0.27 \\ \text { Grainy Flavor } & \mathbf{0 . 9 2} & -0.30 & 0.14 \\ \text { Lentil Flavor } & \mathbf{0 . 9 6} & -0.06 & 0.17 \\ \text { Hardness } & -0.33 & \mathbf{0 . 7 2} & 0.13 \\ \text { Cohesiveness } & \mathbf{0 . 6 8} & \mathbf{0 . 5 0} & -0.36 \\ \text { Cohesiveness of Mass } & \mathbf{0 . 7 0} & \mathbf{0 . 5 8} & 0.02 \\ \text { Moistness } & \mathbf{0 . 8 8} & 0.05 & -0.37 \\ \text { Chewiness } & 0.14 & -0.09 & \mathbf{0 . 9 7} \\ \text { Adhesiveness to Teeth } & \mathbf{0 . 7 9} & -0.15 & \mathbf{0 . 4 4}\end{array}$

${ }^{1}$ Principal component

${ }^{2}$ Bold numbers indicate values over 0.40 as recommended by Stevens (1992) 
Figure 4.14. Scree plot for determination of number of factors to retain from the principal component analysis of attributes evaluated by the descriptive panel $n=11$.

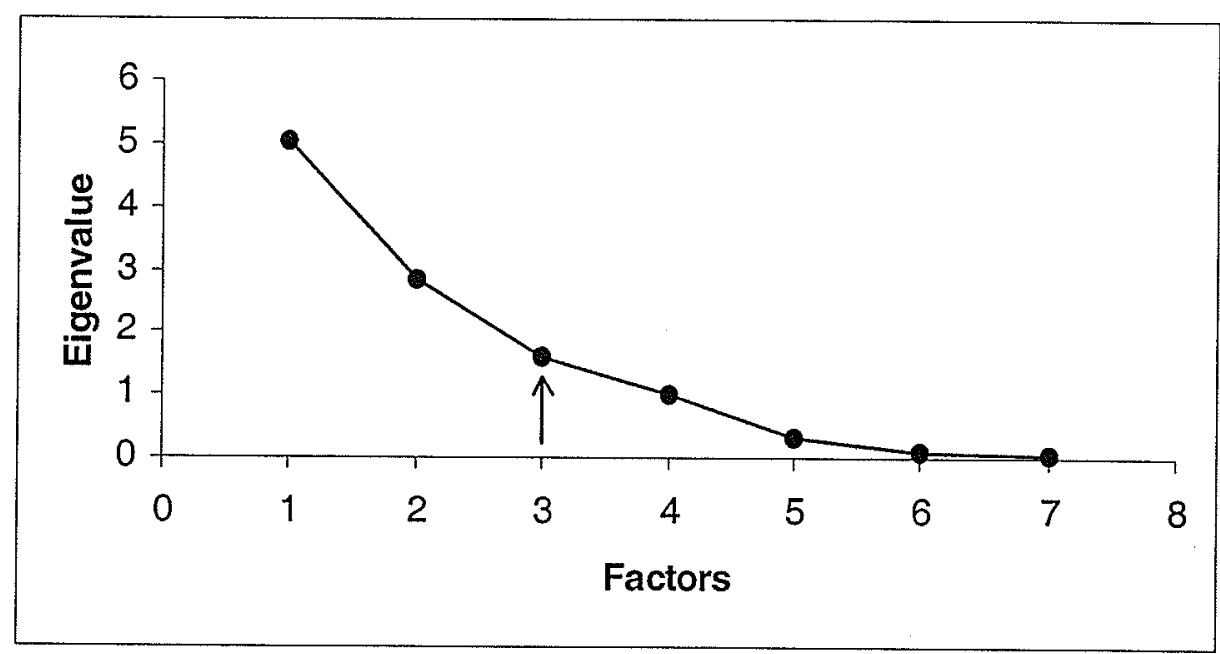


importance of loadings a common rule of thumb can be used. Factor loadings of \pm 0.3 are minimal, \pm 0.4 are more important and those of \pm 0.5 or higher are considered to be of practical importance. The higher the sample size the lower the loading has to be before it is significant (Hair et al., 1995). Stevens (1992) suggests that a loading value of \pm 0.40 is appropriate. Since the variance explained by the factor is the squared value of the loading it would contribute about $15 \%$ of the variance for that component.

Principal component 1 explained $46 \%$ of the variability (Table 4.19 ). Using 0.40 as a guideline this component was composed of sweetness, grainy flavor, lentil flavor, cohesiveness, cohesiveness of mass, moistness and adhesiveness to teeth. The second principal component which explained $26 \%$ of the variability was composed of stickiness to touch, sour/fruity flavor and hardness. The third principal component was composed of chewiness and explained $15 \%$ of the variability. In summary the new principal component one or factor one was made up of a sweet, lentil, flavor with cohesive/adhesive textural parameters. The new principal component two or factor two was made up of sour/fruity flavor with hard, sticky to touch textural parameters.

Figure 4.15 shows these attribute loadings plotted with the coordinates of the snack bars for $\mathrm{PC} 1$ and $\mathrm{PC} 2$. Attributes and samples close to one another indicate that they are related, those in opposite quadrants indicate a negative relationship. Arrowed lines point in the direction of increasing amount of the attribute. By drawing a line perpendicular from the sample to the extended arrowed line one can determine how the samples rank in terms of the amount of the attribute. This is illustrated in Figure 4.16 for stickiness to touch. The sample with the most stickiness to touch would be CB2 since it is at the pointed end 
Figure 4.15. Loadings from the first and second principal components for attributes and snack bars evaluated by the descriptive panel $n=11$.

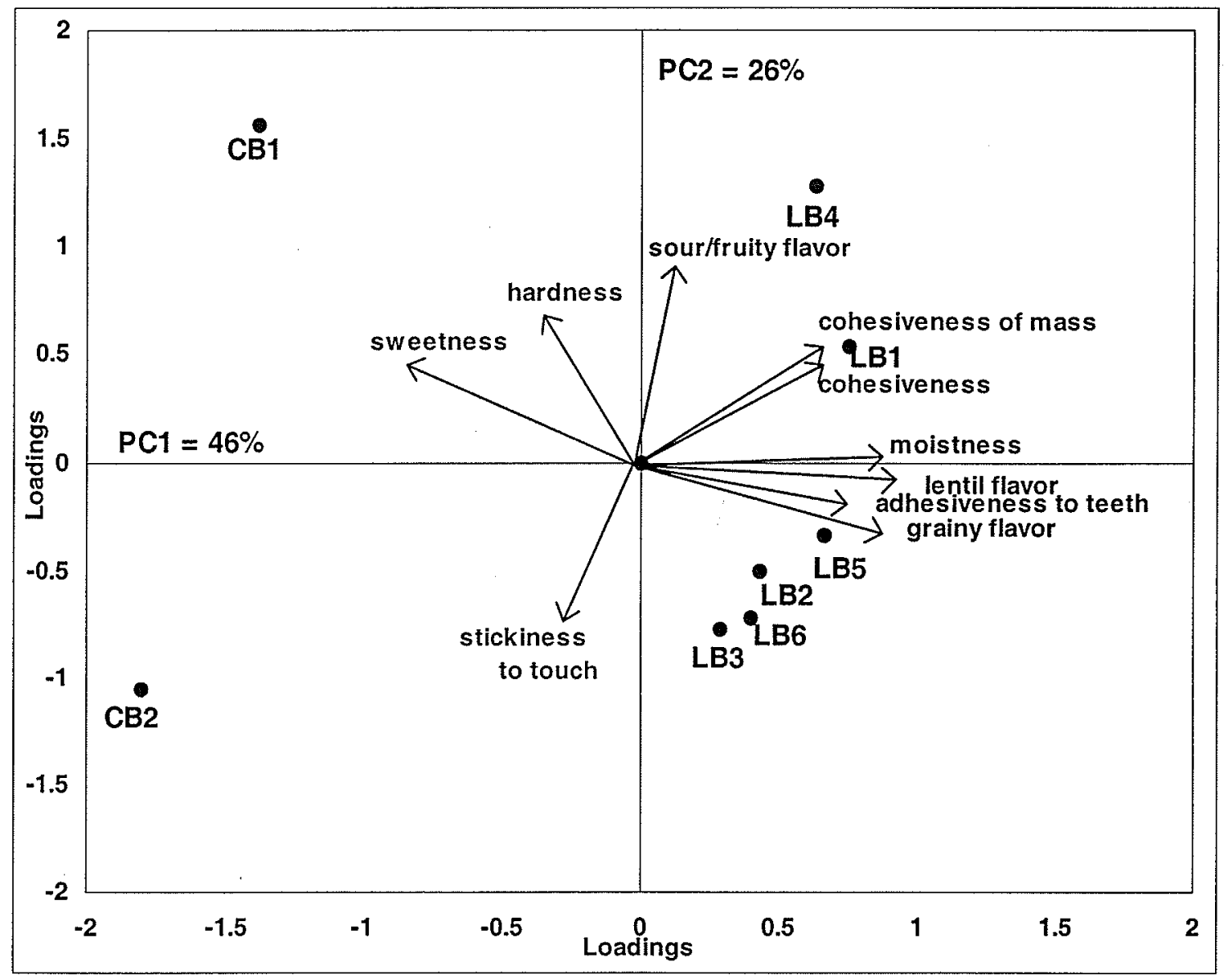


Figure 4.16. Illustration for determining relative amount of stickiness to touch for snack bar samples.

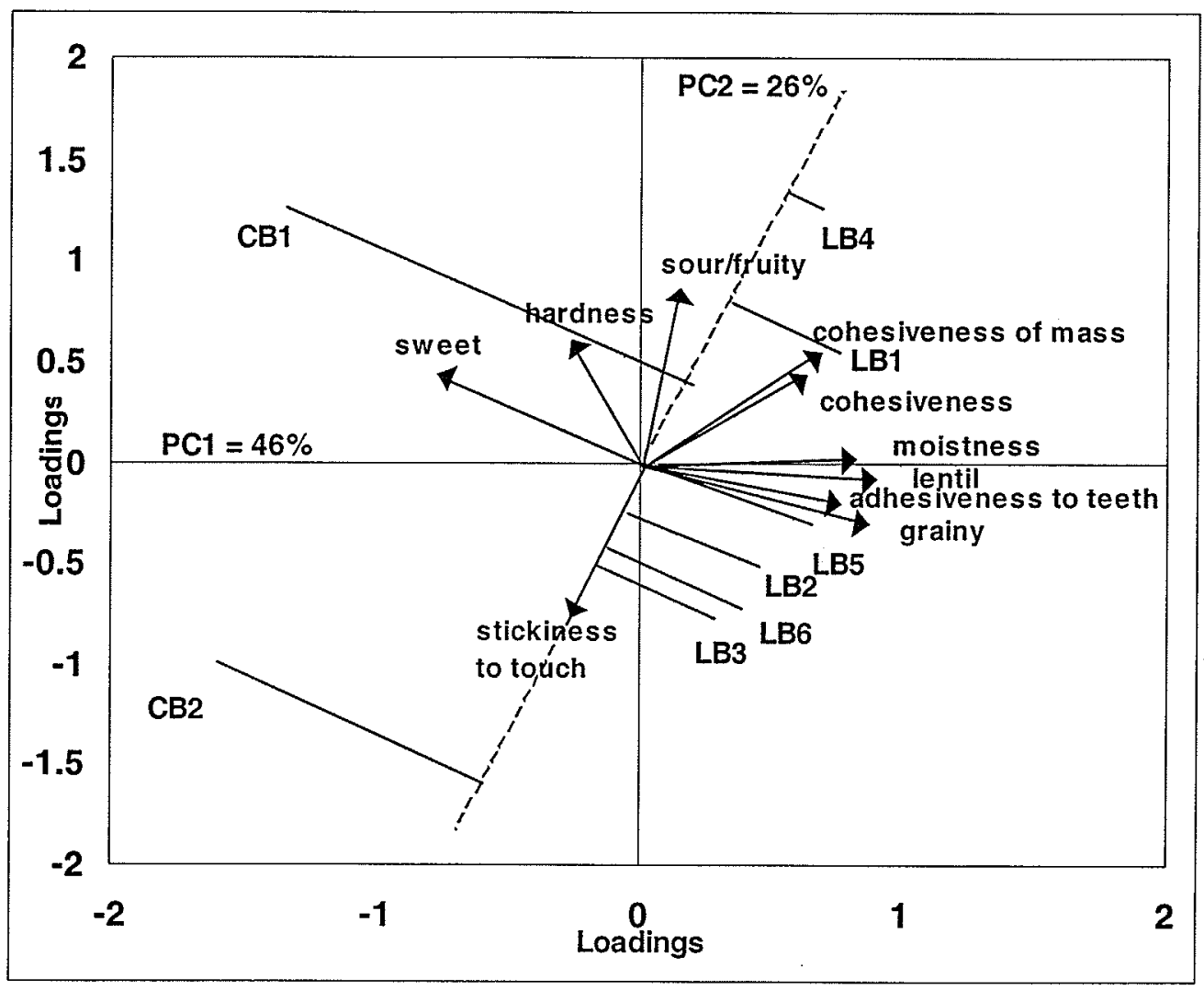


of the arrow. In decreasing amount of stickiness to touch the samples are LB3, LB6, LB2, LB5, CB1, LB1 and LB4.

LB2, LB3, LB5 and LB6 showed higher levels of grainy and lentil flavors and adhesiveness to teeth with lower levels of sweetness and hardness than CB1 (Figure 4.15). LB1 showed higher levels of moistness, cohesiveness and cohesiveness of mass and lower levels of stickiness to touch and LB4 the highest level of sour/fruity of all of the lentil bars and lowest level of stickiness to touch. CB1 had highest levels sweetness and hardness. CB2 had highest levels of stickiness to touch lowest levels of sour/fruity flavor with low cohesiveness and cohesiveness of mass.

A clearer picture of the differences in attribute intensities for LB2, LB3, LB5 and LB6 is shown by plotting PC2 and PC3 the chewiness factor (Figure 4.17). LB2 was lowest in chewiness. LB3 and LB6 showed highest amounts of stickiness to touch. The plot showing PC1 and PC3 (Figure 4.18) also indicated that LB2 seemed to be different than LB3, LB5 and LB6 as it had a higher level of cohesiveness and moistness and lower sweetness than these samples. LB5, the sample with the highest ratio of lentils to oats $(1.60: 1)$, was shown to have the highest grainy and lentil flavors compared to LB2, LB3 and LB6.

LB1 and LB4 had the highest levels of cranberries and CB1 had raisins so that finding these samples grouped with the sour/fruity attribute on the top portion of Figure 4.15 is not surprising.

\subsubsection{External Preference Mapping}

From the partial least squares regression analysis done to relate the attribute 
Figure 4.17. Loadings from the second and third principal components for attributes and snack bars evaluated by the descriptive panel $n=11$.

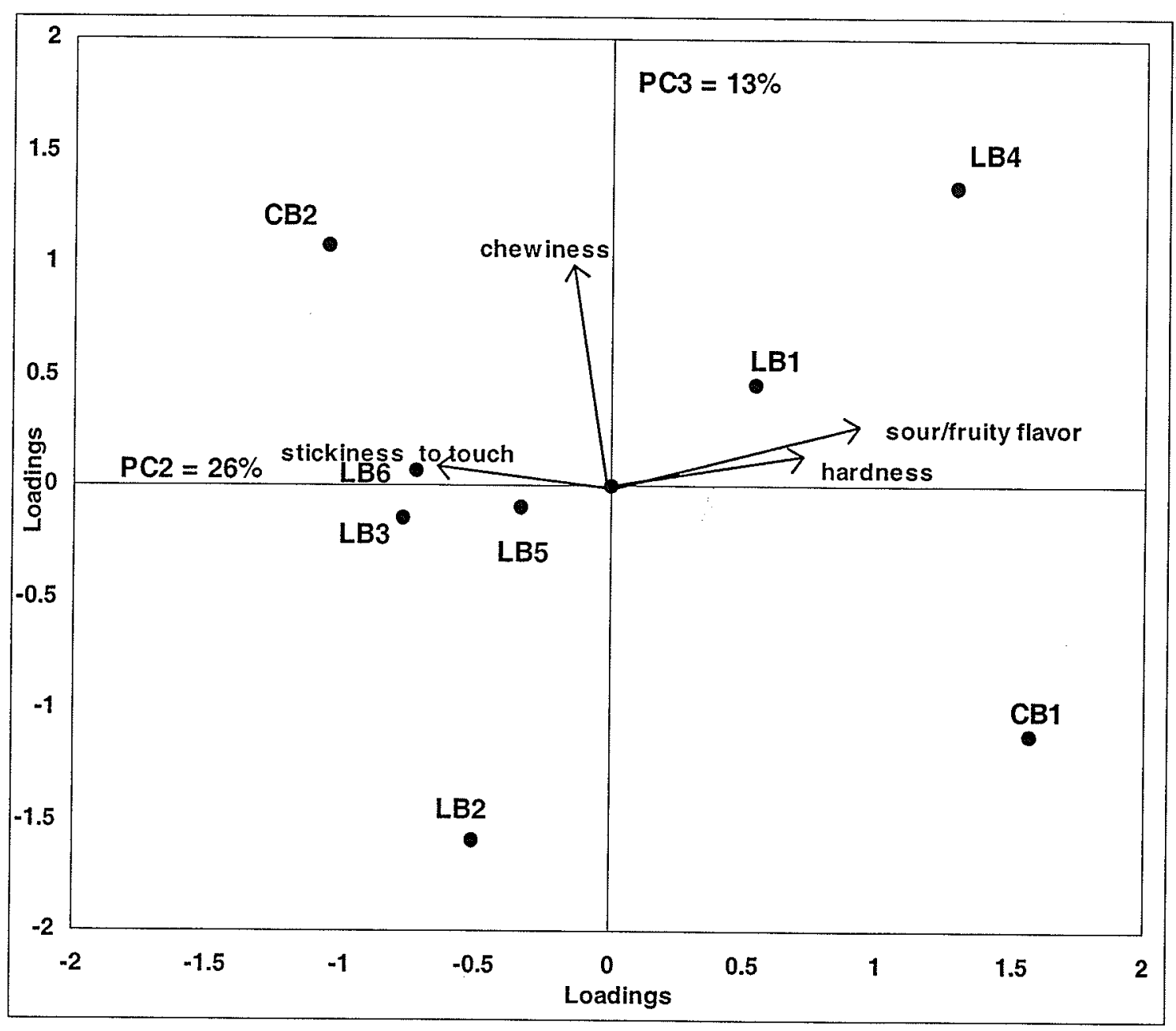


Figure 4.18. Loadings from the first and third principal components for attributes and snack bars evaluated by the descriptive panel $n=11$.

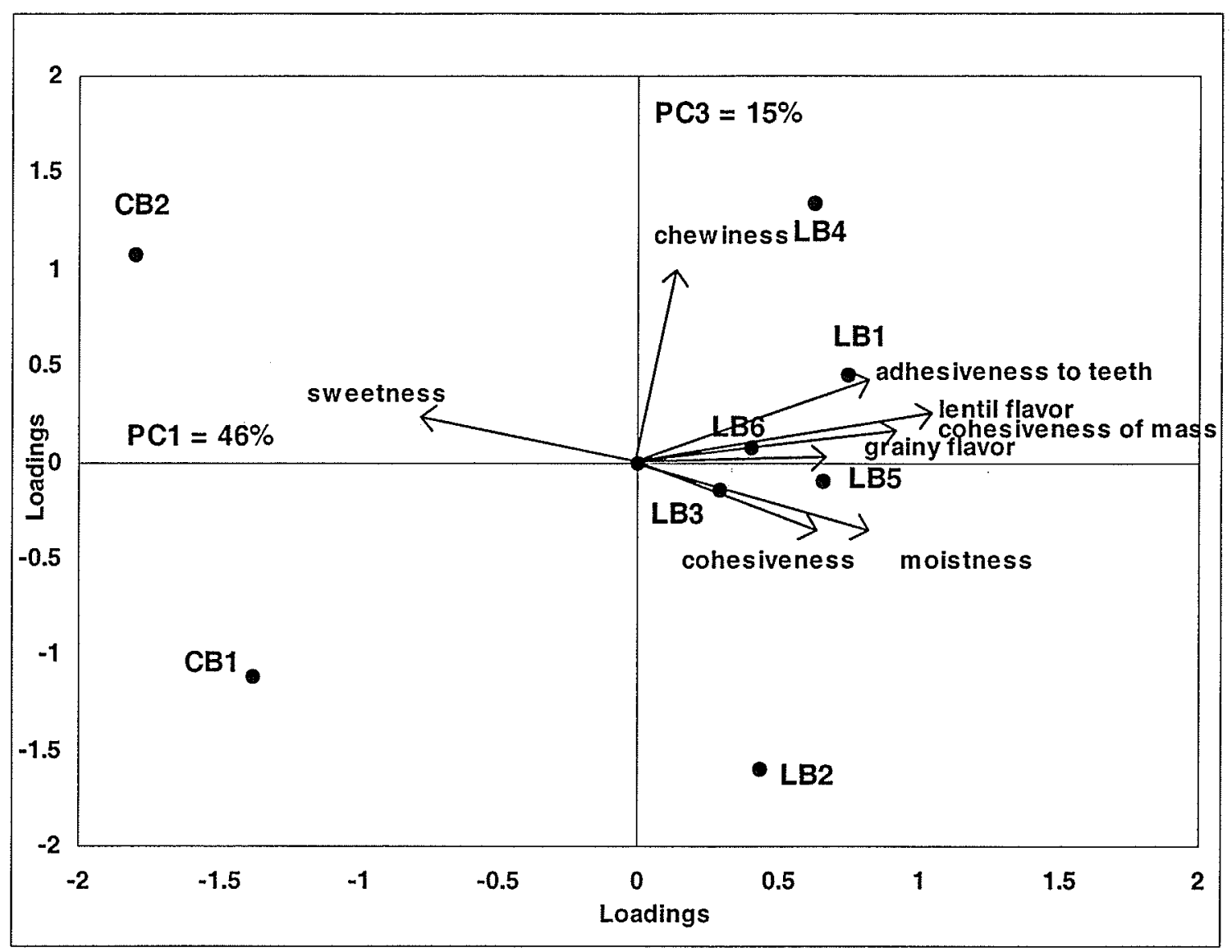


intensities from the descriptive panel to the acceptability/purchase behaviour of the consumers it was found that two factors accounted for $65 \%$ of the variability for the attributes and $97 \%$ of the variability in the consumer acceptability/purchase behaviour (Table 4.20). Adding more factors would provide no more information regarding acceptability. Grainy and lentil flavors had loadings over 0.40 and were most heavily loaded in factor one. Stickiness to touch, sweetness, hardness, cohesiveness of mass and chewiness had loadings over 0.40 and were most heavily loaded in factor two.

A plot of the loadings (Figure 4.19) shows that acceptability and purchase behaviour were found in the same quadrant indicating their relationship. Hardness and sweetness were also found in this quadrant indicating that these attributes have a positive influence on acceptability. Attributes found in the opposite quadrant farthest from acceptability/purchase behaviour indicating a negative influence on acceptability included lentil and grainy flavors. Stickiness to touch, cohesiveness of mass and chewiness had some effect on acceptability.

Regression coefficients, required for the prediction equations, are a combination of the correlations of all of the attributes (loadings) with the amount of liking associated with the attributes (weights) and were calculated as the product of the loadings and weights (Table 4.20). The higher the regression coefficient either in a positive or negative direction the more it contributes to the acceptability/purchase behaviour. Regression coefficients for factor one were highest for sweetness, grainy and lentil flavors. This finding agrees with Bower and Whitten (2000) who concluded in their study of commercial snack bars that aromas and flavors have the most influence on consumer 
Figure 4.19. Loadings of acceptability and purchase behaviour (y variables) with snack bar attributes ( $x$ variables) evaluated by the descriptive panel $n=11$.

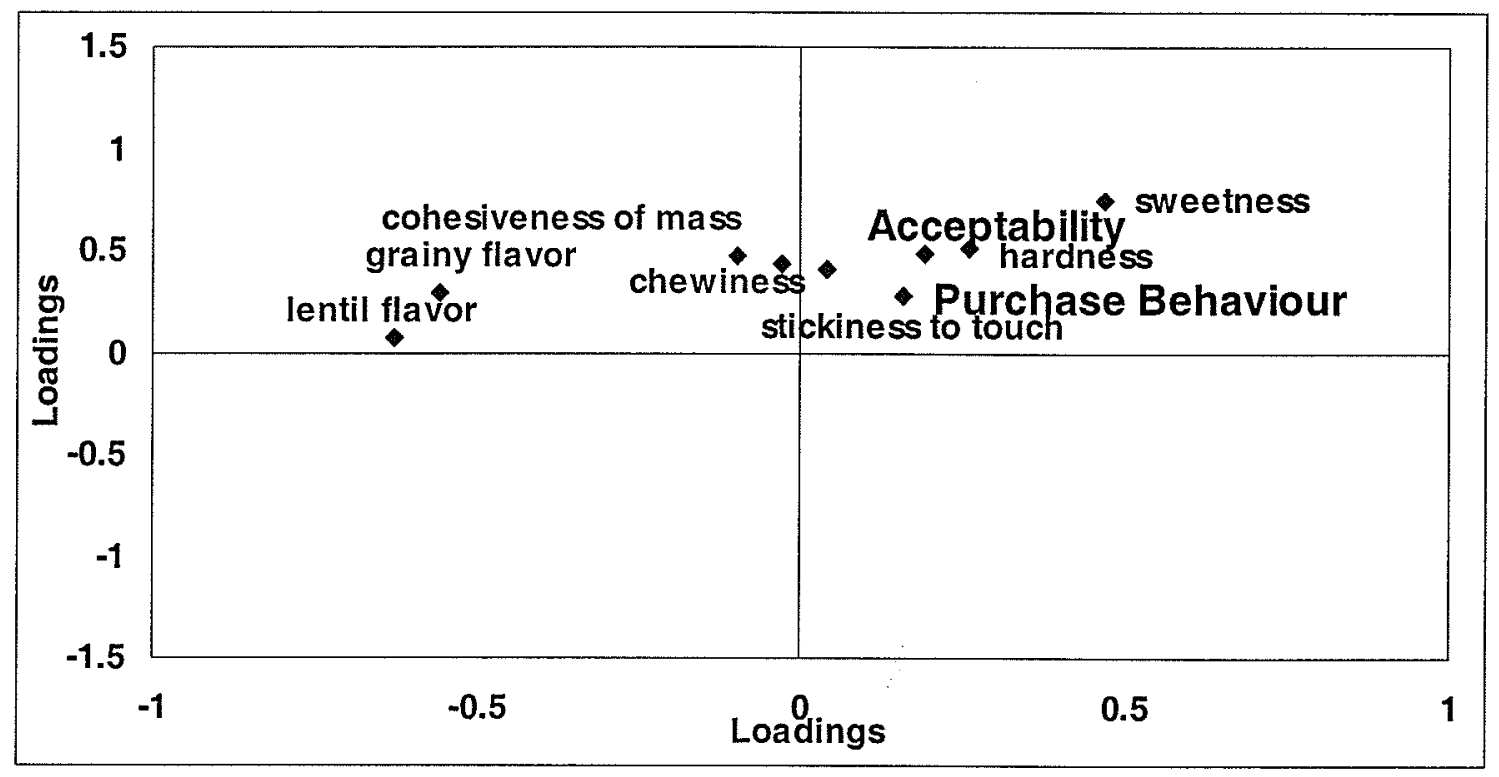


Table 4.20. Variance, loadings, weights and regression coefficients for attributes ( $x$ variables) and consumer acceptability data ( $y$ variables) for the first two factors from the partial least squares analysis.

Parameter

Factor 1

Factor 2

Percentage Variance ( $\mathrm{x}$ variables - attributes)

45.2

20.2

Cumulative percentage variance ( $\mathrm{x}$ variables)

45.2

65.4

Percentage Variance (y variables - acceptability and purchase behaviour)

Cumulative percentage variance (y variables)

88.1

8.9

88.1

97.0

Factor 1

Factor 2

Attributes

Loadings Weights $\mathrm{RC}^{1}$

Loadings Weights $\mathrm{RC}^{\mathbf{1}}$

Stickiness to Touch

0.04

(n)

Sweetness

0.47

0.11

0.0044

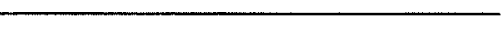

Sour/Fruity Flavor

0.17

0.42

0.1974

$0.41^{2}$

0.22

0.0902

Grainy Flavor

$-0.56$

0.05

0.0085

0.75

$-0.01$

$-0.0075$

Lentil Flavor

$-0.63$

$-0.42$

0.2352

0.39

0.25

0.0975

Hardness

0.26

$-0.45$

0.2835

0.29

0.13

0.0377

Cohesiveness

$-0.10$

0.35

0.0910

0.07

0.01

$-0.0007$

Cohesiveness of Mass

$-0.10$

$-0.14$

0.0140

0.51

0.68

0.3468

Moistness

$-0.23$

$-0.24$

0.0240

0.37

0.64

0.2368

Chewiness

$-0.03$

$-0.31$

0.0713

0.47

0.24

0.1128

Adhesiveness to Teeth

$-0.17$

$-0.09$

0.0027

$-0.41$

0.0697

0.37

0.43

0.1592

0.44

$-0.09$

0.0396

0.21

$-0.14$

0.0294

Acceptability

0.19

0.69

0.1311

0.49

0.80

0.3920

Purchase Behaviour

0.16

0.73

0.1168

0.28

0.60

0.1680

${ }^{1}$ Regression Coefficient $=$ Loadings $*$ Weights

${ }^{2}$ Bold numbers indicate values over 0.40 as recommended by Stevens (1992) 
acceptability. Regression coefficients for factor two were highest for hardness, cohesiveness, cohesiveness of mass and moistness.

A proposed prediction equation for factor one, the flavor factor, would be:

Y1*Y2 (Consumer Acceptability/Purchase Behaviour) $=0.1974$ (sweetness) 0.2352 (grainy flavor) -0.2835 (lentil flavor).

A proposed prediction equation for factor 2 , the texture factor, would be: Y1*Y2 (Consumer Acceptability/Purchase Behaviour) $=+0.3468$ (hardness) 0.2368 (cohesiveness) - 0.1128 (cohesiveness of mass) - 0.1592 (moistness).

In further product development work to determine the optimum formulation, the descriptive panel would evaluate sweetness, grainy and lentil flavors, hardness, cohesiveness, cohesiveness of mass and moistness in new formulations and the mean scores entered into the equations. The higher the result the more likely the product formulation would be acceptable to a consumer group comparable to the one in this study.

New formulations could be generated in the numerical option of Design-Expert using data from the original mixture experiment. Levels for ingredients and attributes could be set at a high level for attributes related to sweetness and hardness variables and at a low level for attributes related to grainy and lentil flavors, cohesiveness, cohesiveness of mass and moistness. A solution selected with a desirability of 0.59 is shown in Table 4.21. The caution with this approach is that the ingredient constraints that were used initially may be too restrictive for the snack bar that would ultimately be the most acceptable to the consumer. This also assumes that expert and descriptive panels are evaluating the attributes equally and that no other ingredients would be added. 
Table 4.21. Constraints for selecting lentil bar sample based on attributes from regression coefficients used in prediction equations for factor 1 and factor 2.

\begin{tabular}{llllll}
\hline & & & & \\
Name & Goal & Lower & Upper & Lower & Upper \\
& Limit & Limit & Weight & Weight & Importance \\
\hline
\end{tabular}

sweetened

honey

lentils

granola

sweetness

oat flavor

toasted

initial bite

cohesiveness

moistness

$\begin{array}{lll}\text { maximize } & 0.28 & 0.40 \\ \text { maximize } & 0.06 & 0.12 \\ \text { minimize } & 0.19 & 0.37 \\ \text { minimize } & 0.20 & 0.40 \\ \text { maximize } & 5.40 & 9.80 \\ \text { minimize } & 5.20 & 9.10 \\ \text { minimize } & 5.80 & 9.80 \\ \text { maximize } & 5.10 & 9.70 \\ \text { minimize } & 5.50 & 9.70 \\ \text { minimize } & 4.90 & 9.90\end{array}$

1
1
1
1
1
1
1
1
1
1

$\begin{array}{ll}1 & 3 \\ 1 & 3 \\ 1 & 3 \\ 1 & 3 \\ 1 & 5 \\ 1 & 3 \\ 1 & 3 \\ 1 & 5 \\ 1 & 3 \\ 1 & 3\end{array}$

The solution provided the following formulation with corresponding attribute mean values associated with the lentil bar.

Formulation

Ingredient

Sweetened Condensed Milk

Honey

Lentils

Granola
Proportion
0.40
0.09
0.22
0.29

Attributes

sweetness

oat flavor

toasted flavor

initial bite

cohesiveness

moistness
Mean Value from 0 to 15

8.2
7.3
7.7
6.1
6.5
7.4


Using a factorial design with two factors, lentils and sweetened condensed milk, set at two levels with honey staying constant and granola added in the amount required to make up the $100 \%$ could also generate formulations to be presented to a descriptive panel. The factorial points are shown in Table 4.22 with the experiment including three centre points for a total of seven runs. Optimum regions for sweetness, lentil and grain flavors, hardness, cohesiveness, cohesiveness of mass and moistness would be generated.

Data from the "just right" scales were used to confirm the importance of the highly weighted attributes based on the most acceptable sample which was CB1. Sweetness and hardness were the attributes which had the highest positive influence on acceptability and purchase behaviour, lentil and grainy flavors, cohesiveness, cohesiveness of mass and moistness the highest negative influence (Table 4.20). For CB1 frequencies were the highest in the "just right" category for hardness, cereal/grain flavor and moistness (Figure 4.9). Frequency for the "just right" category was equal to the "too much" category for sweetness. Cohesiveness and cohesiveness of mass were not evaluated using "just right" scales.

Given that higher levels of sweetness and hardness and low levels of grainy and lentil flavors, cohesiveness, cohesiveness of mass and moistness are more acceptable to consumers of the bars containing no cranberries, LB6 would be chosen as the most likely candidate for further development. Although LB2 appeared to be more acceptable from the internal preference mapping results (Figure 4.10) it was "not firm enough", had "too much cereal/grain flavor" (Figure 4.9) and showed a high level of moistness and cohesiveness (Figure 4.18). LB6 on the other hand had "just right firmness, cereal/grain 
Table 4.22. Proposed $2^{2}$ factorial design for formulations used to develop lentil bar prototypes.

\section{Proportion of Ingredient}

$\begin{array}{ll}\text { Lentils } & \begin{array}{l}\text { Sweetened } \\ \text { Condensed Milk }\end{array}\end{array} \quad$ Honey Granola ${ }^{1}$

range from original

mixture design

$20-40$

$30-40$

$6-12$

$20-40$

Factorial Levels

low, low

low, high

high, high

high, low

centre point
$15^{2}$

15

25

25

20
30

40

40

30

20
$15^{3}$

15

15

15

7.5
40

30

20

30

52.5

\footnotetext{
${ }^{1}$ Ingredient used to make up to $100 \%$ for the formulation

${ }^{2}$ Reduce from original mixture design based on negative influence of lentil flavor on consumer acceptability

${ }^{3}$ Increase from original mixture design based on positive influence of sweetness on consumer acceptability
} 
flavor and moistness" (Figure 4.9) and was sweeter than LB2 (Figure 4.18).

Of the lentil bars containing cranberries LB4 was the most acceptable according to internal preference mapping results (Figure 4.10). It also was "just right" for sweetness and firmness (Figure 4.9), sweeter (Figure 4.18) and harder (Figure 4.15) with less cohesiveness and moistness (Figure 4.19) than LB1, the next most acceptable sample. 


\section{CHAPTER 5}

\section{CONCLUSIONS, LIMITATIONS AND RECOMMENDATIONS}

\subsection{Conclusions}

It was hypothesized that a nutritious snack bar acceptable to women could be made by partially replacing oats with micronized flaked lentils and that sensory attributes of snack bars influence consumer acceptability.

All lentil snack bars provided a source of dietary fibre, non-heme iron and folate (Canada Gazette, 2002). LB1, LB2, LB4 and LB5 provided a good source of folate. Folate level for lentil snack bars was 8 to $10 \%$ of the recommended daily requirement of $400 \mu \mathrm{g}$ for adults. Inclusion of lentils provided 6 to 9 times more folate compared to a snack bar containing only oats. Generally a 30 gram lentil snack bar provided calories, carbohydrate, fat and protein at levels that fit the definition of a carbohydrate/energy endurance bar (Deis, 2000).

Focus groups provided information regarding acceptability for particular sensory attributes at different intensities based on tasting plain and cranberry lentil snack bars as well as commercial snack bars. This information was used to select six lentil bar formulations from a twenty-five run mixture design experiment that exhibited various flavor and texture characteristics. Two commercial snack bars varying in flavor and textural characteristics were also evaluated.

Commercial snack bars were most acceptable and would be purchased more often $(\mathrm{p}<0.05)$ by 62 women 18 to 50 years of age who consume snack bars. Three of the lentil snack bars (LB1, LB3 and LB6) showed no significant difference from one of the 
commercial snack bars for these two acceptance measurements. The six lentil snack bars showed no significant difference from one another with five of the six obtaining mean values corresponding to "like slightly" and "would purchase now and then".

Internal preference mapping confirmed that the majority of consumers preferred the commercial snack bars. Equal numbers of consumers found the plain and cranberry lentil bars acceptable so that the addition of fruit for this particular consumer group appeared to provide no benefit. Separation of the lentil snack bars on the two dimension acceptance plot showed that LB4 was more acceptable than the other two cranberry lentil snack bars and that LB2 was more acceptable than the other two plain lentil snack bars.

Attribute appropriateness measured by "just right" scales determined that among the lentil snack bars LB6 had the highest percentage of attributes falling in the "just right" category, a percentage equal to $\mathrm{CB} 1$, the most acceptable sample.

Measurements of flavor and texture attribute intensities by an eleven member descriptive sensory panel were related to acceptance and purchase behaviour measurements from the consumer panel using partial least squares regression. Based on the magnitude and direction of the loadings it was found that sweetness and hardness had the highest positive influence on acceptability and grainy and lentil flavors had the highest negative influence on consumer acceptability. Acceptability was also influenced to some extent by stickiness to touch, cohesiveness of mass and chewiness.

Two prediction equations were developed using regression coefficients (the product of loadings and weights) from factor one and factor two. These two factors explained $65 \%$ of the variability due to the product attributes and $97 \%$ of the variability 
due to the consumer acceptance. Factor one contained the flavor attributes sweetness, grainy and lentil flavors. This finding agrees with Bower and Whitten (2000) who concluded in their study of commercial snack bars that aromas and flavors have the most influence on consumer acceptability. Factor two contained the texture attributes hardness, cohesiveness, cohesiveness of mass and moistness. Sweetness and hardness had a positive influence on acceptance. Grainy and lentil flavor, cohesiveness, cohesiveness of mass and moistness had a negative influence on acceptance.

The prediction equations were:

Equation Factor 1: Y1*Y2 (Consumer Acceptance/Purchase Behaviour) = 0.1974 (sweetness) - 0.2352 (grainy flavor) - 0.2835 (lentil flavor)

Equation Factor 2: Y1*Y2 (Consumer Acceptance/Purchase Behaviour) = 0.3468 (hardness) - 0.2368 (cohesiveness) - 0.1128 (cohesiveness of mass) -0.1592 (moistness).

In future work on lentil snack bar prototypes mean values for sweetness, grainy flavor, lentil flavor, hardness, cohesiveness, cohesiveness of mass and moistness as determined by a descriptive panel would be substituted in the above equations to obtain a value for acceptance. Prototypes with higher acceptance values would be selected for further development.

From this study it would appear that a nutritious snack bar acceptable to women can be formulated with MFL and that further work on a micronized flaked lentil snack bar is warranted.

\subsection{Limitations}


1. The consumer sample was relatively small and biased. The majority of the 62 consumers attended university courses in a health related discipline.

2. The process for making the snack bars is still at the bench top stage.

3. Nutrients of the lentil snack bars were determined by a database which does not provide information on exact ingredients used, for example, low fat sweetened condensed milk, dried cranberries and MFL.

4. Micronized flaked lentil quality is variable likely due in part to climatic conditions as well as processing conditions.

\subsection{Recommendations}

1. Chemically analyze the lentil snack bars for basic nutrients as well as folate and fibre.

2. Ensure that the micronization/flaking process has accounted for variation in raw lentil quality due to climatic conditions so that consistent lentil quality is achieved. Develop a sensory and/or instrumental method(s) for predicting the softness of the micronized flaked lentils before they are incorporated into the snack bar product.

3. Reset the criteria in the numerical optimization option of Design-Expert to formulate lentil snack bars with high sweetness and hardness and low moistness, cohesiveness, oat and toasted flavors. These were attributes measured by the expert panel that were found to influence the acceptability of this consumer group. A descriptive panel would evaluate these new formulations for sweetness, grainy and lentil flavors, hardness, cohesiveness, cohesiveness of mass and moistness. The mean values for each of these attributes would be used in one of the two corresponding prediction equations to 
determine a Consumer Acceptance/Purchase Behaviour Value. The higher the value the more acceptable the snack bar is likely to be.

4. For final justification and validation of the product, its market and production:

i) increase the size of the consumer sample to one hundred or more (Stone and Sidel, 1985).

ii) recruit female consumers of snack bars who are 18 to 50 years of age at a central location so that results represent the opinions of a diverse group of consumers.

iii) ask consumers "How much more do you like the new snack bar compared to your usual snack bar?". To ensure product success Cooper (1993) recommends that at least $50 \%$ of the consumers should prefer the new product "somewhat" or "very much more" over the product they are currently using. 


\section{REFERENCES}

Agriculture and Agri-Food Canada. 2003. Canada: pulse and special crops, supply and disposition (historical - 1991-1992/2003-2004f Market Analysis Division Online. http://www.agr.gc.ca/mad-dam/e/sd2e/hsd2ez.htm, updated August 8, 2003.

American Association of Cereal Chemists. 2000. Approved Methods of the American Association of Cereal Chemists, $10^{\text {th }}$ ed. Method: 44-15A. The Association. St. Paul, MN.

Anon. 2000. U.S. confectionery sales - total 1999 sales through grocery, drug and mass merchandisers. The Manufacturing Confectioner. 80(4):21, 27.

Anon. 2003. MarketTrack, National All Channel, AC Nielsen, 52 Weeks to Feb. 22, 2003.

Arntfield, S.D., Scanlon, M.G., Malcolmson, L.J., Watts, B., Ryland, D. and Savoie, V. 1997. Effect of tempering and end moisture content on the quality of micronized lentils. Food Research International. 30:371-380.

Arntfield, S.D., Scanlon, M.G., Malcolmson, L.J., Watts, B.M., Cenkowski, S., Ryland, D. and Savoie, V. 2001. Reduction in lentil cooking time using micronization: comparison of 2 micronization temperatures. J. Food Sci. 66:500-505.

Atwell, W.A., Hood, L.F., Lineback, D.R., Varriano-Marston, E. and Zobel, H.F. 1988. The terminology and methodology associated with basic starch phenomena. Cereal Foods World. 33:306-311.

Azlyn, K.L., Toma, R.B., Koval, J.E. and Christopher, S. 1989. Formulation and sensory evaluation of a low calorie fiber bar. J. Food Sci. 54:727-729.

Baker, R.C., Hahn, P.W. and Robbins, K.R. 1988. Fundamentals of New Food Product Development. Elsevier Science Publishing Company, Inc. New York, NY. pp 25-32, 5455.

Berglund, P.T., Fastnaught, C.E. and Holm, E.T. 1992. Food uses of waxy hull-less barley. Cereal Foods World. 37:707-714.

Best, D. 1991. Designing new products from a market perspective in Food Product Development From Concept to the Marketplace, edited by E. Graf and I.S. Saguy, Chapman \& Hall, New York, NY. p. 5.

Bhatty, R.S. 1984. Relationship between physical and chemical characters and cooking quality in lentil. J. Agric. Food Chem. 32:1161-1166. 
Bhatty, R.S. 1995. Lentils as a dietary cereal complement. Cereal Foods World. 40:387392.

Bhatty, R.S. and Slinkard, A.E. 1989. Relationship between phytic acid and cooking quality in lentil. Can. Inst. Food Sci. Technol. J. 22:137-142.

Biliaderis, C.G. 1983. Differential scanning calorimetry in food research - a review. Food Chem. 10:239-265.

Biliaderis, C.G., Maurice, T.J. and Vose, J.R. 1980. Starch gelatinization phenomena studied by differential scanning calorimetry. J. Food Sci. 45:1669-1674,1680.

Boushey, C.J., Beresford, S.A., Omenn, G.S. and Motulsky, A.G. 1995. A quantitative assessment of plasma homocysteine as a risk factor for vascular disease. Probable benefits of increasing folic acid intakes. J. Am. Med. Assoc. 274:1049-1057.

Boustani, P. and Mitchell, V. 1990. Cereal bars: A perceptual, chemical and sensory analysis. British Food J. 92(5):17-22.

Bower, J.A. and Whitten, R. 2000. Sensory characteristics and consumer liking for cereal bar snack foods. J. Sensory Studies. 15:327-345.

Burn, D. 2003. Sweet exports soar. Food in Canada. 63(4):52-54.

Burrington, K.J. 2000. Food, women and health. Food Product Design, Supplement, Functional Foods Annual, 29-42.

Canada Gazette, 2002. Food and Drugs Act, Regulations Amending the Food and Drug Regulations (Nutrition Labelling, Nutrient Content Claims and Health Claims) P.C. 2002-2200 12 December, 2002.

Cenkowski, S. and Sosulski, F.W. 1997. Physical and cooking properties of micronized lentils. J. Food Process Engineering. 20:249-264.

Cenkowski, S. and Sosulski, F.W. 1998. Cooking characteristics of split peas treated with infrared heat. Transactions of the ASAE. 41(3):715-720.

Chambers, E. and Smith, E.A. 1991. The uses of qualitative research in product research and development in Sensory Science Theory and Applications in Foods edited by H.T. Lawless and B.P. Klein, Marcel Dekker, Inc., New York, NY. pp. 395-412.

Cooper, R.G. 1993. Winning at New Products: Accelerating the Process from Idea to Launch, $2^{\text {nd }}$ Ed. Addison-Wesley Publishing Company, Reading, MA. pp. 121-162, 205- 
Daillant-Spinnler, B., MacFie, H.J.H., Beyts, P.K. and Hedderley, D. 1996. Relationships between perceived sensory properties and major preference directions of 12 varieties of apples from the southern hemisphere. Food Qual. Pref. 7:113-126.

Deis, R.C. 2000. Beverages and bars provide nutritional replenishment. Food Product Design, Functional Foods Annual. A Supplement to Food Product Design. pp. 45-56.

Elkowicz, K. and Sosulski, F.W. 1982. Antinutritional factors in eleven legumes and their air-classified protein and starch fractions. J. Food Sci. 47:1301-1304.

Elmore J. R., Heymann, H., Johnson, J. and Hewett, J.E. 1999. Preference mapping: relating acceptance of "creaminess" to a descriptive sensory map of a semi-solid. Food Qual. Pref. 10:465-475.

Estevez, A.M., Escobar, B., Vasquez, M., Castillo, E., Araya, E. and Zacarias, I. 1995. Cereal and nut bars, nutritional quality and storage stability. Plant Foods for Human Nutrition. 47:309-317.

Fellows, P.J. 1990. Food Processing Technology Principles and Practice. Ellis Horwood, New York, NY. pp. 350-354.

Fleming, S.E. 1981. A study of relationships between flatus potential and carbohydrate distribution in legume seeds. J. Food Sci. 46:794-798, 803.

Fuller, G.W. 1994. New Food Product Development from Concept to Marketplace. CRC Press, Boca Raton, FL. pp.1-23.

Garcia-Vela, L.A. and Stanley, D.W. 1989. Protein denaturation and starch gelatinization in hard-to-cook beans. J. Food Sci. 54:1284-1286, 1292.

Gillies, M.T. 1974. Compressed Food Bars. Noyes Data Corporation, Park Ridge, NJ. pp. 88-92.

Greenhoff, K. and MacFie, H.J.H. 1994. Preference mapping in practice in Measurement of Food Preferences, edited by H.J.H. MacFie and D.M.H. Thomson, Chapman \& Hall, London. pp.137-166.

Hair, J.F., Anderson, R.E., Tatham, R.L. and Black, W.C. 1995. Multivariate Data Analysis, $4^{\text {th }}$ ed. Prentice Hall, Englewood Cliffs, NJ. pp. 384-385. 
Heyd, B. and Danzart, M. 1998. Modelling consumers' preferences of coffees: evaluation of different methods. Lebensm.-Wiss. u.-Technol. 31:607-611.

Hollingsworth, P. 2002. Developing and marketing foods for women. Food Tech. 56(1):38-45, 55 .

Hough, G. and Sanchez, R. 1998. Descriptive analysis and external preference mapping of powdered chocolate milk. Food Qual. Pref. 9:197-204.

Hu, R. 1999. Food Product Design: A Computer-aided Statistical Approach. Technomic Publishing Co. Inc. Lancaster, PA. pp. 10, 13.

Jack, F.R., O'Neill, J.O., Piacentini, M.G. and Schroder, M.J.A. 1997. Perception of fruit as a snack: A comparison with manufactured snack foods. Food Qual. Pref. 8:175-182.

Jacques, P.F., Sulsky, S.I., Sadowski, J.A., Phillips, J.C.C., Rush, D. and Willett, W.C. 1993. Comparison of micronutrient intake measured by a dietary questionnaire and biochemical indicators of micronutrient status. Am. J. Clin. Nutr. 57:182-189.

Jaeger, S.R., Wakeling, I.N. and MacFie, H.J.H. 2000. Behavioural extensions to preference mapping: The role of synthesis. Food Qual. Pref. 11:349-359.

Jaeger, S.R., Rossiter, K.L., Wismer, W.V. and Harker, F.R. 2003. Consumer-driven product development in the kiwifruit industry. Food Qual. Pref. 14:187-198.

Jenkins, D.J.A., Wolever, T.M.S., Taylor, R.H., Barker, H.M., Fielden, H. and Jenkins, A.L. 1980. Effects of guar crispbread with cereal products and leguminous seeds on blood glucose concentrations of diabetics. Br. Medical J. 281:1248-1250.

Katz, F. 1999. How nutritious? meets how convenient? Food Tech. 53(10):44-50.

Kennedy, A.R. 1995. The evidence of soybean products as cancer preventive agents. J. Nutr. 125:733S-743S.

King, M.C., Cliff, M.A. and Hall, J.W. 1998. Comparison of projective mapping and sorting data collection and multivariate methodologies for identification of similarity-ofuse of snack bars. J. Sensory Studies. 13:347-358.

Klahorst, S.J. 2000. Pro- and prebiotics for health. Food Product Design, Supplement, Functional Foods Annual, pp. 73-82.

Kon, S. and Dunlap, C.J. 1978. U.S. Patent 4,084,016: April 11, 1978, United States Secretary of Agriculture. 
Lawless, H.T. and Heymann, H. 1998. Sensory Evaluation of Food: Principles and Practices. Chapman \& Hall, New York, NY. pp. 588-622.

Leach, R.L 1997. Nutrient fortified food bar. U.S. Patent. 5,612,074. March 18, 1997. US Patent \& Trademark Office.

Levine, L. 2002. Comparing rolling granola bars with rolling dough. Cereal Foods World. 47:242-243.

Lovett, J.V. and Gent, G.P. 2000. Market demands and research opportunities: addressing the supply/demand gap for pulses. Pages 221-233 in: Proceedings IFLRC-III: Linking Research and Marketing Opportunities for pulses in the $21^{\text {st }}$ century. Knight, R.ed. Kluwer Academic Publishers, The Netherlands.

MacFie, H.J., Bratchell, N., Greenhoff, K. and Vallis, L.V. 1989. Designs to balance the effect of order of presentation and first-order carry-over effects in hall tests. J. Sensory Studies. 4:129-148.

Matz, S.A. 1996. Formulating and Processing Dietetic Foods. Pan-Tech International, Inc., McAllen, TX. p. 279.

Maurer, G.A., Nielsen, S.S. and Mason, A.C. 2002. Development of granola bars using black and red beans. Abstract, IFT 2002 Annual Meeting and Food Expo, Anaheim, CA.

McCurdy, S.M. 1992. Infrared processing of dry peas, canola, and canola screenings, J. Food Sci. 57:941-944.

McDonough, C.M., Anderson, B.J. and Rooney, L.W. 1997. Structural characteristics of steam-flaked sorghum. Cereal Chem. 74:542-547.

McKenzie, R. G. 2000. Solid nutritional foods and methods of making the same. U.S. Patent 6,143,335.

Messina, 1997. Soyfoods: Their role in disease prevention and treatment. In: Soybeans: Chemistry, Technology, and Utilization. Lui, K. Aspen Publishers, Inc. Gaithensburg, MD, USA. pp. 422-477.

Metussin, R., Alli, I. and Kermasha, S. 1992. Micronization effects on composition and properties of tofu. J. Food Sci. 57:418-422.

Moskowitz, H.R. 1994. Food Concepts and Products: Just-in-Time Development. Food and Nutrition Press, Inc., Trumbull, CT. pp. 435-437. 
Muehlbauer, F.J. and Slinkard, A.E. 2000. Regional Reviews, Region 1: North America in Proceedings IFLRC-III: Linking Research and Marketing Opportunities for Pulses in the $21^{\text {st }}$ Century, edited by. R. Knight, Kluwer Academic Publishers, The Netherlands. p. $67-70$.

Murphy, P. 1990. Countlines and cereal bars in Sugar Confectionery Manufacture, edited by E.B. Jackson, Blackie and Son Ltd., Glasgow. pp. 300-310.

O'Mahony, M. 1986. Sensory Evaluation of Food: Statistical Methods and Procedures. Marcel Dekker, Inc. New York, NY. pp.183-209.

Owl Software, 2001, TechWizard ${ }^{\mathrm{TM}}$, Version 3, Columbia, MO.

Painter, J.E. and Prisecaru, V.I. 2002. The effects of various protein and carbohydrate ingredients in energy bars on blood glucose levels in humans. Cereal Foods World. 47:236-241.

Panchuk, B.D., Anderson, M. and Youngs, C.G. 1979. Patent 4,140,803; Feb 20, 1979, Canadian Patents and Development Limited.

Payne, T.J. 2000. Snack ideas from fruits to nuts: cultivated blueberries and California walnuts. Cereal Foods World. 45:453-456.

Perchonok, M. 2002. Shelf-life considerations and techniques in Food Product Development Based on Experience, edited by C. Side, Iowa State Press, Ames, IA. pp. 59-74.

Polizzoto, L.M., Tinsley, A.M., Weber, C.W. and Berry, J.W. 1983. Dietary fibers in muffins. J. Food Sci. 48:111-113, 118.

Prinz-Langenohl, R., Fohr, I. and Pietrzik, K. 2001. Beneficial role for folate in the prevention of colorectal and breast cancer. Eur. J. Nutr. 40:98-105.

Pszczola, D.E. 1999. Nutraceuticals that take the form of candy and snacks. Food Tech. 53(10):74-80.

Pulse Canada. 2000. Breeding a better lentil. Pulse Canada Newsletter. Fall, 2000.

Pulse Canada. 2003. Market outlook. Pulse Canada Newsletter. Spring, 2003.

Ray, J.G., Meier, C., Vermeulen, M.J., Boss, S., Wyatt, P.R. and Cole, D.E.C. 2002. Association of neural tube defects and folic acid food fortification in Canada. The Lancet. 360 (9350):2047-48. 
Rhymer, C.R. 2002. Effects of nitrogen fertilization, genotype and environment on the quality of oats (Avena sativa) grown in Manitoba. Masters Thesis, University of Manitoba. pp. 27-28.

Robbins, P.M. 1976. Convenience Foods - Recent Technology. Noyes Data Corporation, Park Ridge, NJ. pp. 219-220.

Rockland, L.B. and Radke, T.M. 1978. U.S. Patent 4,124,727, November 7, 1978. United States Secretary of Agriculture.

Sarantinos, J. and Black, R. 1996. Effects of micronisation on the chemical and functional properties of chickpeas. Food Australia 48(1), 39-42.

SAS Institute Inc., 1999. SAS/STAT User's Guide, Version 8, Cary, NC: SAS Institute Inc. pp. 2694-2723.

Schiffman, S.S., Reynolds, M.L. and Young, F.W. 1981. Introduction to Multidimensional Scaling: Theory, Methods, and Applications. Academic Press, New York, NY. pp. 255-266.

Sipahioglu, O., Bircan, C., Ratanatriwongi, P. and Barringer, S.A. 2002. Development of a nondairy, ready-to-eat and low fat cereal snack which is an excellent source of fiber. Abstract IFT 2002 Annual Meeting and Food Expo, Anaheim, CA.

Skrypetz, S. 2000. Lentil situation and outlook. Bi-weekly Bulletin, Vol. 13, No. 21, December 15, 2000. Market Analysis Division Online, Agriculture and Agri-Food Canada.

Sloan, A.E. 2000. The top ten functional food trends. Food. Tech. 54(4):33-62.

Sloan, A.E. 2003. Top 10 trends to watch and work on: 2003. Food. Tech. 57(4):30-50.

Sosulski, F.W., Hoover, R., Tyler, R.T., Murray, E.D. and Arntfield, S.D. 1985. Differential scanning calorimetry of air-classified starch and protein fractions from eight legume species. Starch/stärke. 37:257-262.

South, J.B. 1992. Improvements in micronised wheat production. MBAA Technical Quarterly. 29:20-23.

Stat-Ease, 2000. Design-Expert Software, Version 6, Stat-Ease, Inc., Minneapolis, MN.

Stevens, D.J. and Elton, G.A.H. 1971. Thermal properties of the starch/water system: Part I. Measurement of heat of gelatinisation by differential scanning calorimetry. Die Starke. 
23:8-11.

Stevens, J. 1992. Applied Multivariate Statistics for the Social Sciences, $2^{\text {nd }}$ Ed. Lawrence Erlbaum Associates, Inc. Hillsdale, NJ. pp. 383-385.

Stone, H. and Sidel, J.L. 1985. Sensory evaluation practices, Academic Press, Inc. Orlando, FL. p. 240.

Stone, H. and Sidel, J.L. 1993. Sensory evaluation practices, $2^{\text {nd }}$ Ed. Academic Press, Inc. San Diego, CA. pp. 216-235, 240-241.

Tang, C., Heymann, H. and Hsieh, F. 2000. Alternatives to data averaging of consumer preference data. Food Qual. Pref.11:99-104.

Troller, J.A. 1987. Adaptation and growth of microorganisms in environments with reduced water activity in Water Activity: Theory and Applications to Food, edited by L.B. Rockland and L.R. Beuchat, Marcel Dekker Inc., New York, NY. pp 101-102.

Troller, J.A. and Christian, J.H.B. 1978. Water Activity and Food. Academic Press, New York, NY. pp. 215-216.

Troller, J.A. 1989. Water Activity and Food Quality in Water and Food Quality, edited by T.M. Hardman, Elsevier Applied Science, New York, NY. pp. 17-20.

Tucker, K.L., Selhub, J., Wilson, P.W.F. and Rosenberg, I.H. 1996. Dietary intake pattern relates to plasma folate and homocysteine concentrations in the Framingham Heart Study. J. of Nutr. 126:3025-3031.

Van Drunen, K. 2002. Using dried fruits to add essential nutrients to cereals, bars, and breads. Cereal Foods World. 47:311-313.

Vanzetti, R. 1972. Practical Applications of Infrared Techniques: A New Tool in a New Dimension for Problem Solving. John Wiley \& Sons, New York, NY. p. 8.

Van Zuilichem, D.J., Van't Riet, K. and Stolp, W. 1986. An overview of new infrared radiation processes for agricultural products, in Food Engineering and Process Applications, Vol 1, Transport Phenomena, edited by M. Le Maguer and P. Jelen, Elsevier Applied Science Publishers, London. pp. 595-609.

Vickers, Z. 1988. Sensory specific satiety in lemonage using a just right scale for sweetness. J. of Sensory Studies. 3:1-8.

Vidal-Valverde, C., Frías, J. and Valverde, S. 1992. Effect of processing on the soluble 
carbohydrate content of lentils. J. Food Protection. 55:301-303, 306.

Williams. S.R. 1993. Nutrition and Diet Therapy, $7^{\text {th }}$ Ed. Mosby-Year Book, Inc. St. Louis, MO. Appendix B p A-41. Courtesy Orr, M.L. Watt, B.K. Amino acid content of foods, Home Economics Research Report No. 4. U.S. Department of Agriculture, 1966. pp.87-89, G-12

Yackinous, C., Wee, C. and Guinard, J. 1999. Internal preference mapping of hedonic ratings for Ranch salad dressings varying in fat and garlic flavor. Food Qual. Pref. 10:401-409.

Zhao, Y. 2000. The effects of pretreatment and micronization on the quality and cookability of lentils. Masters Thesis, University of Manitoba. pp. 78-82.

Zheng, G.H., Fasina, O., Sosulski, F.W. and Tyler, R.T. 1998. Nitrogen solubility of cereals and legumes subjected to micronization. J Agric. Food Chem. 46:4150-4157. 
Appendix 1 


\section{Appendix 1A}

\section{Formulation and rationale for selecting ingredient proportions for blueberry lentil snack bars}

\section{Ingredients:}

$180 \mathrm{~g}$ low fat sweetened condensed milk

$130 \mathrm{~g}$ micronized flaked lentils (Batch $1^{1}$ )

145 g granola $^{2}$

$40 \mathrm{~g}$ dried blueberries, chopped

\section{On a \% of total raw weight basis}

$36 \%$ low fat sweetened condensed milk

$26 \%$ micronized flaked lentils

$20 \%$ quick cooking rolled oats, $6 \%$ canola

oil, 3.5\% liquid honey

$8 \%$ dried blueberries, chopped

\section{Compared to guidelines by Robbins (1976):}

Sweetened condensed milk - 36\% of total weight - within guideline (30-50\%)

Honey - $10 \%$ of weight of sweetened condensed milk - within guideline $(10-40 \%)$

Fat $-16 \%$ of weight - within guideline (2-20\%)

Oatmeal - $19 \%$ of weight - within guideline (2-20\%)

Lentil - $26 \%$ of weight - outside guideline (2-20\%) too high by $6 \%$

\section{Method:}

Place milk in 3L bowl.

Add lentils and granola alternately in five batches starting with lentils.

Mix thoroughly (by hand) after each addition.

Add blueberries and mix thoroughly.

Spread evenly in a $21 \mathrm{~cm}$ square aluminum cake pan lined with aluminum foil sprayed with non-stick aerosol vegetable oil.

Bake at $150^{\circ} \mathrm{C}$ for 30 minutes.

Cool on rack for 30 minutes. Remove baking foil. Cool for another 30 minutes. Cut into 10 bars approximately $2 \mathrm{~cm} \times 10 \mathrm{~cm} \times 1.5 \mathrm{~cm}$ thick. Wrap in ziploc freezer bags. Over wrap with large freezer bags. Place in freezer bag and store at $-18 \mathrm{C}$ for future testing.

Baked Yield: 10 bars approximately $460 \mathrm{~g}$ each

${ }^{1}$ See Section 3.1.1 for details regarding lentils

${ }^{2} 280 \mathrm{~g}$ quick cooking rolled oats

80 g canola oil

$50 \mathrm{~g}$ liquid honey

Combine all ingredients and mix thoroughly.

Bake at $120^{\circ} \mathrm{C}$ for 1 hour and 50 minutes stirring every 15 minutes.

Cool. Place in plastic container and store at $-18 \mathrm{C}$ for future use.

Yield: $350 \mathrm{~g}$ cooked 


\section{Appendix 1B}

\section{Formulation for plain lentil bars presented to focus groups}

\section{Plain}

\section{Ingredients:}

$220 \mathrm{~g}$ low fat sweetened condensed milk

$30 \mathrm{~g}$ honey

180 g lentils (Batch $2^{1}$ )

220 g granola $^{2}$

\section{Method:}

Combine sweetened condensed milk and honey. Add lentils and granola alternately in four batches mixing well after addition. Spread evenly in $21 \mathrm{~cm}$ square aluminum baking pan lined with aluminum foil sprayed with non-stick aerosol vegetable oil. Bake at $150^{\circ} \mathrm{C}^{3}$ for 30 minutes. Cool on rack for 15 minutes, remove foil and cool another 15 minutes. Wrap in foil and place in freezer bag for storage at $-18^{\circ} \mathrm{C}$ until required for testing.

Yield: 14 bars approximately $38 \mathrm{~g}$ each

${ }^{1}$ See Section 3.1.1 for details regarding lentils

${ }^{2} 280$ g quick cooking oatmeal

$80 \mathrm{~g}$ canola oil

50 g honey

Mix all ingredients thoroughly. Spread on jelly roll pan and bake at $120^{\circ} \mathrm{C}$ for 90 minutes stirring every 15 minutes.

${ }^{3} 180^{\circ} \mathrm{C}$ for second batch presented to two focus groups in Human Ecology 


\section{Appendix 1C}

\section{Formulation for cranberry lentil bars presented to focus groups}

\section{Ingredients:}

$220 \mathrm{~g}$ sweetened condensed milk (low fat)

$30 \mathrm{~g}$ honey

140 g lentils (Batch $2^{1}$ )

180 g granola $^{2}$

$80 \mathrm{~g}$ dried cranberries, cut into small pieces

\section{Method:}

Combine sweetened condensed milk and honey. Add lentils, granola and cranberries alternately in four batches mixing well after addition. Spread evenly in $21 \mathrm{~cm}$ square aluminum baking pan lined with aluminum foil sprayed with non-stick aerosol vegetable oil. Bake at $150^{\circ} \mathrm{C}^{3}$ for 30 minutes. Cool on rack for 15 minutes, remove foil and cool another 15 minutes. Wrap in foil and place in freezer bag for storage at $-18^{\circ} \mathrm{C}$ until required for testing.

Yield:14 bars approximately $38 \mathrm{~g}$ each

${ }^{1}$ See Section 3.1.1 for details regarding lentils

${ }^{2} 280$ g quick cooking oatmeal

$80 \mathrm{~g}$ canola oil

$50 \mathrm{~g}$ honey

Mix all ingredients thoroughly. Spread on jelly roll pan and bake at $120^{\circ} \mathrm{C}$ for 90 minutes stirring every 15 minutes.

${ }^{3} 180^{\circ} \mathrm{C}$ for second batch presented to two focus groups in Human Ecology 


\section{Appendix 1D}

\section{Formulation for cranberry lentil bars presented as a reference sample to the expert panel}

\section{Ingredients:}

$221 \mathrm{~g}$ sweetened condensed milk (low fat)

$58.5 \mathrm{~g}$ honey

182 g lentils (Batch $3^{1}$ )

195 g granola $^{2}$

$39 \mathrm{~g}$ dried cranberries, cut into small pieces

\section{Method:}

Combine sweetened condensed milk and honey. Add lentils, granola and cranberries alternately in four batches mixing well after addition. Spread evenly in $21 \mathrm{~cm}$ square aluminum baking pan lined with aluminum foil sprayed with non-stick aerosol vegetable oil. Bake at $150^{\circ} \mathrm{C}$ for 30 minutes. Cool on rack for 15 minutes, remove foil and cool another 15 minutes. Wrap in foil and place in freezer bag for storage at $-18^{\circ} \mathrm{C}$ until required for testing.

Yield: 28 bars approximately $22 \mathrm{~g}$ each

${ }^{1}$ See Section 3.1.1 for details regarding lentils

${ }^{2} 280$ g quick cooking oatmeal

80 g canola oil

$50 \mathrm{~g}$ honey

Mix all ingredients thoroughly. Spread on jelly roll pan and bake at $120 \mathrm{C}$ for 90 minutes stirring every 15 minutes. 
Appendix 2 
Appendix 2A

Ethics Approval for Consumer Focus Groups 


\section{THE UNIVERSITY OF MANITOBA}

\section{INTER-DEPARTMENTAL CORRESPONDENCE}

Date: $\quad$ June 15,2000

Ref: $\quad \cdot 0008$

To: $\quad$ M. Vaisey-Genser and Donna Ryland, Foods and Nutrition

From: $\quad$ Nancy Higgitt, Chair, Ethics Review Committee

Subject: "Nutrient Dense Snack Bars - Consumer Opinions and Sensory Characterization"

Your memo dated June 13, 2000 adequately addresses the questions asked by the ERC. It now meets ethical guidelines for research with human subjects.

The Ethics Review Committee approves the proposed research procedures for implementation.

lad 
Appendix 2B

Ethics Approval for Consumer and Descriptive Panels 
Appendix 2B

\section{APPROVAL CERTIFICATE}

11 September 2002

TO:

Donna Ryland

(Advisor M. Vaisey-Genser)

Principal Investigator

FROM: Wayne Taylor, Chair

Joint-Faculty Research Ethics Board (JFREB)

Re:

Protocol \#J2002:094

"Sensory Evaluation of Nutritious Snack Bars"

Please be advised that your above-referenced protocol has received human ethics approval by the Joint-Faculty Research Ethics Board, which is organized and operates according to the Tri-Council Policy Statement. This approval is valid for one year only.

Any significant changes of the protocol and/or informed consent form should be reported to the Human Ethics Secretariat in advance of implementation of such changes. 
Appendix 3 
Appendix 3A

Recruitment Package for Consumer Focus Groups 


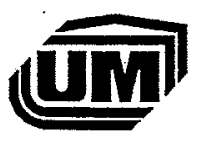

THE UNIVERSITY OF MANITOBA
FACULTY OF HUMAN ECOLOGY

DEPARTMENT OF FOODS AND NUTRITION
Human Ecology Building

Winnipeg, Manitoba

Canadạ R3T 2N2

(204) $474-8071$

(204) 474-7592 FAX

August 16, 2001

Dear Colleague,

As part of the research requirement for my graduate degree I am looking for women 35 to 55 years old to participate in consumer focus groups to gather their opinions about nutritional snack bars.

Criteria for volunteers are that they have eaten nutritional snack bars such as granola, nutri-grain and energy bars at least once. We will meet in small groups to talk about the texture, flavor and nutritional aspects of these products using examples of the bars to facilitate discussion. The single session you would attend will be about $1 \frac{1}{2}$ to 2 hours and will be tape recorded for transcription at a later date.

A known risk is an allergy to the ingredients of the snack bars evaluated. A questionnaire completed by participants regarding allergies and food aversions will be used to screen any potential health risks. Information regarding the project will be given once the session is completed.

Results will not be reported by individuals' names nor will any names be associated with the results. -Participants will be identified by number only. All data will be kept strictly confidential by myself under lock and key until published or for three years whichever is shorter.

If you would like to be part of this research, please read and fill in the required consent form and questionnaire attached to this request and bring them to the session which will be held on at in the Ellis Building on the University of Manitoba Fort Garry Campus (room number posted on entrance door). See enclosed map for building (\#22) and parking location (W). Contact me at 474-8071for more information or if the time is not suitable as we will be running additional sessions.

A $\$ 10$ gift certificate redeemable at the University of Manitoba bookstore will be provided as an honorarium.

Thank you for considering this request and we hope you will be able to assist us with this research.

Sincerely,

Donna Ryland, Graduate Student

Department of Foods and Nutrition
Marion Vaisey-Genser, Advisor

Department of Foods and Nutrition

Enc. 


\section{Consent Form - Focus Group Participants}

Project Title: Nutritional Snack Bars

Participant No.

Contact Person: Donna Ryland, Graduate Student, Foods and Nutrition Diepartment, Room 400FHuman Ecology Building phone 474-8071 email ryland@ms.umanitoba.ca

Names of Investigators: M. Vaisey-Genser, D. Ryland, Department of Foods and Nutrition Please tick either YES or NO in response to each of the following questions.

1. Do you understand that you have been asked to take part in a research study? Yes No

2. Have you read the information or heard the verbal explanation by the contact person regarding the study? Yes No

3. Do you understand the benefits and risks involved in taking part in the research study? Yes No

4. Do you understand that you will be eating nutritional snack bars and discussing your opinions about these bars? Yes No

5. Have you had an opportunity to ask questions and discuss the study? Yes No

6. Do you understand that you are free to withdraw from the study at any time without having to give a reason and without any detriment to your ongoing association with the University of Manitoba? Yes No

7. Do you understand you are required to notify the contact person if you are unable to continue with the study? Yes No

8. Do you understand that you can refuse to answer any questions? Yes No

9. Has the issue of confidentiality been described to you and do you understand a) who will have access to the information you provide, $b$ ) that no reports will identify you as an individual? Yes No

10. Do you agree to have the session tape recorded? Yes No

I agree to take part in this study
Printed Name of Participant
Yes No

Āddress

Telephone Number

E-mail Address 


\section{QUESTIONNAIRE - Nutritional Snack Bar Study - Consumer Focus Group}

Irformation provided in this questionnaire will be kept strictly confidential.

Participant No.

1. How often do you eat nutritional snack bars such as granola, nutri-grain and energy?

More than once per week

Once per week

Once per month

Occasionally

2. Do you eat this type of product to replace a meal? Yes

If yes or sometimes, check the meal replaced.

No Sometimes

\section{Breakfast}

Lunch

Dinner

3. Do you eat this type of product as a snack? Yes

No

If yes, check the time of day most often eaten.

Morning

Afternoon

Evening

4. What product do you eat most often?

Type

Brand

Flavor

5. Are you allergic to any food products or beverages?

Yes _ No__ If yes, note them below.

6. Are there any food products or beverages specifically, or food flavours and textures generally, that you would prefer not to evaluate? Yes No If yes, note them below.

7. Check if you have any of the following.

Dentures Diabetes Oral or gum disease Hypoglycemia Hyperglycemia Hypertension Gastrointestinal Disorder

8. Do you take any medications which affect your senses, especially taste and smell?

Yes No

9. Please check the appropriate age category.

35-45 years

46-55 years
Thank you for completing this questionnaire. 
Appendix 3B

Recruitment Package for Consumer Panel 


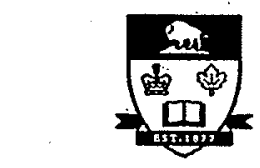

UN IVERSITY of MANITOBA

Faculty of Human Ecology Department of Human Nutritional Sciences

Winnipeg, Manitoba Canada R3T 2N2

Ph: (204) 474-8071

Fax: (204) 474-7592

\section{THE GEORGE WESTON LIMITED SENSORY AND FOOD RESEARCH CENTRE}

Dear Colleague,

September, 2002

We are seeking women volunteers aged 18 to 50 inclusive to participate in a study to find out the acceptability of nutritious snack bars as well as opinions about the texture and flavor of these bars. This information will be used as part of the process in developing a snack bar made from lentils. Lentils are a prairie grown crop that are suitable to include in a nutritious bar because they are low in fat and higher in folic acid, iron, fibre and protein compared to oats.

Criteria for volunteers are that you have eaten nutritious snack bars (eg. granola bars, energy bars, cereal bars) at least once. You will be asked to taste the bars indicating how much you like them; whether you would purchase them, as well as your opinion regarding the texture and flavor. The single session you would attend would take about 1 hour.

A known risk is an allergy to the ingredients of the snack bars. A questionnaire regarding allergies completed by those agreeing to participate will inform the researcher of any possible risk. Also included are questions about snack bar consumption. A summary of the results will be sent to participants within two months from completion of data collection.

Sessions will take place in the George Weston Limited Sensory and Food Research Centre, Fourth Floor Human Ecology Building during the week of September 30.

Results will not be reported by individuals' names nor will any names be associated with the results. Participants will be identified by number only. All data will be kept strictly confidential by $D$. Ryland and under lock and key until published or for five years whichever is shorter.

If you would like to be part of this research, complete the sign-up sheet indicating which time you will attend. Read and fill in the required consent form and questionnaire attached and return them to Donna Ryland before your session. Any questions you have can be directed to her at 474-8071.

Panelists completing the session will receive a $\$ 10$ gift certificate redeemable at the University of Manitoba bookstore.

We hope you will be able to assist us with this project.

Sincerely, Donna Ryland, Graduate Student

and

Marion Vaisey-Genser, Senior Scholar 


\title{
Faculty of Hüman Ecology Department of Human Nutritional Sciences
}

\author{
Winnipeg, Manitoba \\ Canada R3T 2N2 \\ $\mathrm{Ph}:$ (204) 474-8071 \\ Fax: (204) 4747592 \\ ryland®@ms.umanitóba.ca
}

Written Consent Form

Panelist No.

Research Project Title: Sensory Evaluation of Nutritious Snack Bars

Researcher(s): Donna Ryland and Marion Vaisey-Genser

This consent form, a copy of which will be left with you for your records and reference, is only part of the process of informed consent. It should give you the basic idea of what the research is about and what your participation will involve. If you would like more detail about something mentioned here, or information not included here, you should feel free to ask. Please take the time to read this carefully and to understand any accompanying information.

The study is being done to evaluate the acceptability and opinions of consumers regarding flavor and texture attributes of nutritious snack bars including those made with lentils.

Criteria for volunteers are that you have eaten nutritious snack bars (eg. granola bars, energy bars, cereal bars) at least once. You will be asked to taste snack bars indicating how much you like them, whether you would purchase them, as well as your opinion regarding the texture and flavor. The single session you would attend would take about 1 hour.

A concern is a possible allergy to the ingredients of the snack bars. A questionnaire regarding allergies will be used to screen panelists with a potential health risk.

Panelists will be identified by number and all data related to personal information and results obtained will be kept in a locked cabinet for 5 years or until data are published whichever comes first. Access to information linking subject to number will be limited strictly to the researchers named above. All data will be shredded after the time has expired. Data published will be given as group means with no individual names given.

Information regarding the results will be sent to participants within two months from completion of data collection.

A gift certificate for $\$ 10.00$ redeemable at the University of Manitoba Bookstore will be given to those completing the session.

Your signature on this form indicates that you have understood to your satisfaction the information regarding participation in the research project and agree to serve as a subject. In no way does this waive your legal rights nor release the researchers, sponsors, or involved institutions from their legal 
and professional responsibilities. You are free to withdraw from the study at any time, and /or refrain from answering any questions you prefer to omit, without prejudice or consequence. Your continued participation should be as informed as your initial consent, so you should feel free to ask for clarification or new information throughout your participation. This study is being conducted by Donna Ryland, 474-8071 under the supervision of Prof. Marion Vaisey-Genser, 474-9901.

This research has been approved by the Joint-Faculty Research Board of Ethical Review at the University of Manitoba. If you have any concerns or complaints about this project you may contact any of the above-named persons or the Human Ethics Secretariat at 474-7122. A copy of this consent form will be given to you to keep for your records and reference.

Date

Telephone Number Email Address

Researcher and/or Delegate's Signature Date 


\section{Panelíst No.}

\section{Questionnaire \\ Nutritious Snack Bars}

Please answer the following questions by placing a check $(\checkmark)$ where appropriate.

Ail information will be kept strictly confidential.

1. Age
a. $\quad 18-29$
b. $\quad 30-39$
c. $\quad 40-50$

2. How often do you generally eat products such as granola bars, energy bars, cereal bars? Check one only.
a. at least once a week
b. at least once a month
c. a few times a year
d. other
please explain

3. When do you generally eat this type of product?
a. as a snack
b. in place of breakfast lunch dinner
c. other_ please explain

4. What brand and flavor do you normally eat?

Brand Flavor

5. Are you allergic to any food products? Yes No If yes, note them below.

6. Are there any foods specifically, or food flavors and textures generally, that you would prefer not to evaluate? Yes No If yes, note them below.

7. Are you on a restricted diet? Yes No If yes, explain what these restrictions are. 


\section{Appendix 3C \\ Recruitment Package for Descriptive Panel}




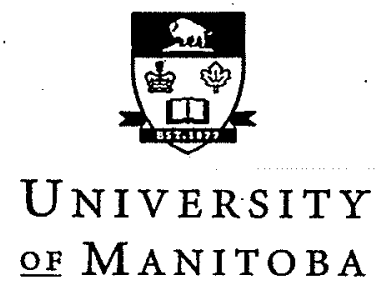

Faculty of Human Ecology Department of Human Nutritional Sciences

Winnipeg, Manitoba Canada R3T 2N2

$\mathrm{Ph}:$ (204) 474-8071

Fax: (204) 474-7592

ryland@ms.umanitoba.ca

\section{THE GEORGE WESTON LIMITED SENSORY AND FOOD RESEARCH CENTRE}

Dear Colleague,

October, 2002

As part of research to complete my Master of Science degree I am inviting you to participate in a trained sensory panel which involves tasting snack bars similar to granola bars that are made from lentils. Prior experience is not necessary. This letter explains what your commitment would be. If you have any questions please call Donna Ryland at 474-8071.

Ten to twelve panelists will take part in group and individual sessions where the flavor and texture of snack bars will be evaluated. Other products may be used to aid in describing these characteristics. Training sessions will include group discussion of sensory attributes and evaluation of their intensities in various samples. Individual evaluation of the samples will follow. There will be approximately 6 training sessions and 2 to 4 individual sessions held from about 11:30 to $12: 15$ during a 3 to 4 week period. The study will take place in the George Weston Limited Sensory and Food Research Centre, Fourth Floor of the Human Ecology Building with anticipated start date of Wednesday, November 6.

Remuneration will be in the form of a $\$ 50.00$ gift certificate redeemable at the University of Manitoba Bookstore.

A potential risk would be allergic reactions to food products. Completing the enclosed questionnaire will alert the researcher to possible risk. If you are interested in helping us with this research please complete the consent form and the questionnaire attached. Return these forms to Donna Ryland by Monday, November 4.

We hope that you will be able to take part in this research and look forward to hearing from you.

Sincerely,

Donna Ryland, Graduate Student

and Marion Vaisey-Genser, Senior Scholar

Department of Human Nutritional Sciences 


\section{nes \\ $D^{2}$ \\ UN I VER S I T Y \\ of MANITOBA}

\section{Faculty of Human Ecology \\ Department of Human Nutritional Sciences}

Winnipeg, Manitoba

Canada R3T 2N2

Ph: (204) 474-8071

Fax: (204) 474-7592

ryland@ms.umanitoba.ca

Panelist No.

\section{Written Consent Form}

\section{Research Project Title: Sensory Evaluation of Nutritious Snack Bars}

Researcher(s): Donna Ryland and Marion Vaisey-Genser

This consent form, a copy of which will be left with you for your records and reference, is only part of the process of informed consent. It should give you the basic idea of what the research is about and what your participation will involve. If you would like more detail about something mentioned here, or information not included here, you should feel free to ask. Please take the time to read this carefully and to understand any accompanying information.

The study is being done to evaluate the flavor and texture attributes of nutritious snack bars made from lentils. Approximately six training sessions will be conducted where panelists meet as a group to learn the flavor and texture attributes as well as the scale used to measure the intensity of the attributes. Samples of snack bars as well as other products useful in defining specific attributes will be tasted to familiarize panelists with procedures. Two to four test sessions will be held in individual booths. All sessions will be 30 to 45 minutes and take place on the fourth floor of the Human Ecology Building.

Possible risk may be allergic reactions to food products sampled. Completion of the accompanying questionnaire will alert the researcher to any potential risk.

Panelists will be identified by number and all data related to personal information and results obtained will be kept in a locked cabinet for 5 years or until data are published whichever comes first. Access to information linking subject to number will be limited strictly to the researchers 
named above. All data will be shredded after the time has expired. Data published will be given as group means with no individual names given.

You will receive a copy of the purpose of the study as well as the results within two weeks after the study is completed.

A gift certificate for $\$ 50.00$ redeemable at the University of Manitoba Bookstore will be given to those completing all of the required group and individual sessions.

Your signature on this form indicates that you have understood to your satisfaction the information regarding participation in the research project and agree to participate as a subject. In no way does this waive your legal rights nor release the researchers, sponsors, or involved institutions from their legal and professional responsibilities. You are free to withdraw from the study at any time, and /or refrain from answering any questions you prefer to omit, without prejudice or consequence. Your continued participation should be as informed as your initial consent, so you should feel free to ask for clarification or new information throughout your participation. This study is being conducted by Donna Ryland, 474-8071 under the supervision of Prof. Marion Vaisey-Genser, 474-9901.

This research has been approved by the Joint-Faculty Research Board of Ethical Review at the University of Manitoba. If you have any concerns or complaints about this project you may contact any of the above-named persons or the Human Ethics Secretariat at 474-7122. A copy of this consent form will be given to you to keep for your records and reference.

Participant's Signature Date

Telephone Number Email Address 


\section{Questionnaire}

\section{Sensory Evaluation of Nutritious Snack Bars}

This information will be kept strictly confidential.

Panelist No.

1. Have you participated on sensory evaluation panels before? Yes__ No ___ If yes,

a) What product(s) did you evaluate?

b) Was training part of the evaluation procedure? Yes No If yes, indicate for which product(s).

2. Are you allergic to any food products? Yes No If yes, note them below.

3. Are there any foods specifically, or food flavors and textures generally, that you would prefer not to evaluate?

4. Do you take any medications which affect your senses, especially taste and smell? Yes No

Do you smokè? Yes No Are you on a restricted diet? Yes No ___ If yes, explain what these restrictions are.

Thank you very much for completing this questionnaire. 
Appendix 4 


\section{Appendix 4}

\section{Outline of focus group ${ }^{1}$ session for snack bars}

\section{1) Introduction of Moderator "and Group"}

So that we don't feel like total strangers toward each other let's go around state our name and what we spend most of our time doing.

I'm Donna and spend most of my time at the university working at my full-time job as food research coordinator in the department and part-time as a graduate student. Next .......

The purpose of this discussion is to find out what your preferences are when you select and eat nutritious snack bars. This focus group technique is commonly used when developing new products to get information about how one can make these products suitable for the people who are consuming them. I am interested in everyone's thoughts and will guide the discussion and keep us on track.

Just a reminder that your personal responses will remain confidential with only myself having access to the recording that I will be making of the session. The results will be summarized and reported on a group basis.

\section{2) General Questions}

First of all let's think about why you choose cereal bars.

Possible responses - quick, tasty, fills the gap, healthier choice than chocolate bar or cookie,

fruit flavors, raisins, fibre source, nutrient source, convenient - eat on the go, no special storage

Now that we've discussed why you choose the bar what do you look for when you select the bar you do?

Possible responses - particular flavor, brand, low fat, price, amount of fruit, appearance

\section{3) Specific Questions}

Could you tell me what you like about this particular bar -

Possible responses - chewiness, flavor, sweetness, color, textural appearance

Explain in more detail - flavor? ex. toasted

What could be improved about this particular bar? 
What would you change about the recipe to improve it?

Start with 2 commercial bars and proceed to 2 experimental bars

940 - Nature Valley - Oats and Honey

628 - Quaker - Chewy - Raisin

774 - Experimental - Plain

873 - Experimental - Cranberry

\section{4) Summary}

To summarize think of which sample you liked the best and why and perhaps which sample yo u liked the least and why.

\section{5) Identification of Samples and Project Summary ${ }^{2}$}

\section{6) Thank Participants.}

Hand out honorarium ( $\$ 10$ gift certificates for University of Manitoba Bookstore)

${ }^{1}$ Adapted Chambers and Smith,1991.

${ }^{2}$ Project Summary

What we are doing is to use micronized flaked lentils to make a food product. Micronization is a precooking step that uses heat to soften the lentils. Flaking is an abrasion technique which helps with moisture absorption. Lentils are a good source of iron, fibre and are low in fat. Compared to oats, on a per 100 gram basis raw, they contain less energy, less fat, more protein, and more fibre. 


\section{Appendix 5 \\ Exercise used during training to teach panelists the appropriate way to use the $15 \mathrm{~cm}$ line scale for measuring attribute intensities}


Panelist No.

Estimate the proportion of the circle that is shaded and place a vertical mark across the line scale to indicate that amount.

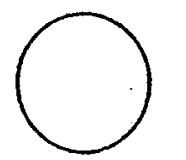

none

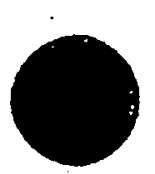

none

211

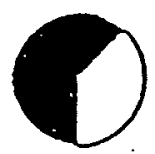

none

all

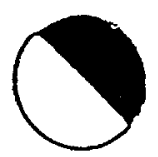

none

a11

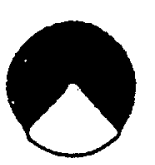

none

al1

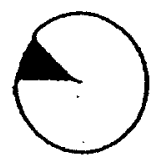

none

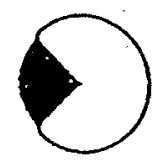

none

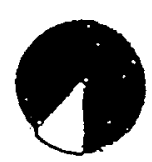

none

all 
Appendix 6 
Appendix 6

Demographic Characteristics of Groupings Created From Internal Preference Mapping

\begin{tabular}{|c|c|c|c|c|c|}
\hline Group & Age $^{1}$ & How Often ${ }^{2}$ & When Eaten ${ }^{3}$ & Brand & Flavor \\
\hline \multirow{4}{*}{$\begin{array}{l}1 \\
n=4\end{array}$} & a & $\mathbf{a}$ & a & various & various \\
\hline & a & a & a & nature valley & peanut butter \\
\hline & a & $b$ & a & gatorade & peanut butter \\
\hline & a & a & a & nature valley & various \\
\hline \multirow[t]{15}{*}{$\begin{array}{l}2 \\
n=15\end{array}$} & a & $\mathrm{a}$ & $a \& c$ & $\begin{array}{l}\text { quaker, nature } \\
\text { valley }\end{array}$ & variety, peanut butter \\
\hline & a & $\mathrm{b}$ & a & $\begin{array}{l}\text { president's choice, } \\
\text { quaker }\end{array}$ & bumble berry, any \\
\hline & a & $b$ & a & no response & no response \\
\hline & a & $\mathrm{b}$ & $\mathbf{a}$ & nutri-grain & strawberry, mixed berry \\
\hline & a & a & a & $\begin{array}{l}\text { body smarts, } \\
\text { sun-rype }\end{array}$ & $\begin{array}{c}\text { caramel/chocolate, } \\
\text { variety }\end{array}$ \\
\hline & a & a & b-lu & clif bar & crunchy peanut butter \\
\hline & a & a & c & president's choice & $\begin{array}{l}\text { chocolate and } \\
\text { marshmallow }\end{array}$ \\
\hline & $\mathbf{a}$ & $\mathrm{b}$ & a & kellogg's & strawberry \\
\hline & a & $\mathrm{b}$ & a & president's choice & $\begin{array}{l}\text { cranberry or chocolate } \\
\text { chip }\end{array}$ \\
\hline & $\mathbf{a}$ & a & a & safeway no name & chocolate chip \\
\hline & a & a & a & nature valley & $\begin{array}{l}\text { peanut butter or apple } \\
\text { cinnamon }\end{array}$ \\
\hline & a & a & a & nature valley & apple, banana \\
\hline & $\mathrm{b}$ & a & a & nestle/cadbury & chocolate/vanilla. \\
\hline & $\mathrm{b}$ & $\mathrm{b}$ & a\&c & variety & no response \\
\hline & a & a & $a \& b-b r$ & quaker & banana nut, berry \\
\hline \multirow{15}{*}{$\begin{array}{l}3 \\
n=29\end{array}$} & $\mathbf{a}$ & a & a & quaker & trail mix \\
\hline & $\mathbf{a}$ & a & $a \& c$ & power bar harvest & blueberry \\
\hline & a & a & a & quaker & apple \\
\hline & a & a & a & nature valley & chocolate chip \\
\hline & a & a & a & multi-grain & strawberry \\
\hline & a & a & $\cdot$ & nature valley & apple \\
\hline & a & a & a & $\begin{array}{l}\text { president's choice } \\
\text { low fat }\end{array}$ & almond and raisin \\
\hline & a & c & b-1u & nature valley & peanut butter \\
\hline & $\mathbf{a}$ & a & a & nature valley & peanut butter/almond \\
\hline & $a$ & b & a & quaker & fruit/nut or chocolate chip \\
\hline & $\mathbf{a}$ & b & $a \& c$ & nature valley & various \\
\hline & $\mathrm{c}$ & $\mathrm{c}$ & a & quaker & chocolate chip \\
\hline & $\mathrm{a}$ & a & b-br & nutri-grain & apple and cinnamon \\
\hline & $\mathbf{a}$ & b & $\mathrm{a}$ & quaker & chocolate \\
\hline & $\mathrm{a}$ & c & $\mathrm{b}$-br or lu & slim fast & chocolate \\
\hline
\end{tabular}


Demographic Characteristics of Groupings Created From Internal Preference Mapping (cont'd)

\begin{tabular}{|c|c|c|c|c|c|}
\hline Group & Age $^{1}$ & How Often ${ }^{2}$ & When Eaten ${ }^{3}$ & Brand & Flavor \\
\hline \multirow[t]{14}{*}{3} & a & $\mathbf{a}$ & b-lu & bioprotein & $\begin{array}{l}\text { chocolate and peanut } \\
\text { butter }\end{array}$ \\
\hline & a & $\mathbf{a}$ & $a \& b-l u \& c$ & power bar/harvest/rebar & \multirow{4}{*}{$\begin{array}{l}\text { not chocolate or fake fruit } \\
\text { no response } \\
\text { chocolate/cranberry oat } \\
\text { chocolate chip, bumble } \\
\text { berry }\end{array}$} \\
\hline & a & $\mathbf{b}$ & $\mathrm{a} \& \mathrm{~b}-\mathrm{br}$ & various & \\
\hline & a & $\mathrm{b}$ & a & powerbar/no name & \\
\hline & a & $\mathrm{a}$ & a & quaker or no name & \\
\hline & a & a & $\mathrm{a} \& \mathrm{~b}-\mathrm{br}$ & nutri-grain & $\begin{array}{l}\text { blueberry, mixed berry, } \\
\text { raspberry }\end{array}$ \\
\hline & a & $\mathbf{b}$ & a & nutri-grain & raspberry \\
\hline & a & $\mathrm{a}$ & a\&b-br & nutri-grain & strawberry \\
\hline & c & $\mathbf{b}$ & a & safeway brand & basic with chocolate chips \\
\hline & c & $\mathbf{a}$ & a & president's choice & \multirow{5}{*}{$\begin{array}{l}\text { apple cinnamon } \\
\text { peanut butter } \\
\text { apple-strawberry-banana } \\
\text { apple or almond }\end{array}$} \\
\hline & c & $\mathrm{c}$ & $a \& b-b r \& l u$ & nature valley & \\
\hline & a & $\mathbf{b}$ & $\mathbf{a}$ & nature valley & \\
\hline & a & $\mathbf{a}$ & a & sun-rype & \\
\hline & a & $\mathbf{a}$ & $a \& b-b r$ & nature valley & \\
\hline \multirow{14}{*}{$\begin{array}{l}4 \\
n=14\end{array}$} & $\mathbf{a}$ & $\mathrm{d}$ & $\mathrm{a} \& \mathrm{~b}-\mathrm{b} r$ & nutri-grain & strawberry \\
\hline & $\mathrm{b}$ & $\mathrm{b}$ & $b-b r$ & chewy & \multirow{2}{*}{$\begin{array}{l}\text { chocolate chip } \\
\text { train mix }\end{array}$} \\
\hline & a & a & a & quaker & \\
\hline & c & $c$ & $\mathrm{a}$ & sun-rype & \multirow{2}{*}{$\begin{array}{l}\text { fruit to go } \\
\text { berries }\end{array}$} \\
\hline & $\mathrm{b}$ & $\mathrm{b}$ & a & president's choice & \\
\hline & a & $\mathbf{b}$ & a & nature valley & apple crisp \\
\hline & a & a & a & quaker & baked apple \\
\hline & a & $\mathbf{b}$ & b-br & vector & $\begin{array}{l}\text { cranberry apple } \\
\text { strawberry }\end{array}$ \\
\hline & a & $\mathrm{c}$ & $a \& b-b r$ & nutri-grain & strawberry \\
\hline & a & $\mathrm{d}-\mathrm{b} w \mathrm{~b} \& \mathrm{c}$ & a & no response & \\
\hline & a & a & a & president's choice & chocolate chip \\
\hline & a & a & a & quaker & $\begin{array}{l}\text { raisin\&honey or cranberry } \\
\text { apple }\end{array}$ \\
\hline & $\mathbf{a}$ & c & a & no response & chewy, chocolate chip. \\
\hline & $a$ & a & a & president's choice & low fat apple cranberry \\
\hline
\end{tabular}

${ }^{1} \mathrm{a}=18-29 ; \mathrm{b}=30-39 ; \mathrm{c}=40-50$

${ }^{2} a=a t$ least once $a$ week; $b=a t$ least once $a$ month; $c=a$ few times a year; $d=0$ ther

${ }^{3} a=$ as a snack; $b=$ in place of breakfast (br), lunch (l) or dinner (d); $c=0$ ther 
Appendix 7 
Appendix 7

Analysis of variance tables for all attributes evaluated by the descriptive panel

Table A - Stickiness to Touch

$\begin{array}{llllll}\text { Source } & \text { DF } & \begin{array}{l}\text { Sum of } \\ \text { Squares }\end{array} & \text { Mean Square } & \text { F Value } & \text { Pr }>\text { F } \\ \text { Model } & 105 & 1378.43 & 13.13 & 6.03 & <.0001 \\ \text { panelist } & 10 & 262.78 & 26.28 & 12.07 & <.0001 \\ \text { rep } & 1 & 3.99 & 3.99 & 1.83 & 0.1801 \\ \text { sample } & 7 & 584.7 & 83.54 & 38.38 & <.0001 \\ \text { panelist*rep } & 10 & 41.92 & 4.19 & 1.93 & 0.0558 \\ \text { panelist*sample } & 70 & 437.87 & 6.26 & 2.87 & <.0001 \\ \text { rep*sample } & 7 & 47.13 & 6.73 & 3.09 & 0.0067 \\ \text { Error } & 70 & 152.37 & 2.18 & & \\ \text { Corrected Total } & 175 & 1530.80 & & & \end{array}$

Table B - Sweetness

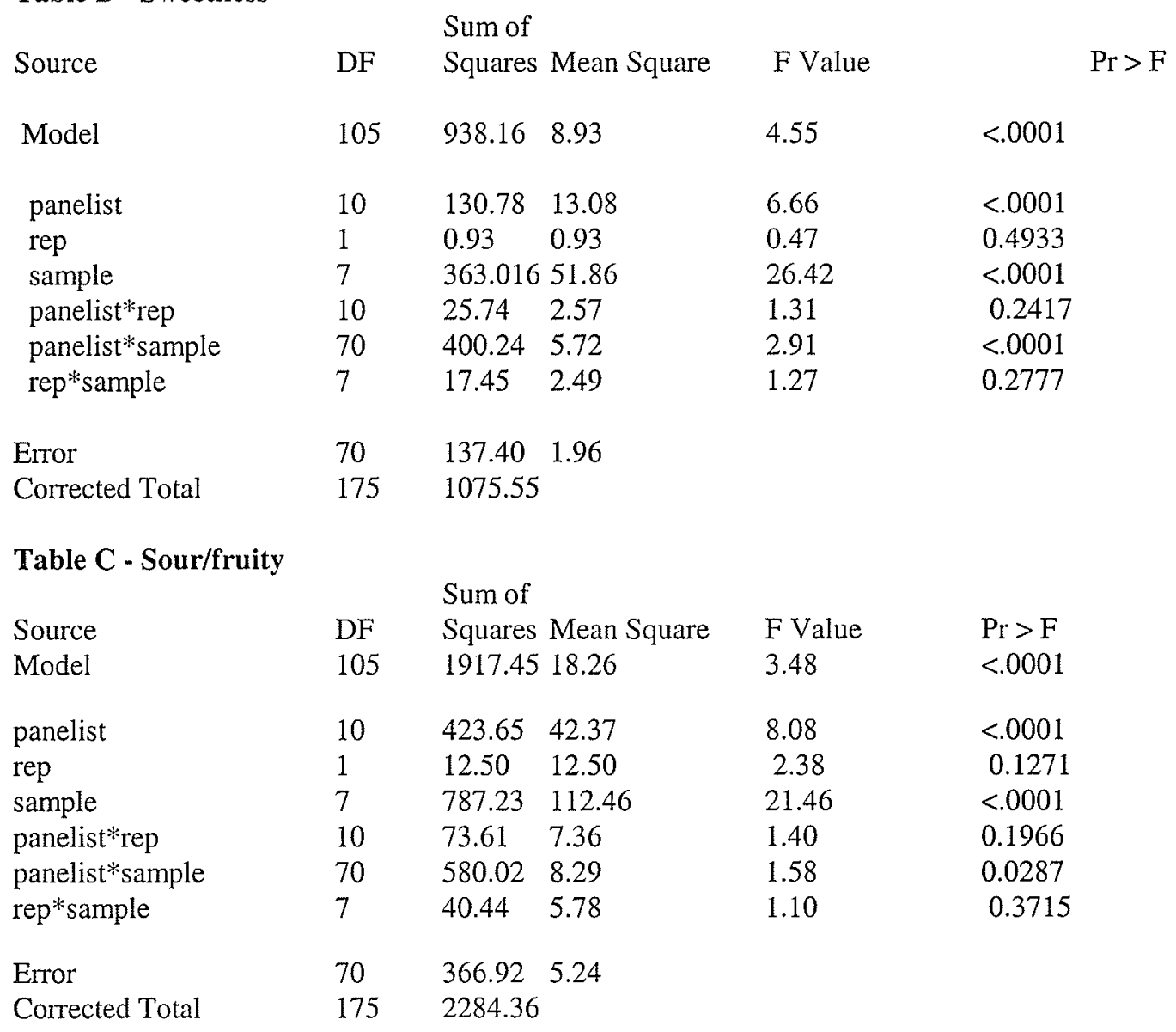


Table D - Grainy

\begin{tabular}{lllllll} 
Source & DF & \multicolumn{2}{l}{$\begin{array}{l}\text { Sum of } \\
\text { Squares Mean Square }\end{array}$} & F Value & Pr $>$ F \\
Model & 105 & 1155.71 & 11.01 & 4.35 & $<.0001$ \\
& & & & & & \\
panelist & 10 & 173.14 & 17.31 & 6.84 & $<.0001$ \\
rep & 1 & 19.31 & 19.31 & 7.63 & 0.0073 \\
sample & 7 & 479.42 & 68.49 & 27.06 & $<.0001$ \\
panelist*rep & 10 & 69.96 & 7.00 & 2.76 & 0.0062 \\
panelist*sample & 70 & 390.07 & 5.57 & 2.20 & 0.0006 \\
rep*sample & 7 & 23.80 & 3.40 & 1.34 & 0.2433 \\
& & & & & \\
Error & 70 & 177.15 & 2.53 & & \\
Corrected Total & 175 & 1332.86 & & &
\end{tabular}

Table E - Lentil

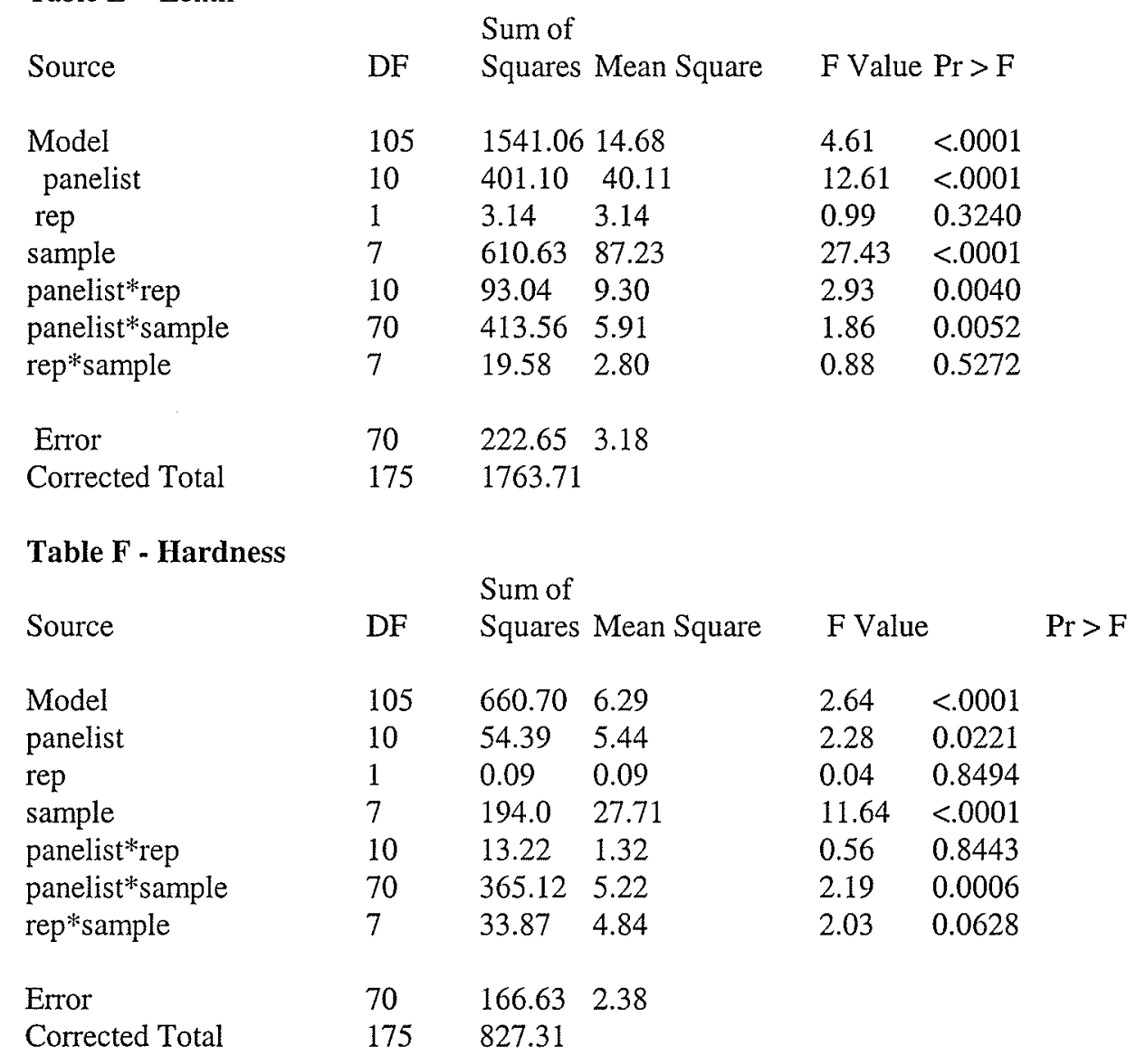


Table G - Cohesiveness

\begin{tabular}{lllllll} 
& \multicolumn{3}{l}{ Sum of } & \multicolumn{2}{c}{ F Value $\operatorname{Pr}>$ F } \\
Source & DF & \multicolumn{2}{l}{ Squares Mean Square } & \multicolumn{2}{l}{1.61} & 0.0171 \\
Model & 105 & 666.91 & 6.35 & & \\
panelist & & & & 1.99 & 0.0476 \\
rep & 10 & 78.45 & 7.85 & 1.43 & 0.2360 \\
sample & 1 & 5.64 & 5.64 & 4.05 & 0.0009 \\
panelist*rep & 7 & 111.78 & 15.97 & 0.91 & 0.5327 \\
panelist*sample & 10 & 35.75 & 3.57 & 1.38 & 0.0922 \\
rep*sample & 70 & 380.12 & 5.43 & 2.00 & 0.0676 \\
Error & 7 & 55.18 & 7.88 & & \\
Corrected Total & 70 & 276.25 & 3.95 & & &
\end{tabular}

Table H - Cohesiveness of mass

\begin{tabular}{llllll} 
& \multicolumn{5}{l}{ Sum of } \\
Source & DF & \multicolumn{2}{l}{ Squares Mean Square } & F Value $\operatorname{Pr}>$ F \\
Model & 105 & 645.46 & 6.14 & 1.87 & 0.0028 \\
panelist & 10 & 42.05 & 4.21 & 1.28 & 0.2588 \\
rep & 1 & 13.98 & 13.98 & 4.25 & 0.0429 \\
sample & 7 & 57.03 & 8.15 & 2.48 & 0.0247 \\
panelist*rep & 10 & 118.50 & 11.85 & 3.61 & 0.0007 \\
panelist*sample & 70 & 405.72 & 5.80 & 1.76 & 0.0094 \\
rep*sample & 7 & 8.18 & 1.17 & 0.36 & 0.9245 \\
& & & & & \\
Error & 70 & 230.01 & 3.29 & & \\
Corrected Total & 175 & 875.47 & & & \\
& & & & & \\
Table I - Moistness & & & & & \\
& & Sum of & & \\
Source & DF & Squares & Mean Square & F Value & Pr > F \\
& & & & & \\
Model & 105 & 508.76 & 4.85 & 1.91 & 0.0021 \\
panelist & 10 & 70.79 & 7.08 & 2.79 & 0.0057 \\
rep & 1 & 1.47 & 1.47 & 0.58 & 0.4483 \\
sample & 7 & 131.91 & 18.84 & 7.44 & $<.0001$ \\
panelist*rep & 10 & 44.79 & 4.48 & 1.77 & 0.0828 \\
panelist*sample & 70 & 229.73 & 3.28 & 1.30 & 0.1404 \\
rep*sample & 7 & 30.07 & 4.30 & 1.70 & 0.1241 \\
& & & & & \\
Error & 70 & 177.30 & 2.53 & & \\
Corrected Total & 175 & 686.06 & & &
\end{tabular}


Table J - Chewiness

\begin{tabular}{lllllll} 
Source & DF & \multicolumn{2}{l}{$\begin{array}{l}\text { Sum of } \\
\text { Squares Mean Square }\end{array}$} & \multicolumn{2}{l}{ F Value Pr $>$ F } \\
Model & & & & & \\
panelist & 105 & 515.37 & 4.91 & 1.62 & 0.0162 \\
rep & 10 & 67.51 & 6.75 & 2.22 & 0.0258 \\
sample & 1 & 12.45 & 12.44 & 4.10 & 0.0467 \\
panelist*rep & 7 & 48.17 & 6.88 & 2.27 & 0.0386 \\
panelist*sample & 10 & 66.15 & 6.61 & 2.18 & 0.0290 \\
rep*sample & 70 & 295.25 & 4.22 & 1.39 & 0.0854 \\
& 7 & 25.85 & 3.69 & 1.22 & 0.3052 \\
Error & & & & & \\
Corrected Total & 70 & 212.39 & 3.03 & & &
\end{tabular}

Table K - Adhesiveness to teeth

\begin{tabular}{lllllll} 
Source & DF & \multicolumn{2}{l}{$\begin{array}{l}\text { Sum of } \\
\text { Squares }\end{array}$} & Mean Square & \multicolumn{2}{l}{ F Value Pr $>$ F } \\
Model & & & & & \\
panelist & 105 & 633.63 & 6.04 & 1.97 & 0.0014 \\
rep & 10 & 332.95 & 33.30 & 10.85 & $<.0001$ \\
sample & 1 & 0.65 & 0.65 & 0.21 & 0.6467 \\
panelist*rep & 7 & 57.42 & 8.20 & 2.67 & 0.0164 \\
panelist*sample & 10 & 28.79 & 2.88 & 0.94 & 0.5047 \\
rep*sample & 70 & 189.28 & 2.70 & 0.88 & 0.7015 \\
& 7 & 24.54 & 3.51 & 1.14 & 0.3475 \\
Error & & & & & \\
Corrected Total & 70 & 214.89 & 3.07 & & &
\end{tabular}

